\begin{tabular}{|l|l|}
\hline $\begin{array}{l}\text { 2. To: (Receiving Organization) } \\
\text { Distribution }\end{array}$ & $\begin{array}{l}\text { 3. From: (Originating Organization) } \\
\text { Process Engineering }\end{array}$ \\
\hline 5. Proj./Prog-/Dept./Div.: & 6. Design Authority/ Design Agent/cog \\
Spent Nuclear Fuel Project & L. H. Goldmann 4
\end{tabular}

8. Originator Remarks:

Distribution of document for approval and release

11. Receiver Remarks: 11A, Design Baseline Document? [] Yes [X] No
4. Related EDT No::

$\mathrm{N} / \mathrm{A}$

7. Purchase order No.:

$\mathrm{N} / \mathrm{A}$

9. Equip./Component No.:

$\mathrm{N} / \mathrm{A}$

10. System/Bldg./Facility:

$\mathrm{N} / \mathrm{A}$

12. Major Assm. Dwg. No.:

$N / A$

13. Permit/Permit Application No.: $\mathrm{N} / \mathrm{A}$

14. Required Response Date:

ASAP

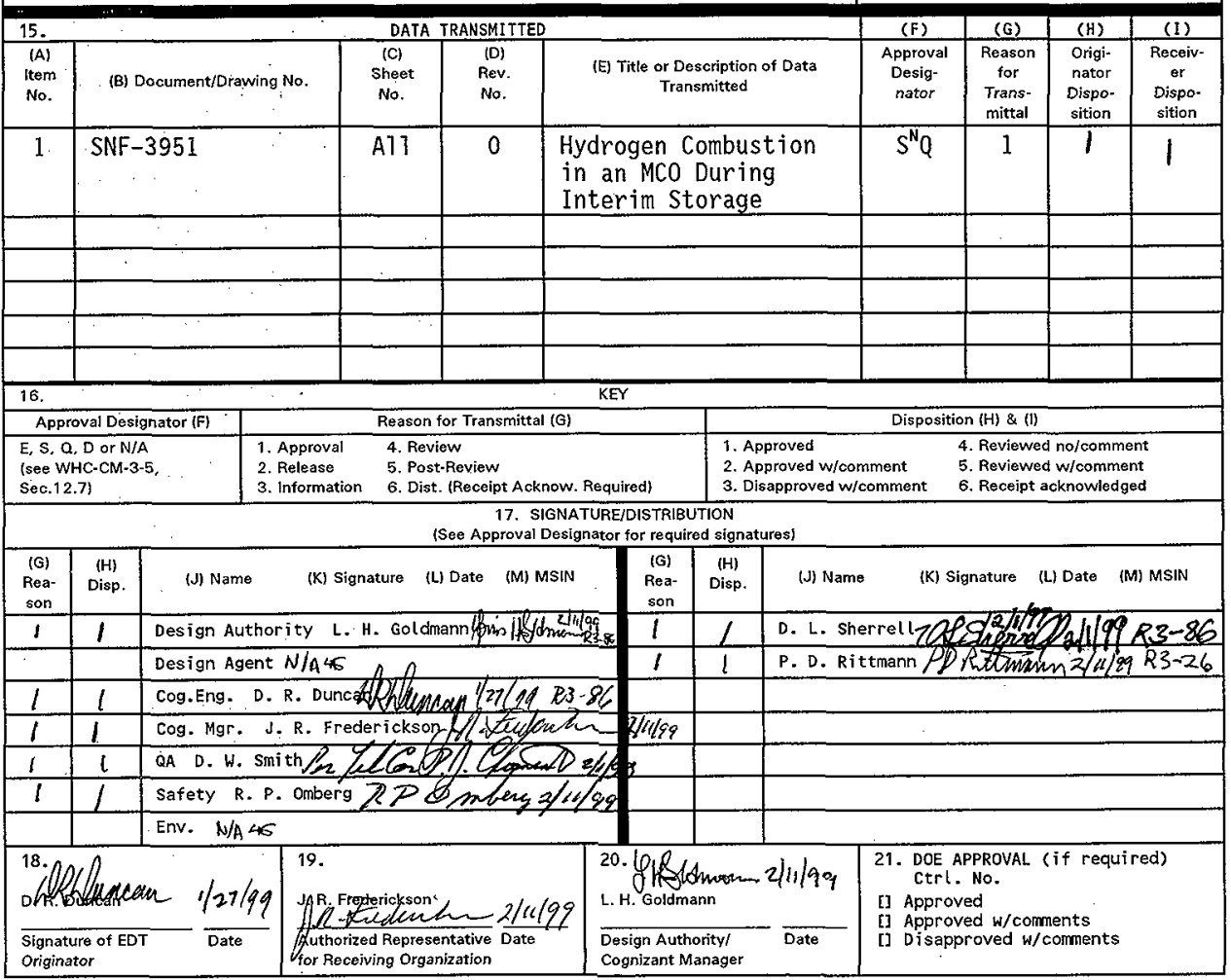




\title{
HYDROGEN COMBUSTION IN AN MCO DURING INTERIM STORAGE (FAUSKE \& ASSOCIATES REPORT 99-14)
}

\author{
M. G. P1ys* and D. R. Duncan
}

Duke Engineering \& Services Hanford, Inc., Richland, WA 99352

U.S. Department of Energy Contract DE-AC06-96RL13200
EDT/ECN: 625804
UC: 510
Org Code: 2F300
Charge Code: 105355/BA40
B\&R Code: EW7040000
Total Pages: 90

Key Words: MCO, flammable, combustion, deflagration, hydrogen

Abstract: Flammable conditions are not expected to develop in an MCO during interim storage. This report considers potential phenomena which, although not expected to occur, could lead to flammable conditions. For example, reactions of hydrogen with fuel over decades are postulated to lead to flammable atmospheric mixtures. For the extreme cases considered in this report, the highest attainable postcombustion pressure is about 13 atmospheres absolute, almost a factor of two and a half beiow the MCO design pressure of 31 atmospheres.

*Fauske \& Associates, Inc.

TRADEMARK DISCLAIMER. Reference herein to any specific comercial product, process, or service by trade name, trademark, manufacturer, or otherwise, does not necessarily constitute or imply its endorsement, recommendation, or favoring by the United States Government or any agency thereof or its contractors or subcontractors.

Printed in the United States of America. To obtain copies of this document, contact: Document Control Services, P.O. Box 950, Mailstop H6-08, Richland WA 99352, Phone (509) 372-2420; Fax (509) 376-4989.

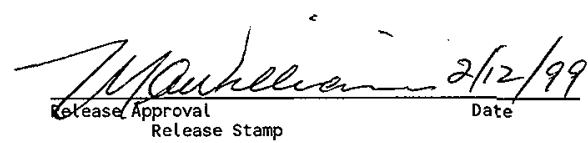

Approved for Public Release 
FAI/99-14, Rev. 1

\title{
HYDROGEN COMBUSTION IN AN MCO DURING INTERIM STORAGE
}

\author{
Submitted To: \\ Duke Engineering \& Services Hanford, Inc. \\ 2355 Stevens Drive \\ Richland, WA 99352
}

Prepared By:

Martin G. Plys

Fauske \& Associates, Inc.

16W070 West 83rd Street

Burr Ridge, minois 60521

Tel: (630) $323-8750$ Fax: (630) $986-5481$

February 1999 


\section{TABLE OF CONTENTS}

\section{Page}

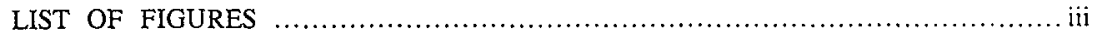

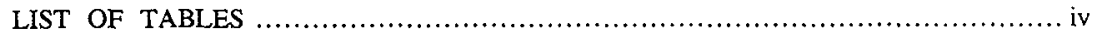

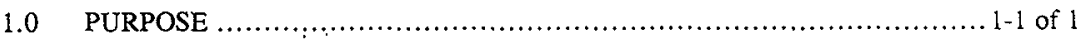

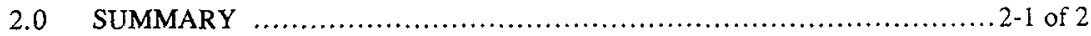

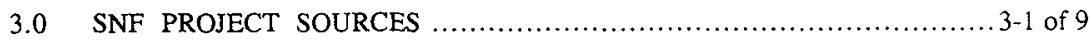

3.1 MCO Initial Conditions .............................................. $3-1$

3.2 MCO Gas Composition Model ........................................ 3-3

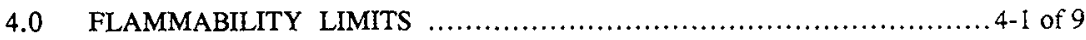

5.0 COMBUSTION MODEL ................................................ 5 - 5

6.0 HYDROGEN REACTIONS WITH URANIUM ........................ $6-1$ of 8

7.0 SUMMARY OF TECHNICAL BASES AND ASSUMPTIONS ............ $7-1$ of 1

8.0 CALCULATIONS .................................................... 8 of 8

8.1 MCO Atmosphere Sensitivity Cases .................................. $8-1$

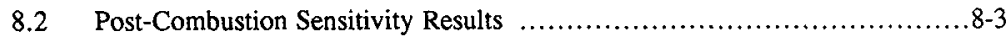

8.3 Conclusions ...............................................................

9.0 REFERENCES ................................................................

APPENDIX A AICC MATHCAD Model ................................ A-1 of 6

APPENDIX B Kirkpatrick-Condon Hydriding Model ....................... B-1 of 4

APPENDIX C Zero Scrap Combustion Sensitivity Cases .................... C-1 of 27

APPENDIX D Quality Assurance Documents ............................ D-1 of 3

FAI/99-14, Rev. $1 \quad$ - ii - Date: 2/9/99 


\section{LIST OF FIGURES}

Figure

Page

3-1 Zero Scrap Bounding High Water Case From [Duncan and Plys, 1998b] ........ 3-9

4-1 Limits of Flammability of Hydrogen-Air Mixtures With Added Nitrogen and Carbon Dioxide at $25^{\circ} \mathrm{C}$ and 1 atm [Kuchta, 1985]

4-2 Hydrogen-Air-Helium Flammability Limits Per [Coward and Jones, 1952] .......4-3

4-3 Hydrogen-Air-Steam Flammability Data and Curve Fit for [Marshall, 1986] .....4-4

4-4 Generalized $\mathrm{H}_{2}-\mathrm{CO}-\mathrm{Air}-\mathrm{H}_{2} \mathrm{O}-\mathrm{CO}_{2}-\mathrm{N}_{2}$ Flammability Limit Diagram ............4-7

4-5 Influence of Temperature on Limits of Flammability of Hydrogen in Air .........4-8

5-1 Pressure and Temperature for $\mathrm{H}_{2}$-Air and $\mathrm{H}_{2}-\mathrm{O}_{2}-\mathrm{He}$ Mixtures .................5-4

5-2 Pressure Ratio For Various Initial $\mathrm{H}_{2} \%$ and $\mathrm{O}_{2} \%$ in an MCO Backfilled to

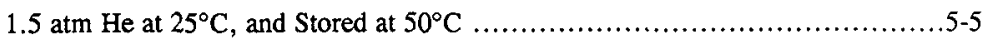

6-1 Fractional Hydriding $\alpha$ of $\mathrm{U}$ Metal Foil for $\mathrm{O}_{2}$ Concentrations .................6-2

6-2 Apparent Spall Front Velocity For a Hydrogen Pressure of $1.0 \mathrm{~atm}$ Showing

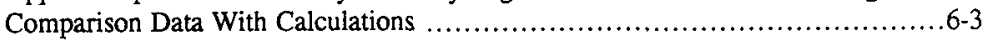

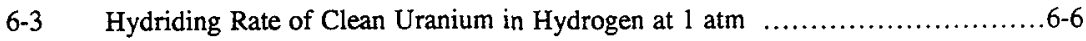

8-1 Oxygen at 40 Years for K-West Zero Scrap Bounding Water Content as Function of Reactive Area

8-2 Pressure vs. Oxygen Concentration for Zero Scrap, Nominal Backfill ............8-4

8-3 Pressure vs. Oxygen Concentration for Zero Scrap Indicating MCO Design

Pressure, Nominal Backfill

8-4 Pressure vs. Oxygen Concentration for Zero Scrap, Bounding Backfill

8-5 Pressure vs. Oxygen Concentration for Zero Scrap Indicating MCO Design

Pressure, Bounding Backfill 


\section{LIST OF TABLES}

Table

3-1 MCO Design Parameters Considered . $3-2$

3-2 Parameters Determining MCO Water Inventory

3-3 $\mathrm{g}\left(\mathrm{H}_{2}\right)$ and $\mathrm{g}\left(\mathrm{O}_{2}\right)$ Values 3-5

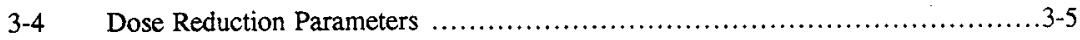

3-5 Average Beginning-of-Storage $\overline{\mathrm{g}}\left(\mathrm{H}_{2}\right)$ and $\overline{\mathrm{g}}\left(\mathrm{O}_{2}\right)$ Values ....................

4-1 Limits of Flammability of Mixtures of Hydrogen and Helium in Air .............. 4-5

5-1 Reference Heat Capacities at Constant Volume .............................5-2

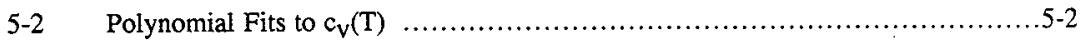




\subsection{PURPOSE}

The purpose of this report is to present a sensitivity analysis of hypothetical conditions beyond those anticipated for safety basis conditions for a Multi-Canister Overpack (MCO) loaded with spent nuclear fuel during interim storage which could lead to flammable gas compositions, to identify a suitable range of compositions and initial pressures, and to calculate corresponding hypothetical post-combustion conditions. Although flammable compositions are not expected according to references [Duncan and Plys, 1998b], initial conditions and phenomena required for flammable compositions to evolve are explored and a range of implied pre-combustion compositions and pressure are evaluated. Adiabatic, isochoric, complete combustion pressure and temperature are shown to conservatively define a post-combustion static pressure, and cases where incomplete combustion and non-adiabatic effects are important are identified.

This report, FAI/99-14, incorporates Hanford Spent Nuclear Fuel Project Review Comment Record dispositions based on FAI/98-113, which was a draft for review of scope and content, and it also includes an internal FAI review in compliance with project requirements. 


\subsection{SUMMARY}

Flammable conditions are not expected to develop in an $\mathrm{MCO}$ during interim storage given the phenomena and MCO material inventory considered by [Duncan and Plys, 1998a and 1998b]. This report considers phenomena and initial conditions which could potentially lead to flammable conditions. For example, reactions of hydrogen with fuel over decades of storage imply that in select cases presented by [Duncan and Plys, 1998b], flammable atmospheres could potentially evolve, although the initial inventories of hydrogen and oxygen would be low, and the initial pressure would be low, so that post-combustion conditions would a priori expected to be within MCO design limits.

Flammability data are presented for gases which may be present in an $\mathrm{MCO}$ during interim storage, namely, $\mathrm{H}_{2}-\mathrm{O}_{2}-\mathrm{He}_{2} \mathrm{H}_{2} \mathrm{O}$ mixtures, and a flammability criterion for oxygen concentration is presented which includes the effect of temperature (see equation (4-2)). The adiabatic, isochoric (constant volume), complete combustion state is conservative for prediction of postcombustion pressures because heat transfer, and in some cases incomplete combustion, would mitigate post-combustion conditions. A general chart (see Figure 5-2) is presented to obtain postcombustion conditions given pre-combustion values for $\mathrm{MCO} \mathrm{O}_{2}$ and $\mathrm{H}_{2}$ concentrations and pressure.

Literature data for reactions of hydrogen with uranium exist predominantly for the case of clean, unoxidized metal surfaces and reveal reaction rates which are several orders of magnitude faster than oxidation. Hydrogen reactions with uranium are likely to occur during interim storage, but the rate cannot be quantified with present information, so a range of possible hydrogen inventories in an MCO must be considered here. Thus the key quantity of interest for combustion evaluation is the $\mathrm{MCO}$ oxygen inventory, because this controls the available chemical energy. 
Worst-case oxygen inventories occur for the case of zero scrap baskets and $\mathrm{K}$-West fuel with the high bounding aluminum hydroxide cladding film inventory, and with other water sources also at the high bounding values. Variation of oxygen inventory is presented (Figure 8-1) and the zero reaction area limit is selected for a bounding inventory. Pre- and post-combustion pressures are shown as a function of end-of-life (40 years interim storage) pre-combustion oxygen concentration for nominal (Figures 8-2 and 8-3) and bounding (Figures 8-4 and 8-5) backfill cases. The worst case occurs for the highest MCO power, about $530 \mathrm{~W}$, for fuel with the bounding cladding film, because this has the highest oxygen inventory. Even in bounding cases considered here, the highest calculated post-combustion pressure is about 13 atmospheres absolute, about a factor of 2.4 below the MCO design pressure of $450 \mathrm{psig}(31 \mathrm{~atm})$ for the bounding helium backfill (Figure $8-5$ ). 


\subsection{SNF PROJECT SOURCES}

\subsection{MCO Initial Conditions}

MCOs are vacuum dried to remove free water and backfilled with helium at the Cold Vacuum Drying (CVD) stations, and are subsequently shipped to the Canister Storage Building (CSB) for interim dry storage. Quasi-steady state temperature and pressure are achieved within a matter of days at the CSB, and these are defined as initial conditions for analysis of the evolution of gas concentrations and pressure during interim storage.

Pertinent MCO design parameters are listed in Table 3-1 [Pajunen and Sederburg, 1998; and Sherrell, 1999], and the interim storage life listed is a definition from [Sellers, 1996]. Relatively quick attainment of quasi-steady temperature and pressure are demonstrated by [Duncan and Plys, 1998b], where a straightforward relationship between MCO temperature and power is developed:

$$
T=T_{a v}+\frac{Q}{U}
$$

where $\mathrm{T}=\mathrm{MCO}$ temperature at a given location, ${ }^{\circ} \mathrm{C}$,

$\mathrm{T}_{\mathrm{av}}=$ Vault ambient temperature, $12^{\circ} \mathrm{C}$,

$\mathrm{Q}=\mathrm{MCO}$ power, $\mathrm{W}$, and

$U \quad=$ Heat transfer conductance to location, $W / K$.

Here the average annual temperature is given, and the impact of annual variations is considered later on reaction rates. Values for the conductance $U$ determine the local temperature. In the cited work, conservative values implied lower temperatures, and hence, lower reaction rates. A conservative value of $12.4 \mathrm{~W} / \mathrm{K}$ applies for scrap, a conservative value for fuel is 9.5 
SNF-3951, Rev. 0

\begin{tabular}{|l|c|l||}
\hline \multicolumn{2}{|c|}{ Table 3-1: } & MCO Design Parameters Considered. \\
\hline Parameter & Value & \multicolumn{1}{c|}{ Comment } \\
\hline Free water inventory & $\leq 200 \mathrm{~g}$ & Radiolysis source \\
\hline Backfill gas & $\begin{array}{c}99.9 \% \mathrm{He} \\
25 \text { to } 35^{\circ} \mathrm{C} \\
0^{\circ} \mathrm{C}\end{array}$ & $\begin{array}{l}\text { Sets nominal initial condition } \\
\text { Backfill temperature }\end{array}$ \\
\begin{tabular}{|l}
40 to $60 \mathrm{kPa}$ gauge \\
$85 \mathrm{kPa}$ gauge \\
$<10^{-5} \mathrm{std} \mathrm{cc} / \mathrm{sec}$ \\
$<10^{-7} \mathrm{std} \mathrm{cc} / \mathrm{sec}$
\end{tabular} & $\begin{array}{l}\text { Sets nominal initial condition } \\
\text { Sets bounding initial condition } \\
\text { Mechanical Seal } \\
\text { Welded Seal }\end{array}$ \\
\hline Leakage test acceptance & $\begin{array}{c}450 \mathrm{psig} \\
\text { Maximum internal pressure }\end{array}$ & 30 atm gauge limit \\
\hline Interim storage duration & $\leq 40 \mathrm{years}$ & Calculation scope \\
\hline Released noble gases and He & $<0.2 \mathrm{~g} \cdot \mathrm{mole}$ & Neglect \\
\hline
\end{tabular}

$\mathrm{W} / \mathrm{K}$, and an average value for fuel is $8.3 \mathrm{~W} / \mathrm{K}$. To calculate $\mathrm{MCO}$ pressure, the average fuel value is recommended here, although the impact of this choice on results will be small.

MCO water inventories are more elaborate to present because they depend upon the number of scrap baskets and because references provide a range of estimates. Detailed values are derived by [Duncan and Plys, 1998a] and used in [Duncan and Plys, 1998b] to develop water inventories that depend upon fuel damage area, based upon the fact that some water sources are directly proportional to the inventory of material associated with fuel damage area. Values used in the previous work are listed in Table 3-2. The line item contributors are kept separate because of their variation with area and because their location determines alpha and beta dose relative to fuel, and chemical form determines gamma dose relative to fuel. 


\begin{tabular}{|c|c|c|}
\hline Parameter & Value & ange \\
\hline $\begin{array}{l}\text { Reactive Area: } \\
\text { Per Fuel Basket }\end{array}$ & $\begin{array}{ll}0.016 & \mathrm{~m}^{2} \text { minimum } \\
0.0425 \mathrm{~m}^{2} \text { average } \\
0.79 \quad \mathrm{~m}^{2} \text { maximum }\end{array}$ & \\
\hline $\begin{array}{l}\text { Reactive Area: } \\
\text { Per Scrap Basket }\end{array}$ & \begin{tabular}{|ll}
1 & $\mathrm{~m}^{2}$ minimum \\
1.7 & $\mathrm{~m}^{2}$ average \\
4.5 & $\mathrm{~m}^{2}$ maximum \\
\end{tabular} & \\
\hline Residual Free $\mathrm{H}_{2} \mathrm{O}$ & $66.7 \mathrm{~g} / \mathrm{m}^{2}$ & $200 \mathrm{~g}$ maximum \\
\hline Adhering Particulate $\mathrm{H}_{2} \mathrm{O}$ & \begin{tabular}{|ll}
50 & $\mathrm{~g} / \mathrm{m}^{2}$ nominal \\
100 & $\mathrm{~g} / \mathrm{m}^{2}$ sensitivity \\
\end{tabular} & $\begin{array}{r}297 \text { g max, } 0 \text { scrap } \\
667 \text { g max, 1 scrap } \\
1,032 \text { g max, } 2 \text { scrap } \\
\end{array}$ \\
\hline Canister Particulate $\mathrm{H}_{2} \mathrm{O}$ & $40 \quad$ g nominal & $\begin{array}{l}240 \text { g max, } 0 \text { scrap } \\
190 \text { g max, } 1 \text { scrap } \\
140 \text { g max, } 2 \text { scrap }\end{array}$ \\
\hline Bounding $\mathrm{H}_{2} \mathrm{O}$ from $\mathrm{Al}(\mathrm{OH})_{3}$ & $\begin{array}{|ll|}3.73 & \mathrm{~kg}, 0 \text { scrap } \\
3.52 & \mathrm{~kg}, 1 \text { scrap } \\
3.32 & \mathrm{~kg}, 2 \text { scrap } \\
\end{array}$ & \\
\hline Bounding $\mathrm{H}_{2} \mathrm{O}$ from $\mathrm{UO}_{4} 2 \mathrm{H}_{2} \mathrm{O}$ & 50 & \\
\hline
\end{tabular}

\subsection{MCO Gas Composition Model}

[Duncan and Plys, 1998b] present a model for the evolution of MCO gas composition which considers radiolysis sources of hydrogen and oxygen, depletion of water-bearing source materials, and consumption of oxygen via reactions with fuel. The model consists of a set of differential equations whose state variables are the numbers of moles of: (1) hydrogen gas, (2) oxygen gas, (3) free water, (4) water associated with the Al(OH) 3 cladding film, (5) water associated with $\mathrm{Al}(\mathrm{OH})_{3}$ in canister particulate, and (6) water associated with $\mathrm{UO}_{3} 2 \mathrm{H}_{2} \mathrm{O}$ and $\mathrm{UO}_{4} 2 \mathrm{H}_{2} \mathrm{O}$ from adhering particulate, canister particulate, and cladding films. The model considers time variation of decay power which reduces the dose rate for radiolysis and also reduces the MCO temperature and hence reactions of oxygen, using an exponential fit: 


$$
\ln \frac{Q_{i}}{Q_{i o}}=-\lambda_{i} t
$$

where $\mathrm{Q}_{\mathrm{i}}=$ Decay power, $\mathrm{W}$, from $\mathrm{i}=\alpha, \beta, \gamma$, or total,

$\mathrm{Q}_{\text {io }}=$ Initial value,

$\lambda_{\mathrm{i}}=$ Decay constant for decay power, $\mathrm{yr}^{-1}$, and

$\mathrm{t}=$ Time, years.

Production of gases by radiolysis is based on a dose fraction relative to uranium and $g$ values (molecules of gas produced per $100 \mathrm{ev}$ absorbed by the matrix) listed in Tables 3-3 and 3-4, respectively. Free water is assumed to be present in cracks in the fuel, and receives all radiation forms. Cladding films do not receive alpha and beta radiation. Canister particulate receives a reduced alpha and beta dose fraction relative to fuel based on the fraction of fuel in the particulate. All water-bearing materials receive a reduced gamma dose relative to uranium because of a lower energy absorption coefficient for gamma radiation relative to uranium metal.

For convenience, average beginning-of-life $g$ values for these materials are listed in Table 3-5. These are defined as:

$$
\bar{g}_{\mathrm{Pj}}=\sum_{i=\alpha, \beta, \gamma} g_{\mathrm{Pi}} r_{j i} f_{q i}(t)
$$

where $\overline{\mathrm{g}}_{\mathrm{Pj}}=$ Average $\mathrm{g}$ value for product gas $\mathrm{p}=\mathrm{H}_{2}$ or $\mathrm{O}_{2}$ from source material $\mathrm{j}$, molecule/ $100 \mathrm{ev}$,

$\mathrm{gPi}_{\mathrm{i}}=\mathrm{g}$ value for product gas $\mathrm{p}$ for radiation type $\mathrm{i}=\alpha, \beta, \gamma$,

$\mathrm{r}_{\mathrm{ji}} \quad=$ Absorption fraction of radiation type $\mathrm{i}$ for material $\mathrm{j}$ relative to $\mathrm{U}$ metal, and

$f_{q i}(t)=$ Power fraction from equation (3-2). 
SNF-3951, Rev. 0

Table 3-3: $\mathrm{g}\left(\mathrm{H}_{2}\right)$ and $\mathrm{g}\left(\mathrm{O}_{2}\right)$ Values, molecules/100 ev

\begin{tabular}{|c|c|c|c|}
\hline $\mathbf{g}\left(\mathbf{H}_{2}\right)$ & Alpha & Beta & Gamma \\
\hline $\mathrm{H}_{2} \mathrm{O}$ - Liquid & (2) & 0.53 & $0.5 \quad(3)$ \\
\hline $\mathrm{H}_{2} \mathrm{O}$ - Vapor & - & - & $0.5 \quad(1)$ \\
\hline $\mathrm{Al}(\mathrm{OH})_{3}$ & 0.525 & $0.1575(6)$ & $1.2 \quad(4)$ \\
\hline $\mathrm{UO}_{3} \cdot 2 \mathrm{H}_{2} \mathrm{O}$ & 0.165 (5) & $0.05 \quad(6)$ & $1.2 \quad(4)$ \\
\hline $\mathrm{UO}_{3} \cdot \mathrm{H}_{2} \mathrm{O}$ & $0.083(5)$ & $0.025 \quad(6)$ & $1.2 \quad(4)$ \\
\hline $\mathrm{g}\left(\mathrm{O}_{2}\right)$ & Alpha & Beta & Gamma \\
\hline $\mathrm{H}_{2} \mathrm{O}$ - Liquid & 0.8 & 0.265 & 0.25 \\
\hline $\mathrm{H}_{2} \mathrm{O}$ - Vapor & - & - & 0.25 \\
\hline $\mathrm{Al}(\mathrm{OH})_{3}$ & $0.2625(9)$ & $0.07875(10)$ & 0.135 \\
\hline $\mathrm{UO}_{3} \cdot 2 \mathrm{H}_{2} \mathrm{O}$ & 0.083 & $0.025 \quad(10)$ & 0.101 \\
\hline $\mathrm{UO}_{3} \cdot \mathrm{H}_{2} \mathrm{O}$ & 0.041 & $0.013 \quad(10)$ & $0.055 \quad$ (11) \\
\hline \multicolumn{4}{|c|}{ 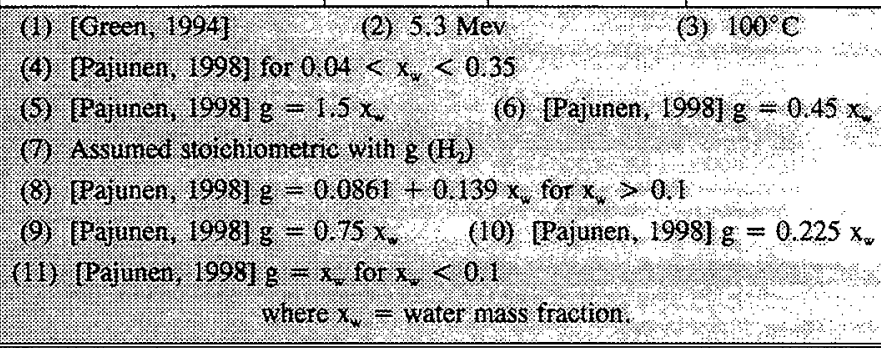 } \\
\hline
\end{tabular}

\begin{tabular}{|c|c|c|c|}
\hline \multicolumn{4}{|c|}{ Table 3-4: Dose Reduction Parameters } \\
\hline $\mathrm{Al}(\mathrm{OH})_{3} / \mathrm{U}$ & 0.35 & & Gamma \\
\hline $\mathrm{UO}_{3} 2 \mathrm{H}_{2} \mathrm{O} / \mathrm{U}$ & 0.86 & & Gamma \\
\hline $\mathrm{H}_{2} \mathrm{O} / \mathrm{U}$ & 0.38 & & Gamma \\
\hline Alpha, Beta for Canister Particulate & $\begin{array}{l}1.0 \\
0.2 \\
\end{array}$ & $\begin{array}{l}\text { Nomine } \\
\text { Boundi }\end{array}$ & $\begin{array}{l}\text { water content } \\
\text { water content }\end{array}$ \\
\hline Alpha decay power constant & -0.00463 & & $\mathrm{yr}^{-1} \quad(1,2)$ \\
\hline Beta decay power constant & +0.0241 & & $\mathrm{yr}^{-1} \quad(2)$ \\
\hline Gamma decay power constant & +0.00242 & & $\mathrm{yr}^{-1} \quad(2)$ \\
\hline Overall decay power constant & +0.0149 & & $\mathrm{yr}^{-1}$ (2) \\
\hline
\end{tabular}


SNF-3951, Rev. 0

\begin{tabular}{|c|c|c|}
\hline \multicolumn{3}{|c|}{$\begin{array}{l}\text { Table 3-5: } \\
\text { Average Beginning-of-Storage } \overline{\mathrm{g}}\left(\mathrm{H}_{2}\right) \text { and } \overline{\mathrm{g}}\left(\mathrm{O}_{2}\right) \text { Values, } \\
\text { molecules } / 100 \mathrm{ev}\end{array}$} \\
\hline $\begin{array}{l}\mathrm{H}_{2} \mathrm{O} \text {-Liquid } \\
\mathrm{H}_{2} \mathrm{O}-\mathrm{Vapor} \\
\mathrm{Al}(\mathrm{OH})_{3} \text {, clad } \\
\mathrm{Al}(\mathrm{OH})_{3} \text {, partic. } \\
\mathrm{UO}_{3} \cdot 2 \mathrm{H}_{2} \mathrm{O}\end{array}$ & $\begin{array}{l}\bar{g}\left(\mathbf{H}_{2}\right) \\
0.63 \\
0.16 \\
0.13 \\
0.31 \\
0.38\end{array}$ & $\begin{array}{l}\bar{g}\left(\mathrm{O}_{2}\right) \\
0.32 \\
0.08 \\
0.015 \\
0.10 \\
0.056\end{array}$ \\
\hline \multicolumn{3}{|c|}{ 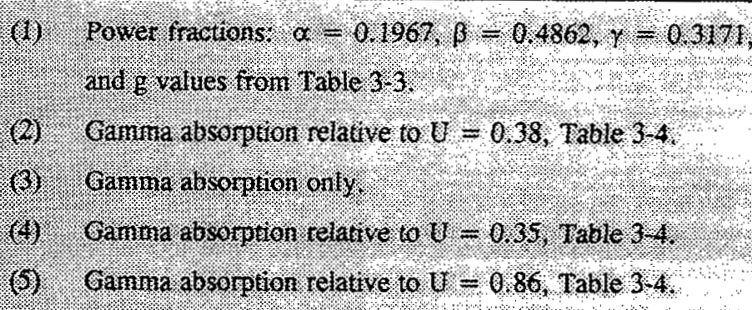 } \\
\hline
\end{tabular}

Differential equations used by [Duncan and Plys, 1998b] are summarized as:

$$
\begin{aligned}
& \frac{d n_{j}}{d t}=-\lambda_{0 j} \bar{g}_{\mathrm{H} 2 \mathrm{j}} n_{j} \\
& \frac{d n_{\mathrm{H} 2}}{d t}=-\sum_{j} \frac{1}{a_{j}} \frac{d n_{j}}{d t} \\
& \frac{d n_{\mathrm{O} 2}}{d t}=R_{O 2}-G_{O 2}
\end{aligned}
$$




$$
\begin{aligned}
& \text { where } \lambda_{o j}=a_{j} C\left(\frac{Q}{M}\right)_{0} M_{j} \\
& \lambda_{\mathrm{j}}=\text { Decay constant, } \mathrm{yr}^{-1} \text {, } \\
& \mathrm{n}_{\mathrm{j}} \quad=\quad \text { Number of moles of water from source compound } \mathrm{j} \text {, } \\
& \mathrm{a}_{\mathrm{j}}=\text { Moles compound } \mathrm{j} \text { depleted per mole } \mathrm{H}_{2} \mathrm{O} \text { decomposed, } \\
& \mathrm{C}=\text { Conversion constant, } 1.038 \times 10^{-7} \text {, } \\
& \left(\frac{\mathrm{Q}}{\mathrm{M}}\right)_{0}=\quad \text { Initial Power per unit mass fuel, } \mathrm{W} / \mathrm{kgU} \text {, } \\
& \mathrm{M}_{\mathrm{j}} \quad=\quad \text { Molecular weight compound } \mathrm{j} \text {, } \\
& \mathrm{R}_{\mathrm{O} 2}=\mathrm{O}_{2} \text { source, mole } 1 \text { year, evaluated like equation (3-5) but using } \mathrm{g} \text { values for } \\
& \mathrm{O}_{2} \text { production, and } \\
& \mathrm{G}_{\mathrm{O} 2}=\mathrm{O}_{2} \text { getter rate, mole/year. }
\end{aligned}
$$

The oxygen getter (consumption) rate is found by applying the appropriate kinetic rate law, evaluated at one average scrap temperature and three fuel temperatures, and considering the reaction area at each location. The Ritchie Law for uranium reactions in moist air and relative humidity less than $75 \%$ :

$$
\log _{10} R_{\text {moist }}=13.808-\frac{5769.6}{T}
$$

where $\mathrm{R}=$ Weight gain, $\mathrm{mg} / \mathrm{cm}^{2} \mathrm{hr}$, and

$$
\mathrm{T}=\text { Temperature, } \mathrm{K} \text {. }
$$

Unless the dry air correlation of Trimble is greater:

$$
\log _{10} R_{d r y}=7.19-\frac{3732}{T}
$$


which occurs below about $40^{\circ} \mathrm{C}$.

A notable model assumption is that hydrogen does not react with fuel. As explained in the source document, there is no reliable technical basis for quantification of the rate of reaction between hydrogen and dirty, oxidized uranium surfaces. Qualitatively, there are indications based upon experience that such reactions will occur over sufficient time. The impact of such reactions is to reduce the inventory of hydrogen, and thereby increase the concentration of all other gases.

Also, reactions between oxygen and uranium hydride are not considered. This is chiefly because the amount of hydride is difficult to quantify. In part however, uranium hydride may form due to reactions between hydrogen and uranium metal, as discussed above. The impact of oxygen reactions with uranium hydride is potentially greater oxygen removal rates and greater hydrogen production rates relative to consideration of fuel reactions alone. Note that a small mass of uranium hydride may provide a lot of surface area due to its small particle size, but assignment of the proper surface area and inventory requires some justification.

Figure 3-1, taken from [Duncan and Plys, 1998b], presents worst case end-of-storage results obtained with the model as described. These are worst case because of the combination of high $\mathrm{Al}(\mathrm{OH})_{3}$ cladding film inventory, i.e., K-West fuel, zero scrap baskets, and other water sources at the high values. The maximum MCO power is $525 \mathrm{~W}$ for this case, so the highest oxygen concentration at 40 years is less than $4 \%$, even when zero reactive area is considered. (A case with initial $\mathrm{He}=1.0 \mathrm{~atm}$ to represent leakage was considered in the reference, but not shown here because leakage over 40 years would also remove oxygen.) 
SNF-3951, Rev. 0

Figure 3-1: Zero Scrap Bounding High Water Case From [Duncan and Plys, 1998b].

Oxygen Porcantage at 40 Years as a Function of MCO Power for Various Reactive Surface Areas. Zero Scrap, Bounding Case: $10.6 \mathrm{~kg} \mathrm{Al}(\mathrm{OH}) 3 \mathrm{Clad}$ Film, $100 \mathrm{~g} / \mathrm{m}^{\wedge} 2$ Adher. Partic. $\mathrm{H} 2 \mathrm{O}, 240 \mathrm{~g}$. Can. Partic. $\mathrm{H} 2 \mathrm{O}, 66.7 \mathrm{~g} / \mathrm{m}^{\wedge} 2$ free $\mathrm{H} 2 \mathrm{O}$

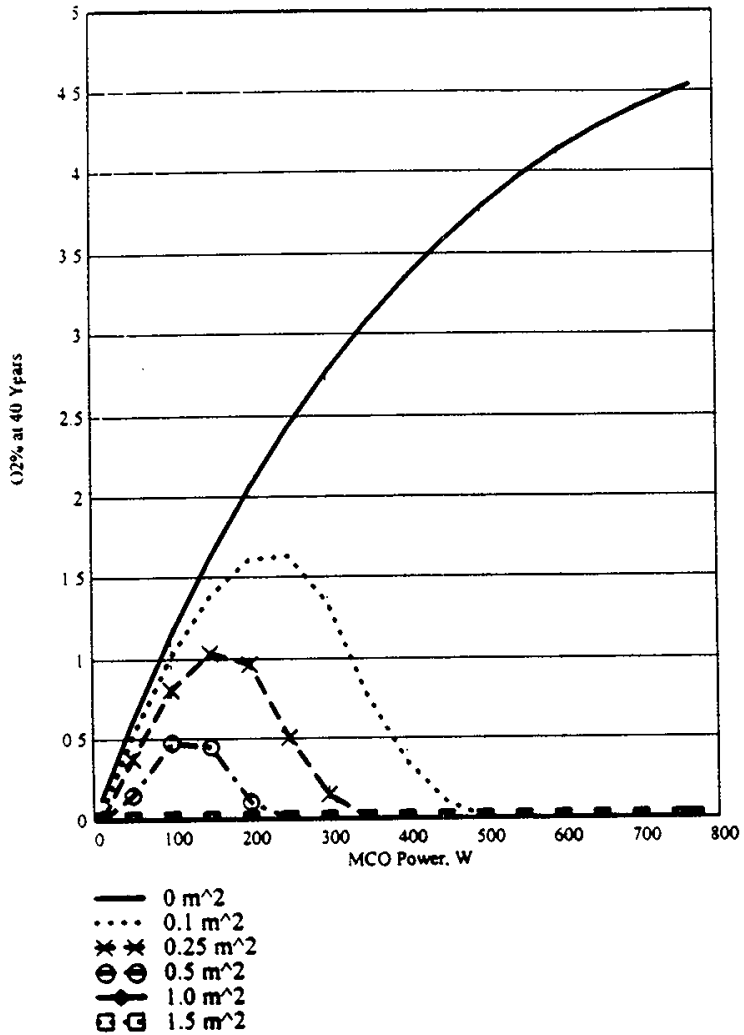




\subsection{FLAMMABILITY LIMITS}

Flammability limit diagrams are typically found in the literature for Fuel-Air-Inertant mixtures. The conditions of interest for the present $\mathrm{MCO}$ analysis are Hydrogen-Oxygen-Inertant mixtures, where the inertant gas is either nitrogen (from air), helium, water vapor, or a combination of the three gases. Air contains $20.8 \%$ oxygen and $79.2 \%$ nitrogen plus other gases (about $1 \%$ argon for example), and nitrogen is not normally present in an $\mathrm{MCO}$. Therefore the issue for MCO application is how to employ the typically available data in a nitrogen-deficient environment.

Figures 4-1, 4-2, and 4-3, respectively, contain flammability limit diagrams for hydrogen in air with added nitrogen, helium, and water vapor inertants, respectively. The flammable region lies inside the curve. The nose of the curve is the inerting point, which establishes the amount of inertant guaranteed to prevent flammability for any fuel-air ratio, and it typically coincides with a stoichiometric fuel-air mixture. The lower portion of the curve is the Lean or Lower Flammability Limit (LFL), corresponding to hydrogen concentrations less than stoichiometric, and the upper portion of the curve is the Rich or Upper Flammability Limit (RFL), corresponding to hydrogen concentrations greater than stoichiometric, or put another way, corresponding to the minimum oxygen requirement for flammability. The axes of the diagram are the concentrations of the fuel and inertant components, so that the air concentration is simply 100 minus the sum; the diagonal border of Figure 4-1 represents the border of possible mixtures.

The diagram for nitrogen appears in [Zabetekis, 1965] and [Kuchta, 1985]. Extra nitrogen in air occurs when air is oxygen-deficient, for example, by design (addition of nitrogen) or after a combustion event which consumes some of the oxygen. The diagram for helium was developed based upon a data table in [Coward and Jones, 1952] reproduced in Table 4-1. The nitrogen and helium diagrams are based on a temperature of $25^{\circ} \mathrm{C}$. The diagram for water vapor contains the data and curve fit of [Marshall, 1986], taken at temperatures above $100^{\circ} \mathrm{C}$ to prevent condensation. Increasing temperature expands the flammability limits, as discussed below. 
SNF-3951, Rev. 0

\section{Figure 4-1:}

Limits of Flammability of Hydrogen-Air Mixtures With Added Nitrogen and Carbon Dioxide at $25^{\circ} \mathrm{C}$ and $1 \mathrm{~atm}$. [Kuchta, 1985]

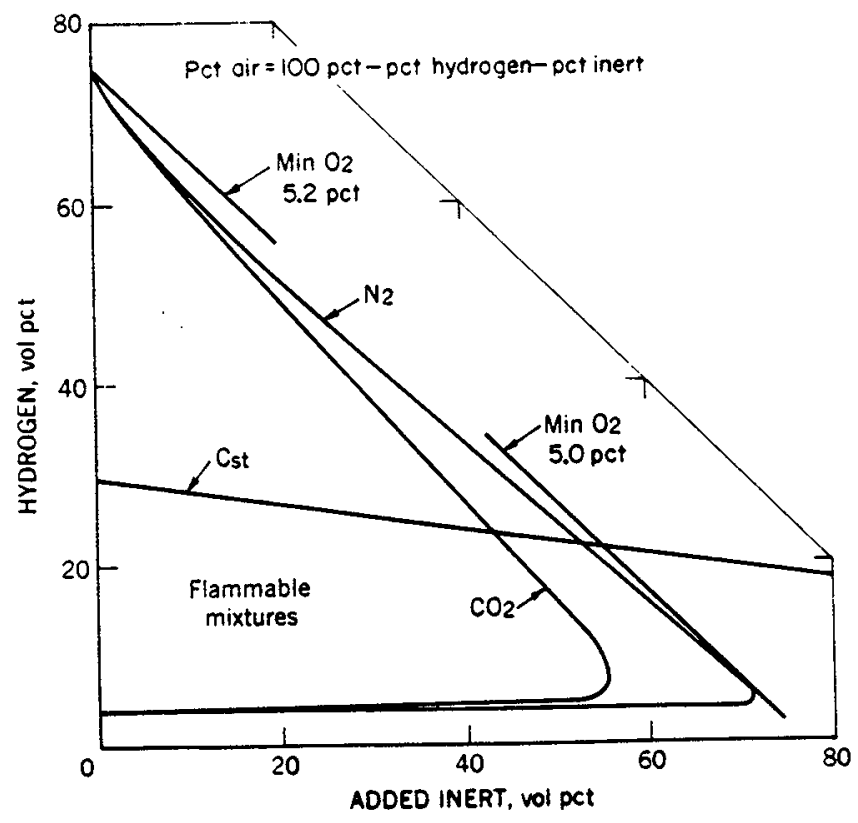


Figure 42: Hydrogen-Air-Helium Flammability Limits Per [Coward and Jones, 1952].

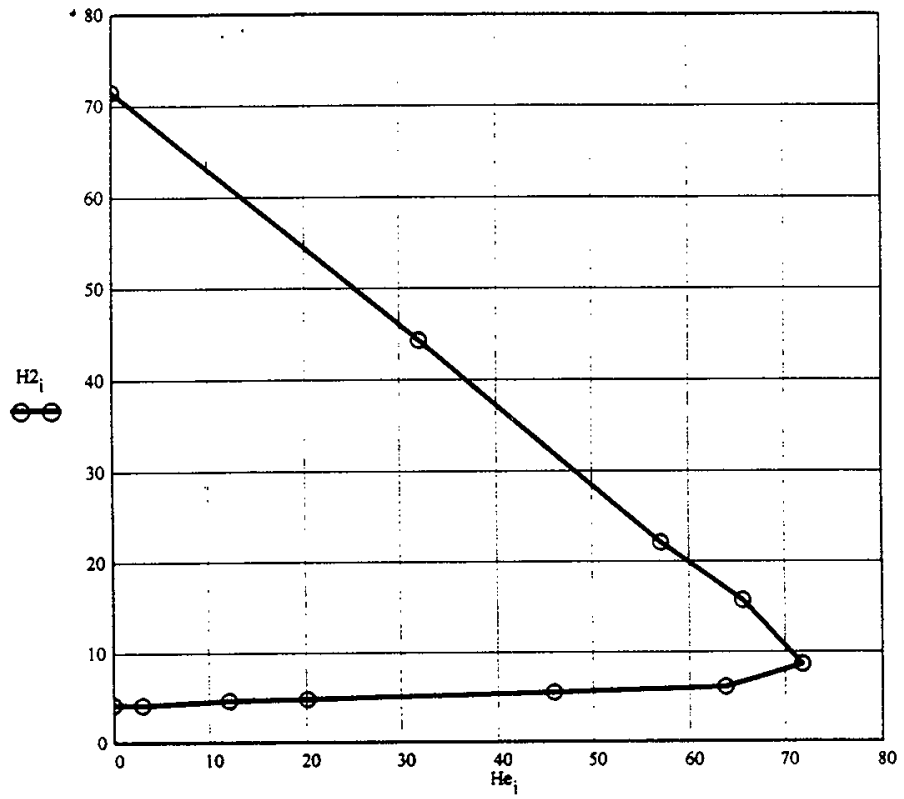


Figure 4-3: Hydrogen-Air-Steam Flammability Data and Curve Fit for [Marshall, 1986].

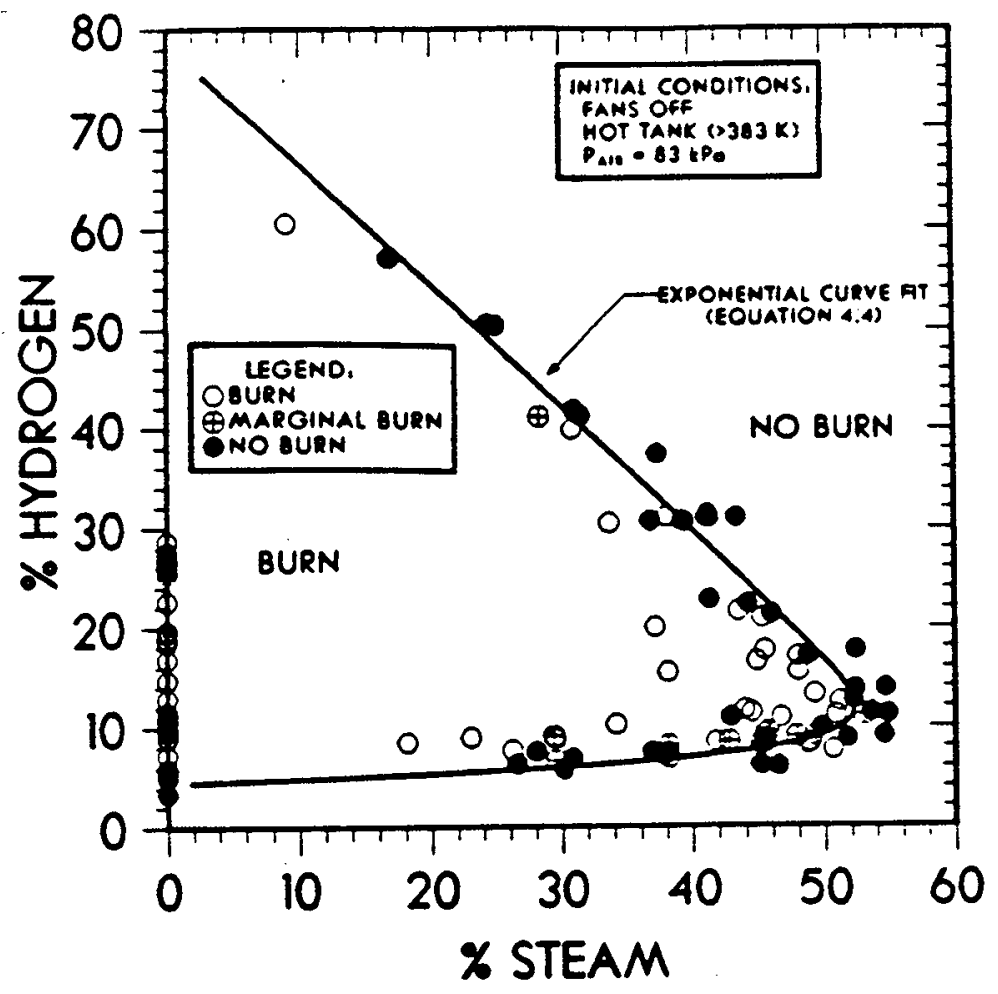




\section{Table 4-1:}

Limits of Flammability of Mixtures of Hydrogen and Helium in Air, Upward Propagation of Flame in Tube $2^{\prime \prime}$ in Diameter and $6^{\prime}$ in Length, Open at its Lower End [Coward and Jones, 1952].

\begin{tabular}{|c|c|c|c|c|}
\hline \multicolumn{2}{|c|}{ Fuel Plus Inertant Gas Mixture, \% } & \multicolumn{2}{|c|}{ Limits of Flammability, \% } & \multirow{2}{*}{$\begin{array}{c}\text { Minimum Oxygen } \\
\text { Concentration, \% }\end{array}$} \\
\hline Hydrogen & Helium & Lower & Upper & 6.00 \\
\hline 58.1 & 0 & 4.2 & 71.5 & 5.00 \\
27.9 & 41.9 & 7.1 & 76.2 & 4.37 \\
19.3 & 72.1 & 16.6 & 79.2 & 3.95 \\
10.7 & 80.7 & 24.9 & 81.2 & 4.14 \\
8.7 & 89.3 & 51.3 & 80.3 & 6.34 \\
\hline
\end{tabular}

Note that for zero inertant, the y-intercepts of all three diagrams should be identical at the LFL and RFL, and take on values of $4 \%$ and $75 \%$, respectively [Kuchta, 1985]. The RFL implies $5.2 \% \mathrm{O}_{2}$ and $19.8 \% \mathrm{~N}_{2}$. The RFL of the $\mathrm{H}_{2}$-Air-He diagram is in conflict with the RFL of the other diagrams, i.e., about $6 \%$ oxygen is demanded for flammability versus the well-established value of $5 \%$, which suggests the possibility that the oxygen concentration for flammability is overestimated by other points of the diagram too.

For the case of zero nitrogen, i.e., pure $\mathrm{H}_{2}-\mathrm{O}_{2}$ mixtures, the LFL and RFL are given as $4 \%$ and $95 \% \mathrm{H}_{2}$, respectively [Zabetekis, 1965]. When He replaces $\mathrm{N}_{2}$ in air, the LFL and RFL are $7.72 \%$ and $75.7 \%$, respectively. Note that the LFL is somewhat higher for He than $\mathrm{N}_{2}$ as the inertant, but the RFL is, for practical purposes, the same for $\mathrm{He}$ and $\mathrm{N}_{2}$, and implies $5 \% \mathrm{O}_{2}$ as the minimum required to support combustion. 
It is possible to create generalized flammability limit diagrams for combinations of fuels and inertants as shown in Figure 4-4 [Plys, 1993]. However, this level of detail is only necessary when the LFL must be considered as well as the RFL. Because the present application is concerned with hydrogen-rich mixtures, a simplified approach may be taken to combine the information provided by the RFL curves of Figures 4-1 to 4-3.

A common feature of the RFL curves for inertants of interest is the $5 \% \mathrm{O}_{2}$ limit for low inertant concentrations. Both the $\mathrm{N}_{2}$ and He RFL curves show deviations from the straight line of constant oxygen concentration, and as seen from Table 4-1 at minimum value of $4 \%, \mathrm{O}_{2}$ was found near the inerting point, for example. For $10 \% \mathrm{H}_{2} \mathrm{O}$, Marshall's curve fit implies $4.8 \%$ $\mathrm{H}_{2} \mathrm{O}$. Typically the $\mathrm{H}_{2} \mathrm{O}$ concentration in an $\mathrm{MCO}$ cannot far exceed $10 \%-20 \%$ because of saturation at the storage temperature, and most of the MCO gas is He due to the backfill. Therefore a conservative RFL curve has $4 \%$ oxygen.

Another prominent feature of the flammability limit curves is the position of the inerting point, or "nose". From Figure 4-1, coordinates of the nose for $\mathrm{H}_{2}$-air- $\mathrm{N}_{2}$ are about $4 \% \mathrm{H}_{2}, 71 \%$ added $\mathrm{N}_{2}$ (see [Kuchta, 1985, p. 32]), implying 5.2\% $\mathrm{O}_{2}$ and $19.8 \% \mathrm{~N}_{2}$ in air, for a total of about $91 \%$ inertant gas. From Figure 4-2, coordinates of the nose for $\mathrm{H}_{2}$-air-He are: $72 \% \mathrm{He}$, $8.6 \% \mathrm{H}_{2}, 4.1 \% \mathrm{O}_{2}$, and $15.6 \% \mathrm{~N}_{2}$, for a total of about $72+16=88 \%$ inertant gas. Less steam, about $55 \%$ in air, is required for inerting, but such high steam concentrations are not of current practical interest for an MCO. Thus a conservative criterion for inerting in an $\mathrm{MCO}$ is a total inertant concentration of $88 \%$.

The flammability envelope expands with increasing temperature, as shown for hydrogen in air in Figure 4-5. Zabetekis proposed a formula known as the modified Burgess-Wheeler Law (after the original authors of such a correlation) for the RFL of hydrocarbons in air:

$$
R(T)=R(25)+\frac{0.75}{\Delta H_{c}}(T-25)
$$


Figure 4-4: Generalized $\mathrm{H}_{2}$-CO-Air- $\mathrm{H}_{2} \mathrm{O}-\mathrm{CO}_{2}-\mathrm{N}_{2}$ Flammability Limit Diagram.

The inertant contains equal mole fractions of $\mathrm{N}_{2}$ and $\left(\mathrm{CO}_{2}+\mathrm{H}_{2} \mathrm{O}\right)$, and separate curves are shown for three fuels: $\mathrm{H}_{2}, \mathrm{CO}$, and $\mathrm{H}_{2}+\mathrm{CO}$ combined at equal mole fraction.

[Plys, 1993].

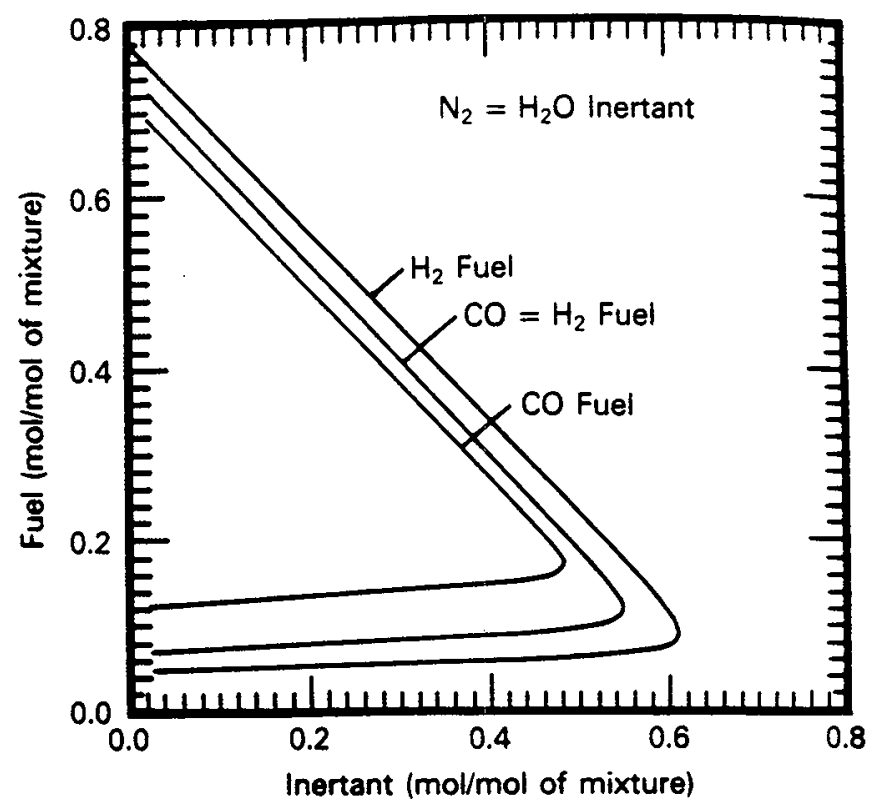

FAI/99-14, Rev. 1 
SNF-3951, Rev. 0

Figure 4-5:

Influence of Temperature on Limits of Flammability of Hydrogen in Air

(Downward Propagation of Flame). [Coward and Jones, 1952].

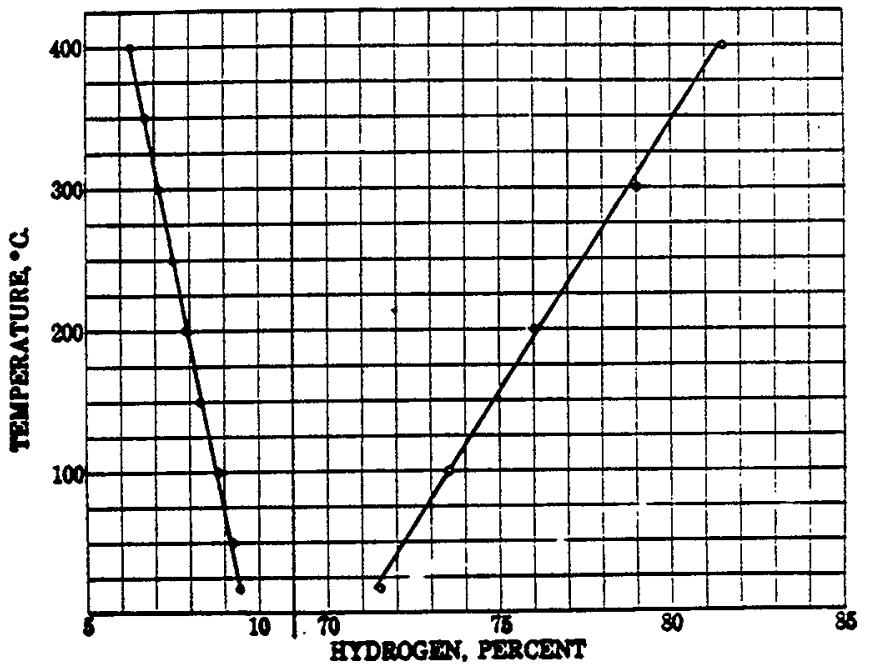




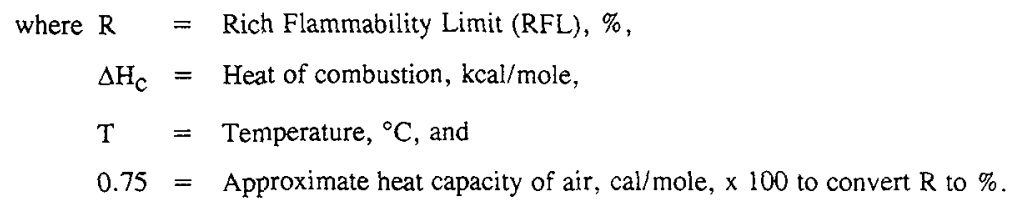

The heat of combustion of hydrogen is $57.8 \mathrm{kcal} / \mathrm{mole}(241.8 \mathrm{~kJ} / \mathrm{mole})$. The modified Burgess-Wheeler Law implies that the flammability envelope expands to its maximum $\left(100 \% \mathrm{H}_{2}\right.$ at the zero inertant limit) at a temperature of $1,952^{\circ} \mathrm{C}$. However, the auto-ignition temperature for hydrogen in air is closer to $700^{\circ} \mathrm{C}$. From hydrogen data of Figure $4-5$, a slope of $(10 \% /$ $380 \mathrm{~K})=0.0263$ is derived, which is greater than $(0.75 / 57.8)=0.013$. Thus for MCO application, since $\mathrm{O}_{2}$ is $20.8 \%$ of the inertant for derivation of the Burgess-Wheeler Law, the $\mathrm{O}_{2}$ concentration for flammability may be written:

$$
\mathrm{O}_{2} \%(\mathrm{~T})=4-0.00547(\mathrm{~T}-25)
$$

This implies zero $\mathrm{O}_{2} \%$ required at $756^{\circ} \mathrm{C}$ because $4 \% \mathrm{O}_{2}$ was taken as the intercept at $25^{\circ} \mathrm{C}$, versus $5.2 \%$ implied by an RFL of $75 \% \mathrm{H}_{2}$ at $25^{\circ} \mathrm{C}$. Equation (4-2) is in accord with measured temperature variation for flammability in the $\mathrm{H}_{2}$-air system and is conservative by use of $4 \%$ oxygen as a limiting value when $\mathrm{He}$ is present. 


\subsection{COMBUSTION MODEL}

Conservative post-combustion static pressure may be calculated using the adiabatic, isochoric (constant volume), complete combustion (AICC) relationship:

$$
\mathrm{U}_{\mathrm{p}}=\mathrm{U}_{\mathrm{r}}+\Delta \mathrm{H}
$$

$$
\text { where } \begin{array}{rll}
\mathrm{U} & = & \text { Internal energy, } \mathrm{J}, \\
\Delta \mathrm{H} & = & \text { Heat of reaction, } \mathrm{J}, \\
\mathrm{p} & = & \text { Product gases, and } \\
\mathrm{r} & = & \text { Reactant gases. }
\end{array}
$$

Specifying the initial temperature as a reference state, $U_{\mathrm{r}}=0$, and the equation may be written

$$
\sum_{i} n_{i p}\left[u_{i}\left(T_{p}\right)-u_{i}\left(T_{r}\right)\right]=\Delta H
$$

$$
\text { where } \begin{aligned}
n_{\mathrm{i}} & =\quad \text { Number of moles of gas } \mathrm{i} \text {, and } \\
\mathrm{u}_{\mathrm{i}} & =\quad \text { Internal energy function of gas } \mathrm{i} \text { (at low pressure). }
\end{aligned}
$$

The internal energy is merely the integral of the specific heat at constant volume, $c_{v}(T)$, and the caveat "at low pressure" is added to indicate that ideal gas behavior is assumed such that $U$ does not also depend on specific volume. Table 5-1 contains reference values for $c_{V}(T)$ and Table 5-2 contains polynomial fits which may be integrated analytically to yield the internal energy.

The heat of combustion and number of product moles are found by determining whether $\mathrm{H}_{2}$ or $\mathrm{O}_{2}$ is the limiting reactant: 


\begin{tabular}{|c|c|c|c|c|c|}
\hline \multicolumn{6}{|c|}{$\begin{array}{c}\text { Table 5-1: Reference Heat Capacities at Constant Volume, J/mole/K } \\
\text { [Chase, et al., 1985] }\end{array}$} \\
\hline $\mathbf{T}(\mathbf{K})$ & $\mathrm{H}_{2}$ & $\mathrm{He}$ & $\mathbf{N}_{2}$ & $\mathrm{O}_{2}$ & $\mathrm{H}_{2} \mathrm{O}$ \\
\hline 298.15 & 20.866 & 12.47 & 20.64 & 20.783 & 25.18 \\
\hline 500 & 20.909 & 12.47 & 21.37 & 22.831 & 26.94 \\
\hline 1,000 & 21.87 & 12.47 & 24.258 & 26.36 & 32.859 \\
\hline 1,500 & 24.056 & 12.47 & 26.647 & 28.045 & 38.756 \\
\hline 2,000 & 27.331 & 12.47 & 27.475 & 28.505 & 43.214 \\
\hline
\end{tabular}

\begin{tabular}{|c|c|c|c|c|c|}
\hline \multicolumn{6}{|c|}{$c_{\mathbf{v}}(\mathbf{T})=\mathrm{A}+\mathrm{BT}+\mathrm{CT}^{2}+\mathrm{DT}^{3}+\mathrm{ET}^{4}$, Output Value in $\mathbf{J} / \mathrm{mole} / \mathrm{K}$} \\
\hline GAS & $\mathbf{A}$ & B & $\mathbf{C}$ & D & $\bar{E}$ \\
\hline $\mathbf{H}_{2}$ & 21.136 & $-1.529 \times 10^{-3}$ & $1.978 \times 10^{-6}$ & $4.018 \times 10^{-10}$ & $-1.171 \times 10^{-13}$ \\
\hline $\mathrm{He}$ & 12.47 & 0 & 0 & 0 & 0 \\
\hline $\mathbf{N}_{2}$ & 20.785 & $-3.871 \times 10^{-3}$ & $1.34 \times 10^{-5}$ & $-7.216 \times 10^{-9}$ & $1.16 \times 10^{-12}$ \\
\hline $\mathbf{O}_{2}$ & 17.045 & 0.014 & $-4.96 \times 10^{-6}$ & $1.375 \times 10^{-10}$ & $1.375 \times 10^{-13}$ \\
\hline $\mathrm{H}_{2} \mathrm{O}$ & 24.044 & $-7.883 \times 10^{-5}$ & $1.513 \times 10^{-5}$ & $-7.323 \times 10^{-9}$ & $1.087 \times 10^{-12}$ \\
\hline
\end{tabular}

$$
\begin{aligned}
& \Delta n_{\mathrm{H} 2 \mathrm{O}}=\min \left(\mathrm{n}_{\mathrm{H} 2, \mathrm{r}}, 2 \mathrm{n}_{\mathrm{O} 2, \mathrm{r}}\right) \\
& \mathrm{n}_{\mathrm{He}, \mathrm{p}}=\mathrm{n}_{\mathrm{He}, \mathrm{r}} \\
& \mathrm{n}_{\mathrm{N} 2, \mathrm{p}}=\mathrm{n}_{\mathrm{N} 2, \mathrm{r}} \\
& \mathrm{n}_{\mathrm{H} 2, \mathrm{p}}=\mathrm{n}_{\mathrm{H} 2, \mathrm{r}}-\Delta \mathrm{n}_{\mathrm{H} 2 \mathrm{O}} \\
& \mathrm{n}_{\mathrm{O} 2, \mathrm{p}}=\mathrm{n}_{\mathrm{O} 2, \mathrm{r}}-\frac{1}{2} \Delta \mathrm{n}_{\mathrm{H} 2 \mathrm{O}} \\
& \mathrm{n}_{\mathrm{H} 2 \mathrm{O}, \mathrm{p}}=\mathrm{n}_{\mathrm{H} 2 \mathrm{O}, \mathrm{r}}+\Delta \mathrm{n}_{\mathrm{H} 2 \mathrm{O}}
\end{aligned}
$$




$$
\Delta \mathrm{H}=241.8 \times 10^{3} \Delta \mathrm{n}_{\mathrm{H} 2 \mathrm{O}}
$$

where $241.8 \mathrm{KJ} /$ mole is the heat of combustion.

Figure 5-1 displays the AICC pressure and temperature as the initial hydrogen content is varied for $\mathrm{H}_{2}$ in air (solid) and $\mathrm{H}_{2}$ in a mixture of $\mathrm{O}_{2}$ and $\mathrm{He}$ where the proportion of $\mathrm{He}$ to $\mathrm{O}_{2}$ is the same as in air (dashed), i.e., as if the $\mathrm{N}_{2}$ of air were replaced by He. Initial pressure is $1 \mathrm{~atm}$ and initial temperature is $298 \mathrm{~K}$. Note that AICC pressure and temperature are higher with He than $\mathrm{N}_{2}$ because of the somewhat lower heat capacity of the noble gas. Functions used to derive Figure 5-1 are contained in Appendix A to demonstrate validation of the technique for later application.

Post-combustion conditions in an $\mathrm{MCO}$ are different than shown in Figure 5-1 because the initial gas concentrations are different. Figure 5-2 presents a general chart which may be used to determine post-combustion conditions in an $\mathrm{MCO}$. For given initial concentrations of $\mathrm{H}_{2}$ and $\mathrm{O}_{2}$ in He, Figure 5-2 provides the pressure ratio $\mathrm{P}_{\text {final }} / \mathrm{P}_{\text {initial }}$. Note that for $\mathrm{H}_{2}$-rich conditions, the ratio is nearly constant, especially for low $\mathrm{O}_{2}$ concentrations. Also, note that the value of the pressure ratio is strictly valid for an $\mathrm{He}$ backfill of $1.5 \mathrm{~atm}$ at $25^{\circ} \mathrm{C}$, which sets the number of moles of $\mathrm{He}$, and stored at $50^{\circ} \mathrm{C}$. However, small departures from these initial conditions $( \pm 0.2$ atm $\mathrm{He}, \pm 25^{\circ} \mathrm{C}$ ) will not cause significant errors in the value of $\mathrm{P}_{\text {final }}$. 
Figure 5-1: Pressure and Temperature for $\mathrm{H}_{2}$-Air and $\mathrm{H}_{2}-\mathrm{O}_{2}$-He Mixtures.

AlCC Pressure for $\mathrm{H} 2-\mathrm{Air}$ and $\mathrm{H} 2-(21 \% 02,79 \% \mathrm{He})$ Mixtures, $25 \mathrm{C}$, $\uparrow$ atm Initial

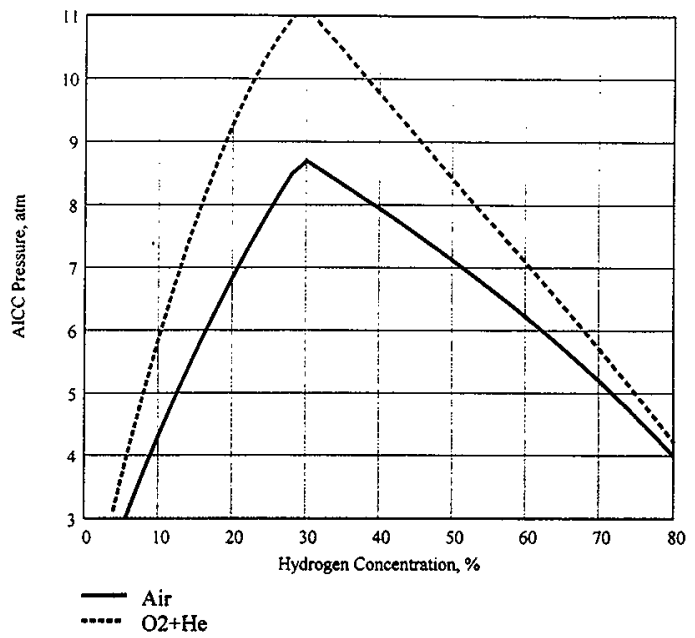

AlCC Temperature for $\mathrm{H} 2$-Air and $\mathrm{H} 2-(21 \% 02,79 \% \mathrm{He})$ Mixtures, $25 \mathrm{C}$, 1atm Initial

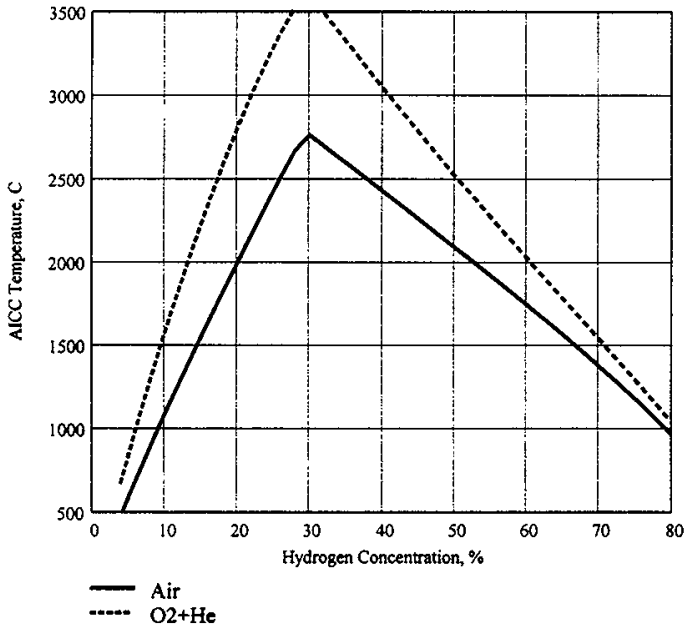




\section{Figure 5-2:}

\section{Pressure Ratio ( $\left.P_{\text {final }} / \mathbf{P}_{\text {initial }}\right)$ For Various Initial $\mathrm{H}_{2} \%$ and $\mathrm{O}_{2} \%$ in an $\mathrm{MCO}$}

Backfilled to $1.5 \mathrm{~atm} \mathrm{He}$ at $25^{\circ} \mathrm{C}$, and Stored at $50^{\circ} \mathrm{C}$.

Multiply plotted value by initial pressure to yield final pressure in atm. Some combinations of initial $\mathrm{H}_{2} \%$ and $\mathrm{O}_{2} \%$ on the plot are not considered possible.

Pressure Ratio (P-final / $\mathrm{P}$-initial) for various initial $\mathrm{H} 2 \%$ and $\mathrm{O} 2 \%$ in an MCO backfilled to $1.5 \mathrm{~atm} \mathrm{He}$ at $25 \mathrm{C}$, and stored at $50 \mathrm{C}$. Multiply plotted value by initial pressure to yield final pressure in atm. Some combinations of initial $\mathrm{H} 2 \%$ and $\mathrm{O} 2 \%$ on the plot are not considered possible.

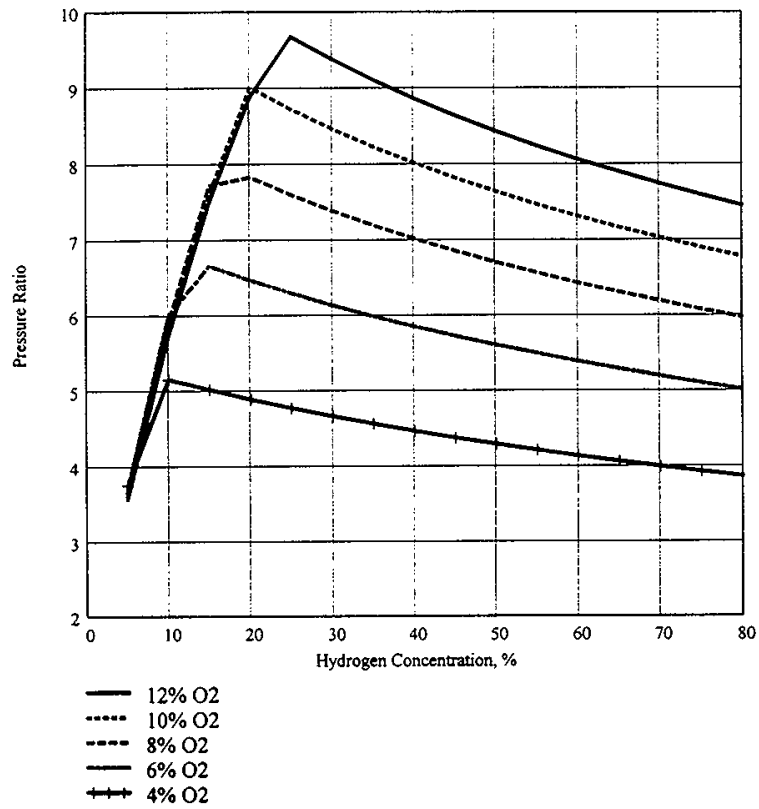

FAI/99-14, Rev. 1 


\subsection{HYDROGEN REACTIONS WITH URANIUM}

Hydrogen can react with uranium metal to form uranium hydride,

$$
\mathrm{U}+\frac{3}{2} \mathrm{H}_{2} \rightarrow \mathrm{UH}_{3}
$$

at rates which are potentially significant for interim storage of spent nuclear fuel. The rate of reaction depends upon temperature and pressure, and is the subject of numerous investigations. A valuable source of rate data is given by [Bloch and Mintz, 1981]; the effect of oxidizing gases to inhibit hydriding is demonstrated by [Bloch, et al., 1989]; and a useful model for the kinetics is given by [Kirkpatrick and Condon, 1991].

The key issue for interim storage is that hydrogen reactions with uranium are at least temporarily inhibited in the presence of oxygen and water vapor, as shown by [MCD Baker, et al., 1966] and [Bloch, et al., 1989] and discussed by [Duncan and Plys, 1998b]. That is, when water vapor is present, hydrogen is observed as a reaction product in proportions nearly in stoichiometry with an oxidation reaction alone. But given sufficient time, hydriding can commence. At present, there are insufficient data to identify the combination of temperature, gas concentrations, and dwell time required to initiate hydriding during interim storage, and there are insufficient data to quantify the subsequent rate of reaction for "dirty" uranium systems (hydriding experiments are typically conducted with clean polished metal, in contrast to the current damage state of $\mathrm{N}$ reactor fuel). [Bloch, et al., 1989] suggest that hydriding can commence after a dwell time on the order of hours when the hydrogen pressure is between 10 and 20 atmospheres (Figure 6-1), but this pressure range is an order of magnitude higher than pertinent for most interim storage applications.

The rate of hydriding is actually faster than the rate of oxidation in the temperature range of interest during interim storage. Figure 6-2, taken from [Kirkpatrick and Condon, 1991], contains hydriding data and a detailed model fit for a hydrogen pressure of 1 atmosphere. Note 
Figure 6-1:

Fractional Hydriding $\alpha$ of $\mathrm{U}$ Metal Foil for $\mathrm{O}_{2}$ Concentrations

from ( $<10$ to $\mathrm{f} 16,000) \mathrm{ppm}$ [Bloch, et al., 1989].

Curves a through $\mathrm{f}$ represent increasing initial oxygen concentrations in a fixed gas volume.

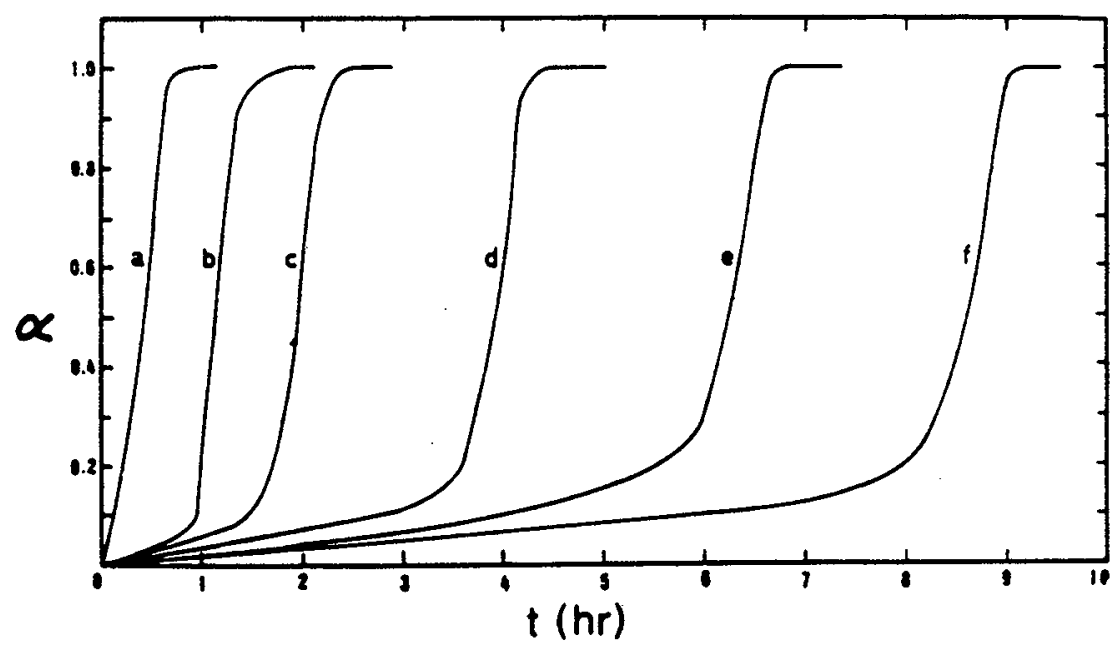




\section{Figure 6-2:}

Apparent Spall Front Velocity For a Hydrogen Pressure of 1.0 atm

Showing Comparison Data With Calculations:

- Data; and Data; - - Spall Velocity Using Proposed Fits

[Kirkpatrick and Condon, 1991].

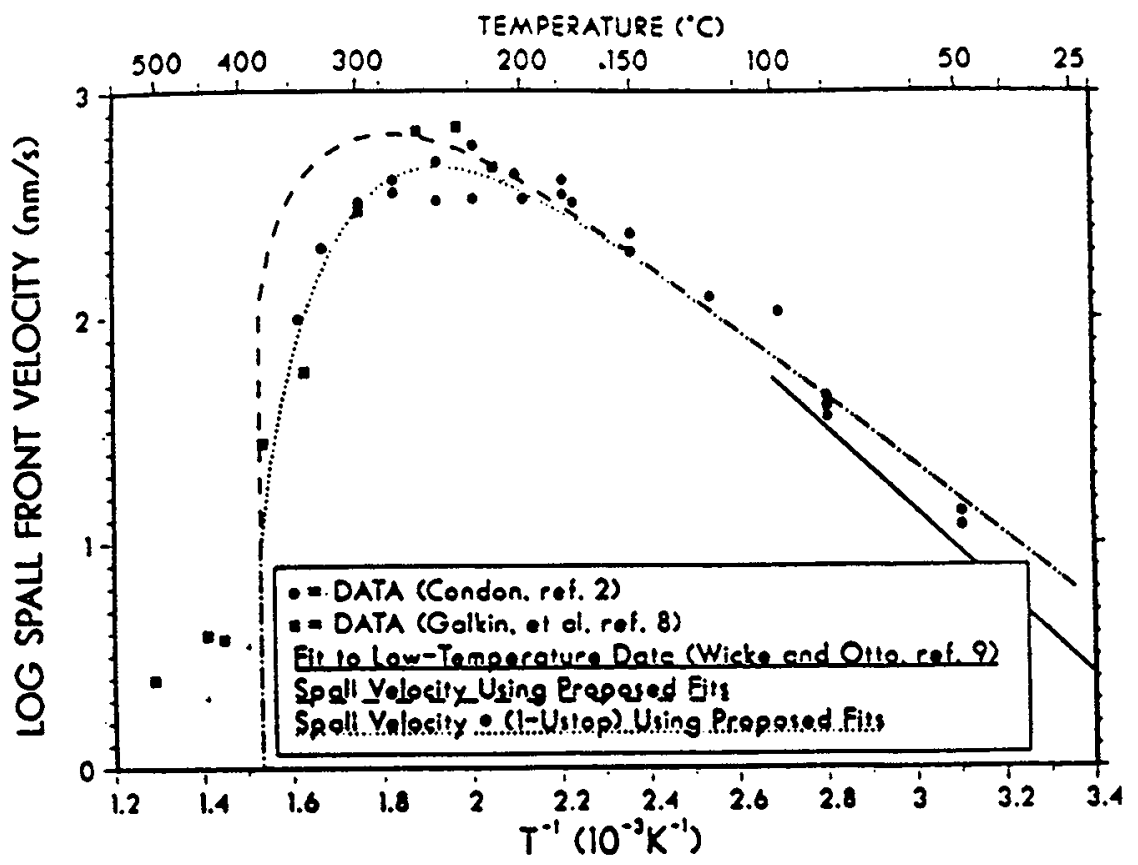


that the rate of hydriding attains a maximum between $250^{\circ} \mathrm{C}$ and $300^{\circ} \mathrm{C}$, and that it changes sign so that de-hydriding occurs at about $375^{\circ} \mathrm{C}$. For interim storage application, de-hydriding is simply not possible because the equilibrium hydrogen pressure above the metal and hydride is very low. The Kirkpatrick and Condon model may be simplified for low temperature applications and applied to interim storage calculations, as follows:

$$
\begin{aligned}
& V_{s}=\frac{1}{t_{1}} \sqrt{\frac{D_{E}}{s k_{1} U_{E}}} \\
& t_{1}=\frac{-\ln U_{c}}{k_{1} C_{0}} \\
& D_{E}=D \sqrt{\frac{N}{N-C_{o}}} \\
& \mathrm{U}_{\mathrm{E}}=\mathrm{U}_{\mathrm{c}}^{1 / 2} \\
& U_{c}=0.989 \text { for } \mathrm{T} \leq 250^{\circ} \mathrm{C} \\
& \mathrm{s}=3 \text { for } \mathrm{UH}_{3} \\
& k_{1}=10.4 \exp \left(\frac{1,592}{T}\right) \\
& \mathrm{D}=1.9 \times 10^{-6} \exp \left(\frac{5,820}{\mathrm{~T}}\right) \\
& N=\exp \left(-2.362-\frac{2,305}{T}\right) \\
& C_{0}=\frac{N ~ S}{N+S} \\
& S=4.183 \times 10^{-6} \exp \left(\frac{-894}{T}\right) \sqrt{P}
\end{aligned}
$$




$$
\begin{aligned}
\text { where } \mathrm{V}_{\mathrm{S}} & =\text { Spaliation velocity, } \mathrm{m} / \mathrm{s}, \\
\mathrm{t}_{1} & =\text { Time to first spallation, } \mathrm{s}, \\
\mathrm{D}_{\mathrm{E}} & =\text { Effective diffusion coefficient, } \mathrm{m} 2 / \mathrm{s}, \\
\mathrm{D} & =\text { Diffusion coefficient, } \mathrm{m} / \mathrm{s}, \\
\mathrm{N} & =\text { Maximum diffusing hydrogen mole fraction in uranium, } \\
\mathrm{U}_{\mathrm{E}} & =\text { Effective mole fraction for spall, } \\
\mathrm{U}_{\mathrm{C}} & =\text { Uranium mole fraction for spall, } \\
\mathrm{k}_{1} & =\text { Hydriding rate constant, } 1 / \mathrm{s}, \\
\mathrm{C}_{\mathrm{O}} & =\text { Solubility of free hydrogen in uranium, } \\
\mathrm{T} & =\text { Temperature, } \mathrm{K}, \text { and } \\
\mathrm{P} & =\text { Hydrogen pressure, Pa. }
\end{aligned}
$$

Figure 6-3 compares the simplified model to selected points from the detailed curve of Figure 6-2, and demonstrates that the simplified model is valid.

The reaction rate of hydrogen with clean uranium surfaces may be compared with the reaction rate of oxygen by casting the latter in terms of an oxide front velocity. Evaluating the Ritchie correlation at $50^{\circ} \mathrm{C}$, yields:

$$
\begin{aligned}
\mathrm{w}^{\prime \prime} & \approx 10^{-4} \mathrm{mg} / \mathrm{cm}^{2} \cdot \mathrm{hr} \\
& \approx 3 \times 10^{-10} \mathrm{~kg} / \mathrm{m}^{2} \cdot \mathrm{s}
\end{aligned}
$$

$$
\begin{aligned}
\text { Using } w^{\prime \prime} & =\frac{32}{238} \rho U, \text { yields: } \\
U & \approx 10^{-13} \mathrm{~m} / \mathrm{s} \approx 10^{-4} \mathrm{~nm} / \mathrm{s}
\end{aligned}
$$

for a metal density of $19,000 \mathrm{~kg} / \mathrm{m}^{3}$. 
SNF-3951, Rev. 0

Figure 6-3:

Hydriding Rate $(\mathrm{nm} / 2)$ of Clean Uranium in Hydrogen at $1 \mathrm{~atm}$;

With de-hydriding neglected for low temperatures and hydrogen pressures above saturation.

Solid line is correlation of [Kirkpatrick and Condon, 1991].

Diamonds are values from published curve for validation.

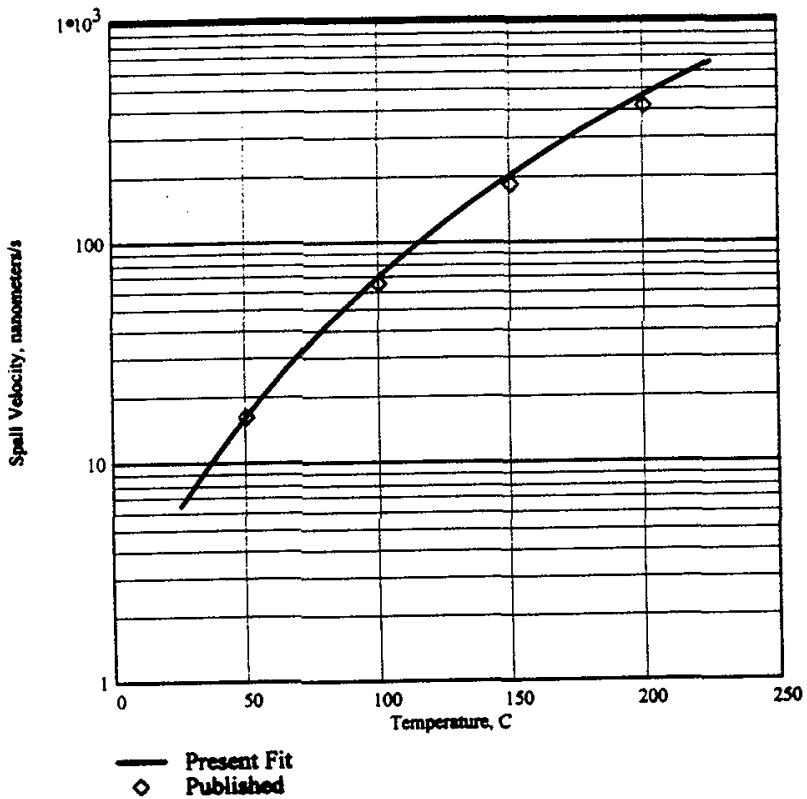


This is five orders of magnitude lower than the hydriding rate of about $10 \mathrm{~nm} / \mathrm{s}$ for 1 atmosphere hydrogen! In real systems with "dirty" uranium surfaces, either an oxide layer may substantially reduce the hydriding rate - which is contradicted by [Bloch, et al., 1989] - or else hydriding can, after a suitable dwell period, proceed far faster than oxidation.

However, typical industrial experience with storage of uranium reveals that some hydrogen is encountered in containers to which water was either accidentally or inadvertently admitted. For example, [Wood, et al., 1994] describes a hydrogen explosion upon opening a drum containing uranium metal and wood; which was the inadvertent moisture source. The drum contained hydrogen at somewhat sub-atmospheric pressure, whereas the rate law used above would suggest near complete hydrogen removal.

Relating this to interim storage, an example presented by [Duncan and Plys, 1998b] for an average power $\mathrm{MCO}$ with bounding water content results in praduction of about 22 moles hydrogen over 40 years. This hydrogen source can be consumed by a hydriding rate given by:

$$
\begin{aligned}
\dot{\mathrm{n}}^{\prime \prime}(\text { mole } / \text { year }) & \approx 3.15 \times 10^{7} \frac{3}{2} \frac{\rho}{238} \mathrm{~V}_{\mathrm{s}}(\mathrm{m} / \mathrm{s}) \\
& \approx 3.78 \times 10^{9} \quad \mathrm{~V}_{\mathrm{s}}(\mathrm{m} / \mathrm{s})
\end{aligned}
$$

Assigning $\dot{\mathrm{n}}^{\prime \prime}=0.5 \mathrm{~mole} / \mathrm{m}^{2} /$ year, (i.e., allowing $1 \mathrm{~m}^{2}$ reaction area) and taking an average reaction temperature of $50^{\circ} \mathrm{C}$, results in a steady-state hydrogen pressure of only $2.3 \mathrm{~Pa}$ to force equal rates of production and consumption.

The clear implication is that either: (a) the rate of hydriding of oxidized uranium surfaces is far lower than given by literature correlations for clean uranium surfaces, (b) hydriding of oxidized surfaces requires a minimum hydrogen pressure far greater than implied by the correlation for clean surfaces, or (c) both statements are partially true. 
For interim storage application, the implication is that hydrogen should react with fuel, but not completely as otherwise predicted from literature correlations. For MCOs whose capacity to react oxygen exceeds the radiolytic production rate, this merely implies that the pressures predicted by [Duncan and Plys, 1998b] are conservative overestimates. For MCOs which can yield net oxygen production over the interim storage period, however, the oxygen concentrations of [Duncan and Plys, 1998b] are underestimated because less hydrogen would be present. Based on the industrial experience, the gas compositions are likely (but not certain) to still be hydrogenrich. Because the extent of hydriding cannot be reliably predicted, the gas compositions cannot be specified and a range of potentially flammable mixtures needs to be considered. The postcombustion pressure is not sensitive to the amount of hydrogen gettering when the pre-combustion mixture is hydrogen-rich because the oxygen inventory limits energy release (see Figure 5-2). 


\subsection{SUMMARY OF TECHNICAL BASES AND ASSUMPTIONS}

Technical bases for this work are:

1. Initial MCO material inventories are given by [Duncan and Plys, 1998a], as discussed in Section 3.1.

2. Initial MCO conditions are provided by [Pajunen and Sederburg, 1998; Sherrell, 1999; and Duncan and Plys, 1998b], as discussed in Section 3.2.

3. Flammability data provide a conservative criterion of $4 \%$ oxygen in an MCO for storage temperatures $25^{\circ} \mathrm{C}-75^{\circ} \mathrm{C}$ (Section 4.0 ).

4. The maximum static post-combustion pressure in an $\mathrm{MCO}$ is given by an adiabatic, isochoric, complete combustion model (Section 5.0).

5. Slow reactions of hydrogen with uranium may occur when water vapor and oxygen are present (Section 6.0).

An assumption is:

1. Because the actual rate of hydrogen reactions with fuel cannot be quantified, the key feature of the [Duncan and Plys, 1998b] model to investigate is sensitivity to these reactions. Therefore the oxygen inventory predicted by this reference yields the bounding energy source for combustion, and the amount of hydrogen may be parametrically varied. 


\subsection{CALCULATIONS}

\subsection{MCO Atmosphere Sensitivity Cases}

Worst-case end-of-life oxygen concentrations arise for MCOs with low reactive area for oxygen consumption and high inventories of water-bearing compounds as described in Section 3.2. Figure 8-1 provides the number of moles of oxygen for various small reactive areas and two different $\mathrm{MCO}$ powers, $530 \mathrm{~W}$ (the maximum for $\mathrm{K}$-West fuel with the aluminum hydroxide cladding film) and $400 \mathrm{~W}$ (approximate average power), using the bounding MCO water content (note, this is independent of the backfill conditions). Cases shown are consistent with Figure 3-1 taken from [Duncan and Plys, 1998b] and simply include more detail at low reactive area. The calculation file appears in Appendix C. Any other case group from [Duncan and Plys, 1998b] would result in a lower oxygen inventory; there are no instances with one or two scrap baskets where combustion is an issue because the reactive area is a minimum of $1 \mathrm{~m}^{2}$ and only a trivial or zero oxygen inventory is calculated.

Oxygen is the critical reactant gas for determination of the potential for flammability and for prediction of post-combustion conditions. As mentioned, the model used for prediction of MCO gas composition did not consider hydrogen reactions with fuel. However, experimental evidence suggests that some reaction of hydrogen may take place during the relatively long interim storage period. Thus, the number of moles of oxygen in Figure 8-1 essentially determines the worst-case post-combustion conditions for a given reactive area.

Clearly, there can be no hydrogen reactions with fuel when the reactive area is zero. When the reaction area is only $0.01 \mathrm{~m}^{2}$, the number of moles of oxygen drops nearly in half for the $530 \mathrm{~W}$ case, and declines by about $10 \%$ in the $400 \mathrm{~W}$ case. The actual reactive area in an MCO is unknown and could be between 0 and $0.01 \mathrm{~m}^{2}$, and the inventory of oxygen is clearly bounded by the value given for zero area. The inventory of hydrogen is variable between the amount calculated by the reference model with zero hydrogen reactions, and an amount less than the 
SNF-3951, Rev. 0

Figure 8-1:

Oxygen at 40 Years for K-West Zero Scrap Bounding Water Content as Function of Reactive Area $\left(\mathrm{m}^{2}\right), Q=530 \mathrm{~W}$ and $Q=400 \mathrm{~W}$.

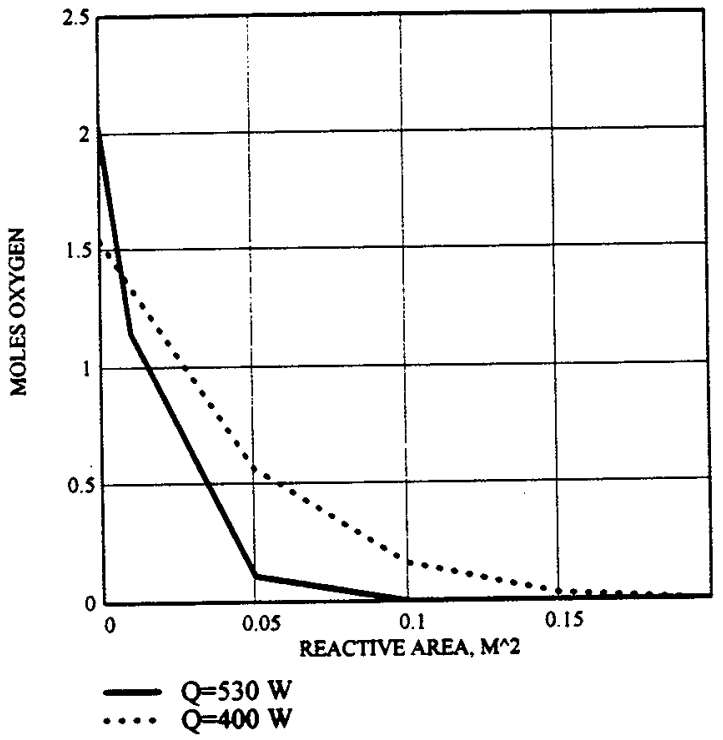


inventory of oxygen. However, it is a moot point to consider less hydrogen than in stoichiometry with the oxygen because this would provide the same post-combustion condition as some other rich hydrogen inventory greater than stoichiometry.

Thus, even though it is somewhat unrealistic, a bounding MCO atmosphere for consideration of combustion combines the zero-area oxygen inventory limit (because some finite area which negligibly reacts oxygen could be chosen) with a variable amount of hydrogen between an amount evaluated at zero hydrogen reaction with fuel to an amount in stoichiometric proportion with the oxygen (because the actual rate of reaction cannot be specified).

\subsection{Post-Combustion Sensitivity Results}

Figures 8-2 and 8-3 contain pre- and post-combustion pressure as a function of precombustion oxygen concentration for MCO atmospheres, as described above, given a nominal helium backfill. The only difference between these figures is that the scale has been expanded in the latter to illustrate the margin between $\mathrm{MCO}$ design pressure and the bounding post-combustion pressure. In these figures, lower curves represent pre-combustion conditions as a function of reactive area. A reactive area of zero corresponds to the highest oxygen concentration on the lower curves, and symbols represent oxygen concentration - pressure pairs at the reactive areas considered by Figure 8-1. Eventually, as reactive area increases, the oxygen concentration is reduced to zero by reactions with fuel; the MCO pressure however can increase because higher reactive areas provide more water source and hence more hydrogen from radiolysis.

The upper curves of Figures 8-2 and 8-3 show post-combustion pressure as the amount of hydrogen in the $\mathrm{MCO}$ is varied. The highest amount of hydrogen corresponds to the lowest precombustion oxygen concentration and yieids the highest post-combustion pressure because the available energy is the same but the initial pressure is higher versus a case with less hydrogen. The lowest amount of hydrogen corresponds to the highest pre-combustion oxygen concentration. The highest post-combustion pressure is about $11.9 \mathrm{~atm}$, and is a factor of 2.6 less than the design 
Figure 8-2: Pressure vs. Oxygen Concentration for Zero Scrap, Nominal Backfill.

Pressure vs Oxygen Concentration for Zero Scrap, K-West bounding water inventory. Lower lines with symbols indicate MCO conditions for various reactive areas with no combustion. Upper lines with no symbols are for post-burn sensitivity cases with hydrogen gettering to increase the $\mathrm{O} 2$ concentration up to stoichiometry.

Combustion is impossible for $\mathrm{O} 2<4 \%$. The worst case group is for $\mathrm{A}=0$, zero reactive area, because this maximizes the number of moles of oxygen. The worst case is for the highest power, hence highest moles of oxygen. The highest post-burn pressure is $11.9 \mathrm{~atm}$.

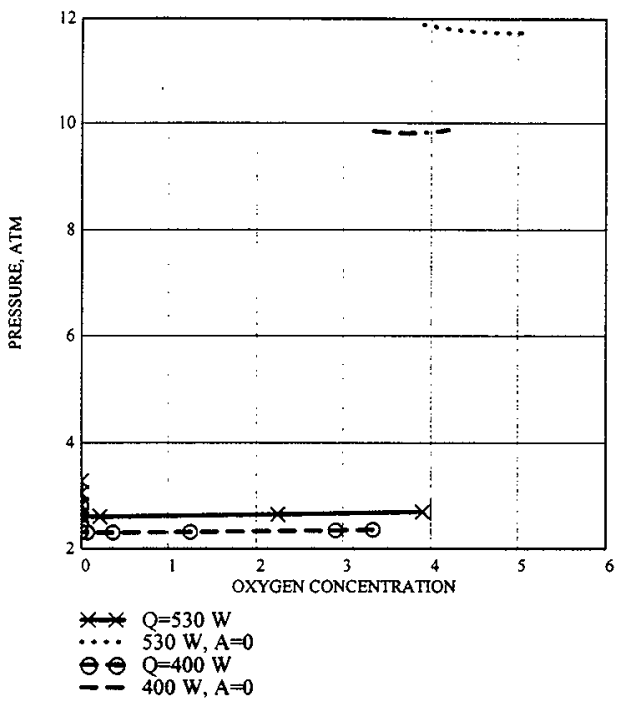


Figure 8-3;

Pressure vs. Oxygen Concentration for Zero Scrap Indicating MCO Design Pressure, Nominal Backfill.

Pressure vs Oxygen Concentration for Zero Scrap. K-West bounding water inventory. Lower lines with symbols indicate MCO conditions for various reactive areas with no combustion. Upper lines with no symbols are for post-burn sensitivity cases with hydrogen gettering to increase the $\mathrm{O} 2$ concentration up to stoichiometry. The upper horizontal dashed line is the MCO design pressure 450 psig ( 31 atm absolute).

Combustion is impossible for $\mathrm{O} 2<4 \%$. The worst case group is for $A=0$, zero reactive area, because this maximizes the number of moles of oxygen. The worst case is for the highest power, hence highest moles of oxygen. The highest post-burn pressure is $11.9 \mathrm{~atm}$.

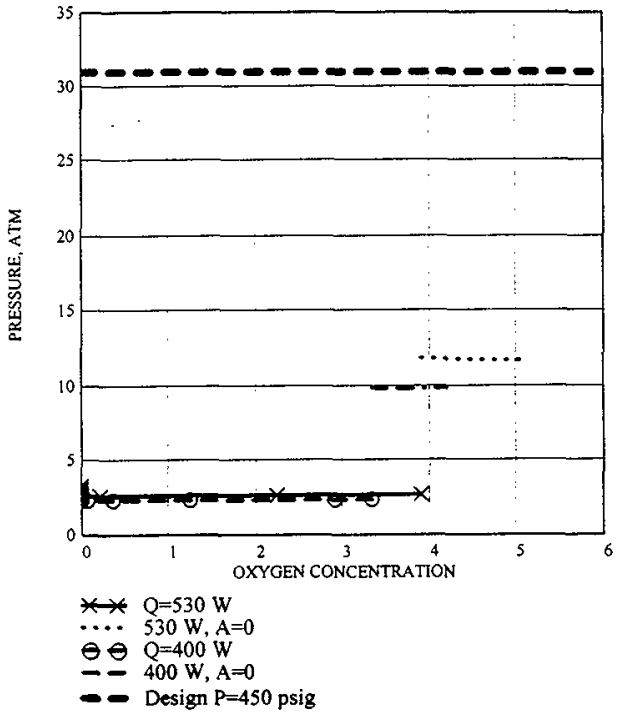

FAI/99-14, Rev. 1 
value (about $31 \mathrm{~atm}$ absolute). Note that in the $400 \mathrm{~W}$ case, combustion is not possible until enough hydrogen is consumed that nearly stoichiometric conditions are attained.

Clearly, a similar exercise using the oxygen molar inventory from a case with non-zero reactive area would yield lower pressure than indicated in Figures $8-2$ and 8-3. For a reactive area of $0.01 \mathrm{~m}^{2}$, the oxygen inventory in the $530 \mathrm{~W}$ case drops below the zero area inventory in the $400 \mathrm{~W}$ case, so its maximum post-combustion pressure would be below 8 atm.

The preceding calculation is repeated using a bounding initial helium backfill inventory in order to bound the final pressure, and results appear in Figures 8-4 and 8-5 which are analogous to Figures 8-2 and 8-3. The initial number of moles of helium is about $33 \%$ higher in this case ( 41 moles versus 30.3 moles), but the heat capacity of the helium is significant and the maximum plotted post-combustion pressure is 13 atm, only about $10 \%$ higher than the analogous nominal case. Note that because $4 \% \mathrm{O}_{2}$ is required, in this case combustion is barely possible.

\subsection{Conclusions}

A worst-case $\mathrm{MCO}$ from the point of view of flammability and combustion has a very low reactive area, so that little oxygen consumption occurs, but some consumption of hydrogen can occur, so as to allow the gas mixture to be flammable. Worst-case oxygen inventories are bounded by calculations for zero reactive area, though obviously some finite non-zero reaction area must be present for reaction of some hydrogen to proceed. Worst-case oxygen inventories occur for the case of zero scrap baskets and $\mathrm{K}$-West fuel with the high bounding aluminum hydroxide cladding film inventory, and with other water sources also at the high bounding values. Even in such cases, the highest calculated post-combustion pressure is about a factor of 2.4 below the $\mathrm{MCO}$ design pressure of $450 \mathrm{psig}$. 
SNF-3951, Rev. 0

Figure 8-4: Pressure vs. Oxygen Concentration for Zero Scrap, Bounding Backfill.

Pressure vs Oxygen Concentration for Zero Scrap, K-West bounding water inventory, and high helium backfill. Lower lines with symbols indicate MCO conditions for various reactive areas with no combustion. Upper lines with no symbois are for post-burn sensitivity cases with hydrogen gettering to increase the $\mathrm{O} 2$ concentration up to stoichiometry.

Combustion is impossible for $02<4 \%$. The worst case group is for $A=0$, zero reactive area, because this maximizes the number of moles of oxygen. The worst case is for the highest power, hence highest moles of oxygen. The highest post-burn pressure is $13 \mathrm{~atm}$.

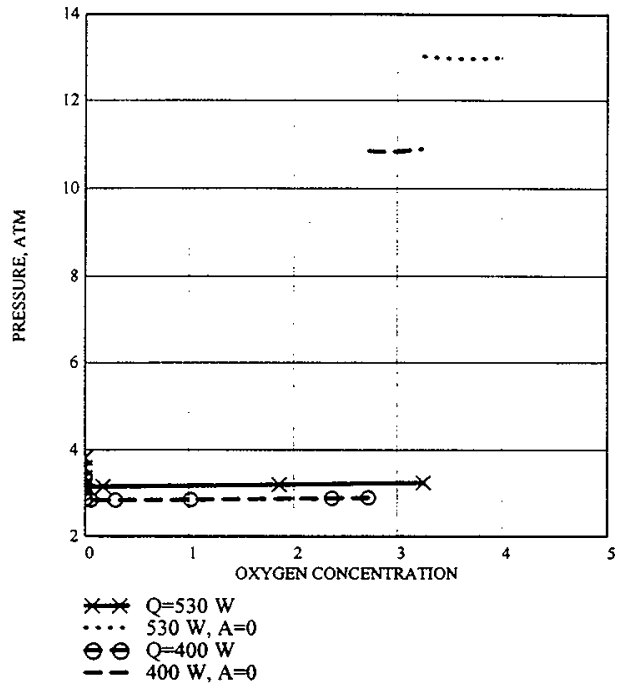


SNF-3951, Rev. 0

Figure 8-5:

Pressure vs. Oxygen Concentration for Zero Scrap Indicating MCO Design Pressure, Bounding Backfill.

Pressure vs Oxygen Concentration for Zero Scrap, K-West bounding water inventory, and high helium backfill. Lower lines with symbols indicate MCO conditions for various reactive areas with no combustion. Upper lines with no symbols are for post-burn sensitivity cases with hydrogen gettering to increase the $\mathrm{O} 2$ concentration up to stoichiometry. The upper horizontal dashed line is the MCO design pressure 450 psig (31 atm absolute).

Combustion is impossible for $\mathrm{O} 2<4 \%$. The worst case group is for $\mathrm{A}=0$, zero reactive area, because this maximizes the number of moles of oxygen. The worst case is for the highest power, hence highest moles of oxygen. The highest post-burn pressure is $13 \mathrm{~atm}$.

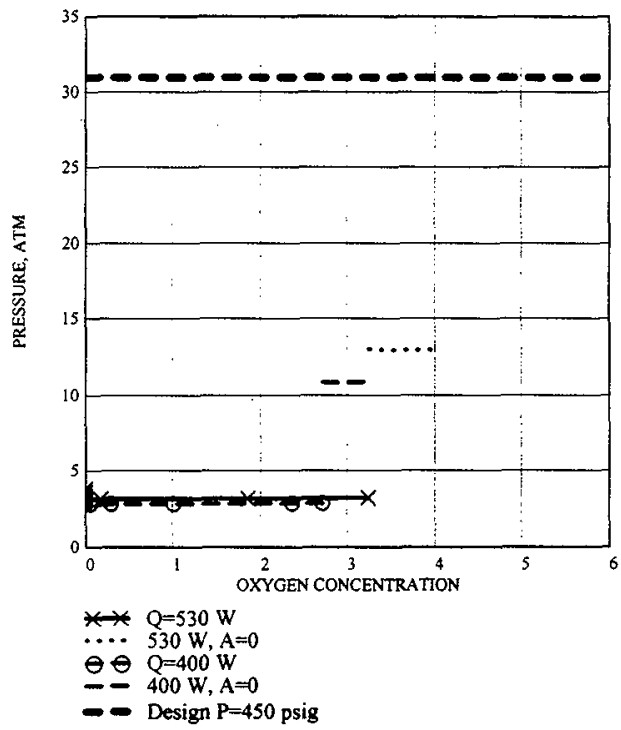




\subsection{REFERENCES}

M. McD. Baker, L.N. Less, and S. Orman, "Uranium + Water Reaction," Transactions of the Faraday Society, No. 525, Vol. 62, Pt. 9, September 1966.

J. Bloch and M.H. Mintz, "Kinetics and Mechanism of the U-H Reaction," Journal of the Less Common Metals, Vol. 81, pp. 301-320, 1981.

J. Bloch, et al., "Effects of Gas Phase Impurities on the Topochemical Kinetic Behavior of Uranium Hydride Development," Journal of the Less Common Metals, Vol. 139, pp. 371$383,1989$.

M.W. Chase, et al., "JANAF Thermochemical Tables," Third Edition, J. Physical and Chemical Reference Data, Vol. 14, Supplement No. 1, 1985.

H.F. Coward and G.W. Jones, "Limits of Flammability of Gases and Vapors," U.S. Bureau of Mines Bulletin 503, 1952.

D.R. Duncan and M.G. Plys, 1998a, "K-Basins Particulate Water Content, Behavior, and Impact," HNF-1523, Rev. 1, DE\&S Hanford, Richland, WA.

D.R. Duncan and M.G. Plys, 1998b, "MCO Internal Gas Composition and Pressure During Interim Storage," HNF-SD-SNF-TI-040, Rev. 3, DE\&S Hanford, Richland, WA, October.

J.R. Green, "Radcalc, Hydrogen Gas Generation, Gamma Absorption, G(H2) Values, Low-Level Waste, High-Level Waste Solutions, and Slurries," WHC-SD-TP-RPT-014, Westinghouse Hanford Co., Richland, WA, September 1994.

J.R. Kirkpatrick and J.B. Condon, "The Linear Solution for Hydriding of Uranium," Journal of the Less Common Metals, Vol. 172-174, pp. 124-135, 1991.

J.M. Kuchta, "Investigation of Fire and Explosion Accidents in the Chemical, Mining, and FuelRelated Industries - A Manual," U.S. Bureau of Mines Bulletin 680, 1985.

B,W. Marshall, Jr., "Hydrogen:Air:Steam Flammability Limits and Combustion Characteristics in the FITS Vessel," NUREG/CR-3468, SAND98-0383, Rev. 3, December, 1986.

A.L. Pajunen, "Evaluation of Radiolytic Gas Generation from Water Dissociation in a Multicanister Overpack," HNF-SD-SNF-CN-006, Rev. OA, SGN Eurisys Services Corp., Richland, WA, October 1998.

A.L. Pajunen and J.P. Sederburg, "Spent Nuclear Fuel Project Product Specification," HNF-SDSNF-OCD-001, Rev. 2, SGN Eurisys Services Corp., Richland, WA, October 1998. 
M.G. Plys, "Hydrogen Production and Combustion in Severe Reactor Accidents: An Integral Assessment Perspective," Nuclear Technology, Vol. 101, Fauske \& Associates, Inc., Burr Ridge, IL, March 1993.

E.D. Sellers, Director, Spent Nuclear Fuels Project Division, Dept. of Energy, Richland Operations Office, Letter to President, Westinghouse Hanford Co., Richland, WA, Ref. \#96-SFD-128, May 22, 1996.

D.L. Sherrell, "Multi-Canister Overpack Combustible Gas Management Leak Test Acceptance Criteria," HNF-2155, Rev. 1, DE\&SH, Inc., Richland, Washington, 1999.

D.H. Wood, et al., "Regarding the Chemistry of Metallic Uranium Stored in Steel Drums," Journal of Nuclear Materials, 209, pp. 113-115, 1994.

M. Zabetekis, "Flammability Characteristics of Combustible Gases and Vapors," U.S. Bureau of Mines Bulletin 627, 1965. 
SNF-3951, Rev. 0

\section{APPENDIX A}

AICC MATHCAD MODEL 
File: AlCCMCO1.MCD Date: 2/4/99 Page:1SNF-3951, Rev. 0

ADIABATIC, ISOCHORIC, COMPLETE COMBUSTION FUNCTION AND

APPLICATION FOR HYOROGEN - AIR - HELIUM MIXTURES

BY: Martin G. Plys, Fauske \& Associates, Inc. 16 W070 W. 83rd St. Burr Ridge IL 60521 USA

FOR: Hanford Spent Nuclear Fuel Project, contact Darrell Duncan 509-372-1013.

Contains $\mathrm{CV}(T)$ Polynomial fit used by transient analysis program HANSF. This fit is based on AIChE data, converted to this format for ease of integration.

Expand for other inert gases simply by adding polynomial fits and extra indices in the functions. For other fuels or oxidants, require rutes for proportion of reactants consumed.

\subsection{GAS SPECIFIC HEAT DATA: CV(T) POLYNOMIAL FIT.}

Gases are entered in the order: $\mathrm{H} 2, \mathrm{He}, \mathrm{N} 2, \mathrm{O} 2, \mathrm{H} 2 \mathrm{O}$ from HANSF input GASPROP.DAT. Values in $\mathrm{J} / \mathrm{g}$-mole/K!!! $F W$ is the formula weight vector, assists to identify each gas.

$$
C C V:=\left[\begin{array}{ccccc}
21.136 & -1.529 \cdot 10^{-3} & 1.978 \cdot 10^{-6} & 4.018 \cdot 10^{-10} & -1.171 \cdot 10^{-13} \\
12.47 & 0 & 0 & 0 & 0 \\
20.785 & -3.871 \cdot 10^{-3} & 1.34 \cdot 10^{-5} & -7.216 \cdot 10^{-9} & 1.16 \cdot 10^{-12} \\
17.045 & 0.014 & -4.96 \cdot 10^{-6} & 1.375 \cdot 10^{-10} & 1.375 \cdot 10^{-13} \\
24.044 & -7.883 \cdot 10^{-5} & 1.513 \cdot 10^{-5} & -7.323 \cdot 10^{-9} & 1.087 \cdot 10^{-12}
\end{array}\right] \quad F W:=\left[\begin{array}{c}
2 \\
4 \\
28 \\
32 \\
18
\end{array}\right]
$$

Functions for $\mathrm{Cv}$ and $\mathrm{Ug}$ of a specific gas:

$$
\begin{aligned}
& \mathrm{fCv}(\mathrm{i}, \mathrm{T}):=\mathrm{CCV}_{i, 0}+\mathrm{CCV}_{\mathrm{i}, 1} \cdot \mathrm{T}+\mathrm{CCV}_{i, 2} \cdot \mathrm{T}^{2}+\mathrm{CCV}_{i, 3} \cdot \mathrm{T}^{3}+\mathrm{CCV}_{\mathrm{i}, 4} \cdot \mathrm{T}^{4} \\
& \operatorname{fug}(\mathrm{i}, \mathrm{T}):=\mathrm{T} \cdot\left[\mathrm{CCV}_{i, 0}+\mathrm{T} \cdot\left[\frac{1}{2} \cdot \mathrm{CCV}_{i, 1}+\mathrm{T} \cdot\left[\frac{1}{3} \cdot \mathrm{CCV}_{i, 2}+\mathrm{T} \cdot\left(\frac{1}{4} \cdot \mathrm{CCV}_{i, 3}+\mathrm{T} \cdot \frac{1}{5} \cdot \mathrm{CCV}_{i, 4}\right)\right]\right]\right]
\end{aligned}
$$

Function for energy of a gas with mole vector $\mathrm{N}$ at temperature $\mathrm{T}$ (without integration constant):

$$
f U g(N, T):=\mid \begin{aligned}
& U \leftarrow 0 \\
& \text { for } i \in 0 . .4 \\
& U \leftarrow U+N_{i} \cdot f u g(i, T) \\
& U
\end{aligned}
$$

Test energy function by evaluating at 300 and $301 \mathrm{~K}$, difference numerically equals $\mathrm{Cv}$ :

$$
\mathrm{N}:=\left(\begin{array}{llllll}
1 & 1 & 1 & 1 & 1
\end{array}\right)^{\mathrm{T}} \quad \mathrm{fUg}(\mathrm{N}, 301)-\mathrm{fUg}(\mathrm{N}, 300)=99.986
$$


2.0 AICC Function input is mole vector (see order above) and initial Temperature, Output is a vector with: post-burn mole vector, AICC temperature. AICC pressure.

$$
\begin{aligned}
& \text { fAICC } N, T_{0}, V^{\prime}:=\mid \begin{array}{l}
\mathrm{H} 2 \leftarrow \mathrm{N}_{0} \\
\mathrm{O} \leftarrow \mathrm{N}_{3}
\end{array} \\
& \Delta \mathrm{H} 2 \mathrm{O} \leftarrow \mathrm{if}(\mathrm{H} 2 \leq 2 \cdot \mathrm{O} 2, \mathrm{H} 2,2 \cdot \mathrm{O} 2)
\end{aligned}
$$

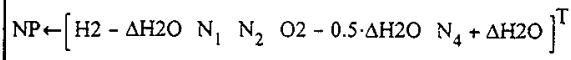

$$
\begin{aligned}
& \mathrm{Q} \leftarrow \Delta \mathrm{H} 2 \mathrm{O} \cdot 241.8 \cdot 10^{3} \\
& \left\{\begin{array}{l}
\mathrm{U}_{0} \leftarrow \mathrm{fUg}(\mathrm{N}, \mathrm{T} \text { o) } \\
\mathrm{T} \leftarrow \mathrm{T}_{0}+\mathrm{Q} \cdot\left(\mathrm{fUg}\left(\mathrm{N}, \mathrm{T}_{0}+1\right)-\mathrm{U}_{0}\right)^{-1}
\end{array}\right. \\
& \begin{array}{l}
\mathrm{T} \leftarrow \operatorname{root}\left(\mathrm{fUg}(\mathrm{NP}, \mathrm{T})-\mathrm{U}_{\mathrm{o}}-\mathrm{Q}, \mathrm{T}\right) \\
\mathrm{n}_{\mathrm{f}} \leftarrow \Sigma \mathrm{NP}
\end{array} \\
& \begin{array}{l}
\mathrm{P}_{\mathrm{f}^{\leftarrow}} \mathrm{n}_{\mathrm{f}}^{-8.314 \cdot \mathrm{T}} \mathrm{f}^{-1} \\
\mathrm{TP}-\left[\mathrm{T}_{\mathrm{f}} \mathrm{P}_{\mathrm{f}}\right]^{\mathrm{T}} \\
\mathrm{f} \leftarrow \operatorname{stack}(\mathrm{NP}, \mathrm{TP}) \\
\mathrm{f}
\end{array}
\end{aligned}
$$

Test by creating atmospheres with various amounts of $\mathrm{H} 2$ in air, then $\mathrm{H} 2$ in air with He replacing $\mathrm{N} 2$ :

$$
\begin{array}{lcccc}
\mathrm{V}:=1 & \mathrm{~T}_{\mathrm{O}}:=298.15 & \mathrm{P}_{\mathrm{O}}:=1.013 \cdot 10^{5} & \mathrm{n}_{\mathrm{O}}:=\frac{\mathrm{P}_{\mathrm{o}} \cdot \mathrm{V}}{8.314 \cdot \mathrm{T}_{\mathrm{O}}} & \mathrm{n}_{\mathrm{O}}=40.866 \\
\mathrm{i}:=2 . .40 & \mathrm{H} 2 \%_{\mathrm{i}}:=2 \cdot \mathrm{i} & \mathrm{H} 2_{\mathrm{i}}:=\mathrm{n}_{\mathrm{o}} \cdot \frac{\mathrm{H} 2 \%_{\mathrm{i}}}{100} & \mathrm{O} 2_{\mathrm{i}}:=0.208 \cdot\left(\mathrm{n}_{\mathrm{O}}-\mathrm{H} 2_{\mathrm{i}}\right) & \mathrm{N} 2_{\mathrm{i}}:=0.792 \cdot\left(\mathrm{n}_{\mathrm{O}}-\mathrm{H} 2_{\mathrm{i}}\right)
\end{array}
$$

H2 in Air:

$\mathrm{N} 1_{0, \mathrm{i}}:=\mathrm{H} 2_{\mathrm{i}} \quad \mathrm{N} 1_{\mathrm{i}, \mathrm{i}}:=0 \quad \mathrm{~N} 1_{2, \mathrm{i}}:=\mathrm{N} 2_{\mathrm{i}} \quad \mathrm{N} 1_{3, \mathrm{i}}:=\mathrm{O} 2_{\mathrm{i}} \quad \mathrm{N} 1_{4, \mathrm{i}}:=0$

$$
A l^{\langle i\rangle}:=\text { fAICC }^{\prime}\left(\mathbf{N 1}^{\langle i\rangle}, \mathbf{T}_{0}, \mathrm{~V}\right) \quad \operatorname{Tair}_{i}:=\mathbf{A l}_{5, i} \quad \text { Pair }_{i}:=\mathbf{A l}_{6, i} \cdot \mathbf{P}_{0}^{-1}
$$

Check Vs. values published by Kuchta, USBOM, $1985: 4 \%, 746 \mathrm{~K}, 8 \%, 1151 \mathrm{~K}, 12 \%, 1528 \mathrm{~K}$ :

$\begin{array}{llll}\mathrm{H} 2 \%_{2}=4 & \mathrm{H} 2 \%_{4}=8 & \mathrm{H}_{2} \%_{\mathrm{K}}=12 & \begin{array}{l}\text { Error less than } 1 \% \text {, attributable } \\ \text { to small CV differences. }\end{array} \\ \mathrm{Tair}_{2}=749.17 & \mathrm{Tair}_{4}=1.16 \cdot 10^{3} & \mathrm{Tair}_{6}=1.542 \cdot 10^{3} & \end{array}$

$\mathrm{H} 2$ combustion in $\mathrm{O} 2+\mathrm{He}$ mixtures where He has same proportion as $\mathrm{N} 2$ in air:

$$
\begin{aligned}
& \mathrm{Nl}_{0, \mathrm{i}}:=\mathrm{H} 2_{\mathrm{i}} \quad \mathrm{N} 1_{1, \mathrm{i}}:=\mathrm{N} 2_{\mathrm{i}} \quad \mathrm{Nl}_{2, \mathrm{i}}:=0 \quad \mathrm{Nl}_{3, \mathrm{i}}:=\mathrm{O} 2_{\mathrm{i}} \quad \mathrm{N1}_{4, \mathrm{i}}:=0 \\
& A 1^{\langle i\rangle}:=\operatorname{fAICC}\left(\mathrm{Nl}^{\langle i\rangle}, \mathrm{T}_{\mathrm{O}}, \mathrm{V}\right) \quad \mathrm{THe}_{\mathrm{i}}:=A 1_{5, i} \quad \mathrm{PHe}_{\mathrm{i}}:=A \mathrm{~A}_{6, i} \mathrm{P}_{\mathrm{O}}{ }^{-1}
\end{aligned}
$$


File: AlCCMC01.MCD Date: 2/4/99 Page:3 SNF-3951, Rev. 0

AICC Pressure for $\mathrm{H} 2-$ Air and $\mathrm{H} 2-(21 \% \mathrm{O} 2,79 \% \mathrm{He})$ Mixtures, $25 \mathrm{C}$, 1atm Initial

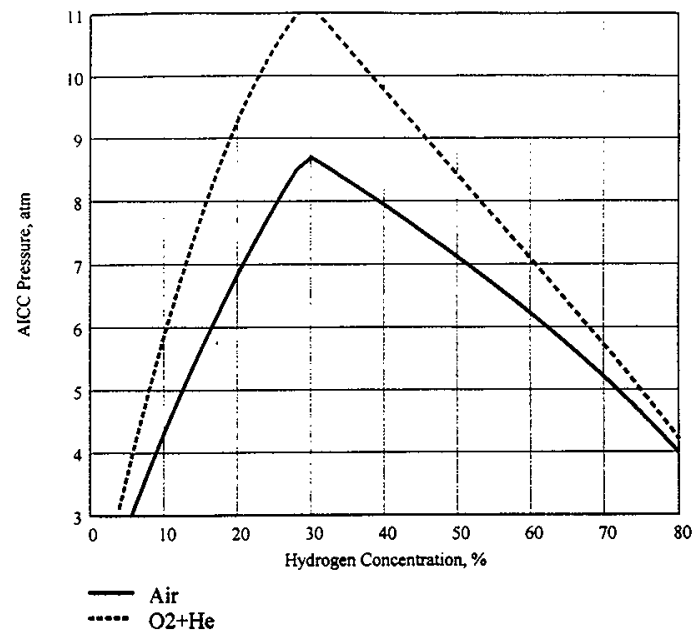

AlCC Temperature for $\mathrm{H} 2-\mathrm{Air}$ and $\mathrm{H} 2-(21 \% \mathrm{O} 2,79 \% \mathrm{He})$ Mixtures, $25 \mathrm{C}$, 1atm Initial

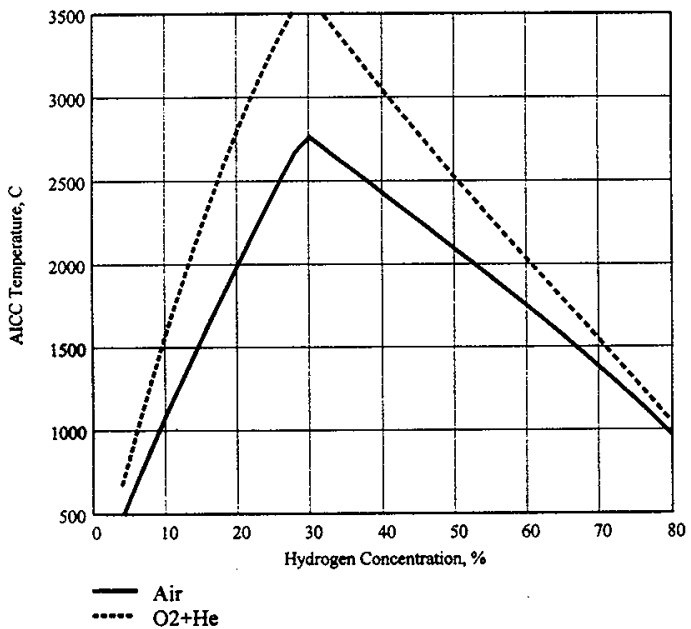


Post-Combustion conditions in an MCO: Initial 1.5 atm He, various initial $\mathrm{H} 2$ and $\mathrm{O} 2$ moles
$V:=0.5 \quad \tau_{0}:=298.15$
$P_{0}:=1.5 \cdot 10^{5}$
$\mathrm{n}_{\text {he }}:=\frac{\mathrm{P}_{\mathrm{o}} \cdot \mathrm{V}}{8.314 \cdot \mathrm{T}_{\mathrm{O}}}$
$\mathrm{n}_{\text {he }}=30.256$

Vary initial $\mathrm{H} 2$ from $5 \%$ to $75 \%$ in steps of $5 \%$ : Vary initial 02 from $4 \%$ to $12 \%$ in steps of $2 \%$ :

$\mathrm{i}:=0.15 \quad \mathrm{H} 2 \%_{\mathrm{i}}:=5 \cdot(\mathrm{i}+1) \quad \mathrm{j}:=0 . .4 \quad 02 \%_{\mathrm{j}}:=4+2 \cdot \mathrm{j}$

Solve for sum of $\mathrm{H} 2$ and $\mathrm{O} 2$ moles: $\quad \mathrm{OH}_{\mathrm{i}, \mathrm{j}}:=0.01 \cdot\left(\mathrm{H} 2 \%_{\mathrm{i}}+\mathrm{O} 2 \%_{\mathrm{j}}\right) \cdot \mathrm{n}_{\mathrm{he}}\left[1-0.01 \cdot \mathrm{H} 2 \%_{\mathrm{i}}+\mathrm{O} 2 \%_{\mathrm{j}}\right]^{-1}$

$\mathrm{nH}_{i, j}:=0.01 \cdot \mathrm{H} 2 \%_{i} \cdot\left(\mathrm{n}_{h e}+\mathrm{OH}_{i, j}\right) \quad \mathrm{nO} 2_{i, j}:=0.01 \cdot 02 \%_{j} \cdot\left(\mathrm{n}_{h e}+\mathrm{OH}_{i, j}\right)$

Use $50 \mathrm{C}$ as an average storage temperature for pre-combustion conditions:

$\mathrm{PO}_{i, j}:=\frac{\mathrm{n}_{h e}+\mathrm{OH}_{i, j}}{\mathrm{n}_{h e}} \cdot \frac{\mathrm{P}_{\mathrm{o}}}{10^{5}} \cdot \frac{323.15}{298.15}$

$$
P_{i, j}:=10^{-5} \cdot \text { fAICC }\left[\begin{array}{c}
\mathrm{nH}_{i, j} \\
n_{h e} \\
0 \\
n O 2_{i, j} \\
0
\end{array}\right], 323.15, V \mathbf{R}_{i, j}:=\frac{P_{i, j}}{\mathrm{PO}_{i, j}}
$$


Pressure Ratio ( $P$-final / $P$-initial) for various initial $\mathrm{H} 2 \%$ and $\mathrm{O} 2 \%$ in an $\mathrm{MCO}$ backfilled to $1.5 \mathrm{~atm} \mathrm{He}$ at $25 \mathrm{C}$, and stored at $50 \mathrm{C}$. Multiply plotted value by initial pressure to yield final pressure in atm. Some combinations of initial $\mathrm{H} 2 \%$ and $\mathrm{O} 2 \%$ on the plot are not considered possible.

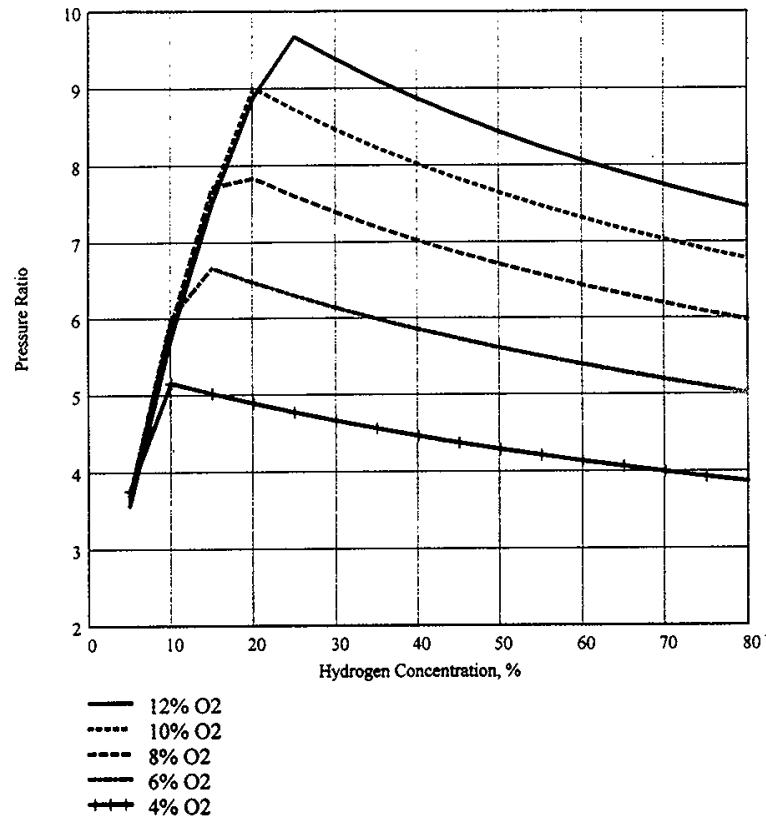


SNF-3951, Rev. 0

APPENDIX B

KIRKPATRICK - CONDON HYDRIDING MODEL 
HYDRIDING OF URANIUM METAL

Kirkpatrick and Condon Hydriding model from J. Less Common Metals 172-174, 1991

Limit of no dehydriding. temperatures below $300 \mathrm{C}$.

By: Martin G. Plys, Fauske \& Associates, Inc. 16W070 W. 83rd St. Burr Ridge. IL 60521 USA

For: Hanford Spent Nuclear Fuel Project, Duke Engineering \& Services Hanford, Darrel Duncan.

Hydriding constant (Eq. 7), 1/s

Diffusion constant (Eq. 9), $\mathrm{m}^{\wedge} 2 / \mathrm{s}$

Saturation parameter (Eq. 12), mf

Solubility of $\mathrm{H}_{2}$ in $U$ (Eq. 10), $\mathrm{mf}$ where $P$ is in $\mathrm{Pa}$

Mole fraction $U$ of spall material (Eq. 13)

asymptotic value below 250 to $300 \mathrm{C}$.

and generalized mole fraction for spall

Stoichiometry factor for $\mathrm{UH} 3$

Generalized effective diffusivity (Eq. 16), $\mathrm{m}^{\wedge} 2 / \mathrm{s}$

Time to spall (Eq. 15), s

Spall front velocity (Eq. 14), m/s

$$
\begin{aligned}
& \mathrm{fk}_{[}(T):=10.4 \cdot \exp : \frac{1592}{T} \\
& \mathrm{fD}(T):=1.9 \cdot 10^{-6} \cdot \exp \frac{-5820}{T}
\end{aligned}
$$$$
\mathrm{fN}(T):=\exp !-2.362-\frac{2305}{T}
$$

$f_{0}(T, P):=\mid \begin{aligned} & N \leftarrow f N(T) \\ & E \leftarrow 4.183 \cdot 10^{-6} \cdot \exp \frac{-894}{T} \cdot \sqrt{P} \\ & \frac{N \cdot E}{N+E}\end{aligned}$

$$
\begin{aligned}
& \mathrm{U}_{\mathrm{C}}:=0.989 \quad \mathrm{U}_{\mathrm{E}}:=\sqrt{\mathrm{U}_{\mathrm{C}}} \\
& \mathrm{s}:=3
\end{aligned}
$$

$\mathrm{fD}_{E}(\mathrm{~T}, \mathrm{P}):=\mathrm{fD}(\mathrm{T}) \cdot \sqrt{\frac{\mathrm{fN}(\mathrm{T})}{\mathrm{fN}(\mathrm{T})-\mathrm{fC}_{0}(T, P)}}$

$$
\mathrm{ft}_{1}(\mathrm{~T}, \mathrm{P}):=\frac{-\ln : \mathrm{U}_{\mathrm{C}}}{\mathrm{k}_{1}(\mathrm{~T}) \cdot \mathrm{fC}_{\mathrm{O}}(\mathrm{T}, \mathrm{P})}
$$

$$
f V_{S}(T, P):=\frac{1}{f_{1}(T, P)} \cdot \sqrt{\frac{f_{E}(T, P)}{s \cdot k_{1}(T) \cdot U_{E}}}
$$

To reproduce Fig. 1 of paper, set $P=1$ atm, loop from $25 \mathrm{C}$ to $225 \mathrm{C}$, get $\mathrm{V}$ in $\mathrm{nm} / \mathrm{s}$ :

$T_{k}:=273.15 \quad P:=1.013 \cdot 10^{5} \quad i:=0 . .20 \quad T_{i}:=T_{k}+25+i \cdot 10 \quad T_{i}:=1000 \cdot: T_{i} i^{-1} \quad V_{i}:=f V S . T_{i}, P \cdot 10^{9}$

Datapoints from published curve: $\quad \mathrm{j}:=0 . .3$

$\mathrm{TD}:=\left(\begin{array}{llll}50 & 100 & 150 & 200\end{array}\right)^{\mathrm{T}}+T_{k} \quad$ LVD $:=\left(\begin{array}{llll}1.2 & 1.8 & 2.25 & 2.6\end{array}\right)^{\mathrm{T}} \quad$ VD $:=\overrightarrow{10^{\mathrm{LVD}}} \quad$ TDI $:=\frac{\overrightarrow{1000}}{\mathrm{TD}}$

Values at $0.5 \mathrm{~atm} \mathrm{H} 2$ and $2 \mathrm{~atm} \mathrm{H} 2$ :

$$
V 2_{i}:=f V_{S}: T_{i}, 2 \cdot P: 10^{9} \quad V_{05}:=f V_{S}\left(T_{i}, 0.5 \cdot P: \cdot 10^{9}\right.
$$


SNF-3951, Rev. 0

Hydriding rate $(\mathrm{nm} / \mathrm{s}$ ) of clean uranium in hydrogen at 1 atm, with de-hydriding neglected for low temperatures and hydrogen pressures above saturation. Solid line is correlation of Kirkpatrick and Condon, 1991, diamonds are values from published curve for validation.

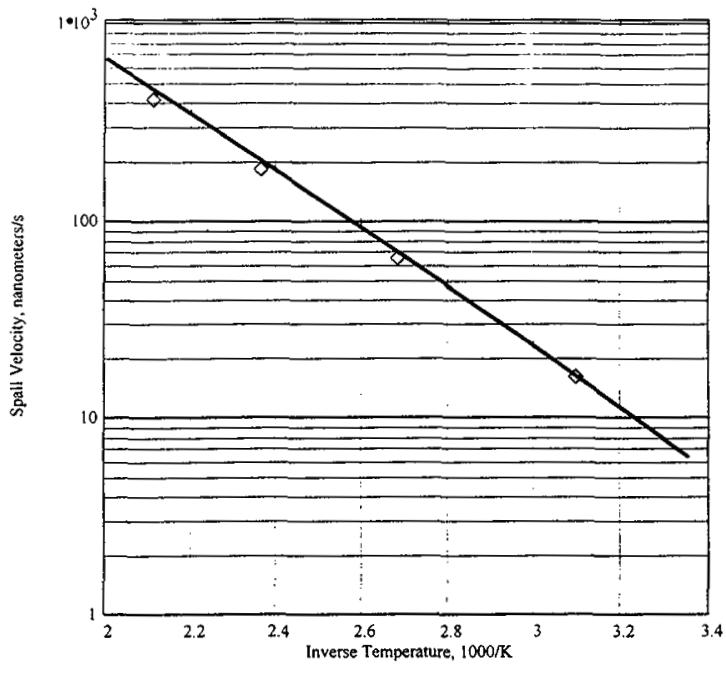

Present Fit

$\diamond \quad$ Published 
SNF-3951, Rev. 0

Hydriding rate $(\mathrm{nm} / \mathrm{s})$ of clean uranium in hydrogen at $1 \mathrm{~atm}$, with de-hydriding neglected for low temperatures and hydrogen pressures above saturation. Solid line is correlation of Kirkpatrick and Condon, 1991, diamonds are values from published curve for validation.

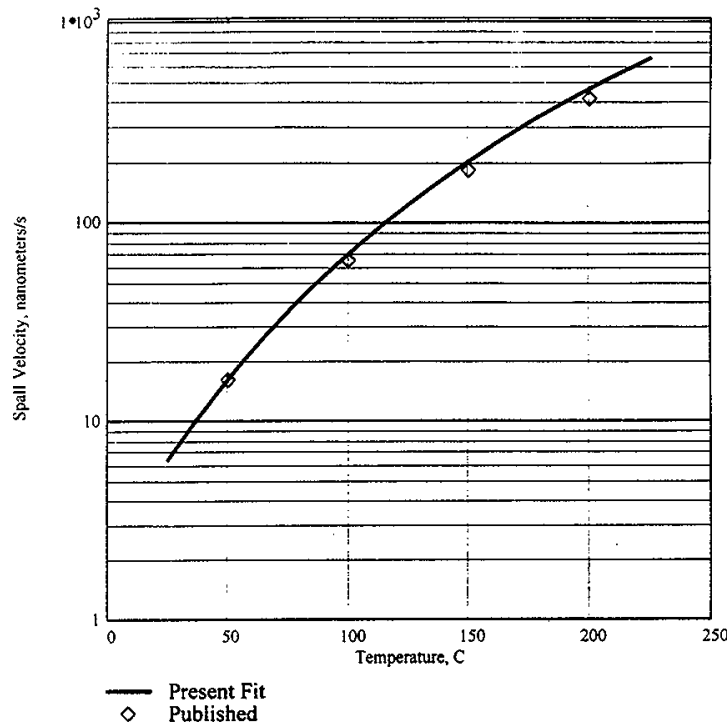


SNF-3951, Rev. 0

\section{APPENDIX C \\ ZERO SCRAP COMBUSTION SENSITIVITY CASES}

FAI/99-14, Rev. 1

C -1

Date: $2 / 9 / 99$ 


\section{MCO 02\% AND PRESSURIZATION: RADIOLYSIS AND GETTERING OF 02}

\section{ZERO SCRAP BASKET END-OF-LIFE CASES}

BY: Martin G. Plys, Fauske \& Associates, Inc. 16W070 W.83rd St.

Burr Ridge IL 60521 Phone 630-323-8750

FOR: Hanford Spent Nuclear Fuel Project - Duke Engineering \& Services Hanford - Richland, WA Contact: Darrell Duncan 509-372-1013.

DATE: October, 1998

\section{Calculation Technical Basis and Assumptions:}

1. Decay power varies per HNF-SD-SNF-CN-006 Regulatory/Safety Design Basis; see below. Alpha, beta. and gamma fractions are applied for all total MCO powers. Absorption based on fuel mass of $6339 \mathrm{~kg}$.

2. Water-bearing materials are: $\mathrm{Al}(\mathrm{OH}) 3$ cladding film, Canister particulate composed of $(\mathrm{Al}, \mathrm{Fe})(\mathrm{OH}) 3$, adhering particulate containing $\cup \mathrm{O} 3.2 \mathrm{H} 2 \mathrm{O}$, and free water. Other sources are negligible for radiolysis.

3. $g(\mathrm{O} 2)$ and $g(\mathrm{H} 2)$ values from HNF-SD-SNF-CN-006; see below.

4. Gamma absorption by $\mathrm{Al}(\mathrm{OH}) 3, \mathrm{UO} 3.2 \mathrm{H} 2 \mathrm{O}$, and $\mathrm{H} 2 \mathrm{O}$ relative to that by $\mathrm{U}$ based on $0.6 \mathrm{MeV}$ gamma.

5. Al(OH) 3 cladding film radiolysis is by gamma dose aione; all other materiais get aipha,beta, and gamma.

6. Canister particulate has alpha, beta dose/kg reduced by the U fraction; $20 \%$ for bounding case.

7. Uranium Oxide Hydrates are conservatively represented by UO3.2H2O.

8. No thermal decomposition of hydrates - residual $\mathrm{H} 2 \mathrm{O}$ evaporates first, system is saturated.

9. Fuel and scrap temperatures related to decay power as a function of time by conservative conductances.

10. No hydrogen gettering - only occurs when Oxygen is depleted. This allows the maximum presssure to be calculated, before substantial $\mathrm{H} / 2$ gettering.

11. Oxygen gettering by Ritchie's moist air correlation, since $\mathrm{H} 2 \mathrm{O}$ present, with a minimum limit of Trimble's dry air correlation.

12. MCO is backfilled to $1.5 \mathrm{~atm}$ He at $25 \mathrm{C}$ - normaily. Neglect difference between atm and $10^{* *} 5$ Pascals.

12. Calculations may be conducted with bounding or best-estimate values.

Parameter

$\mathrm{H} 2 \mathrm{O}$ from $\mathrm{UO} 3.2 \mathrm{H} 2 \mathrm{O}$ canister particulate

Scrap reactive area / basket

Fuel reactive area / basket

$\mathrm{H} 2 \mathrm{O}$ from $\mathrm{UO} 3.2 \mathrm{H} 2 \mathrm{O}$

$\mathrm{H} 2 \mathrm{O}$ from canister particulate

water:

Bound

$100 \mathrm{~g} \mathrm{H}^{2} \mathrm{O} / \mathrm{m}^{\wedge} 2$

$4.5 \mathrm{~m}^{\wedge} 2$

$0.79 \mathrm{~m}^{\wedge} 2$

$1036 \mathrm{~g}$ two scrap

$667 \mathrm{~g}$ one scrap

2979 no scrap

$80 \% \mathrm{Al}, 20 \%$ U hydrate $\quad 25 \% \mathrm{Al}, 75 \%$ U hydrate

$144 \mathrm{~g}$ two scrap

$192 \mathrm{~g}$ one scrap

$240 \mathrm{~g}$ no scrap

$29 \mathrm{~g}$ two scrap

$39 \mathrm{~g}$ one scrap

49 g no scrap

$66.7 \mathrm{grams} / \mathrm{m}^{\wedge} 2,200 \mathrm{gram}$ limit, all cases!
$50 \mathrm{~g} \mathrm{H} 2 \mathrm{O} / \mathrm{m}^{\wedge} 2$

$0.0425 \mathrm{~m}^{\wedge} 2$

** Units: time in years, mass in grams, area in $m^{\wedge} 2$, with appropriate conversions used. 


\subsection{INPUT AND DERIVED VALUES}

\section{Constants}

Avogadro's number

$$
\mathrm{Na}:=6.022 \cdot 10^{23}
$$

Conversion factor $\mathrm{J} / 100 \mathrm{ev}$

$\mathrm{Jev}:=1.6 \cdot 10^{-17}$

Seconds in a year

Secy $:=3600 \cdot 24 \cdot 365$

Ideal gas constant

$R_{\text {gas }}:=8.314$

Molecular weights of $\mathrm{Al}(\mathrm{OH}) 3, \cup \mathrm{O} 3.2 \mathrm{H} 2 \mathrm{O}, \mathrm{H} 2 \mathrm{O}$ :

$\mathrm{M}_{\mathrm{ah}}:=78 \quad \mathrm{M}_{\mathrm{uh}}:=322$

$M_{w}:=18$

MCO Backfill and Fuel Inventory

MCO volume, $m^{\wedge} 3$, backfill temperature, $K$

MCO backfill temperature, $K$, and Pressure, atm:

$\mathrm{V}_{\text {mco }}:=0.5$

$T_{\text {bf }}:=298$

$P_{b f}:=1.5$

Helium backfill moles:

$\mathrm{n}_{\text {he }}:=\mathrm{P}_{\mathrm{bf}} 10^{5} \cdot \mathrm{V}_{\mathrm{mco}}, \mathrm{R}_{\text {gas }} \cdot \mathrm{T}_{\mathrm{bf}} \tilde{\circ}^{-1}$

${ }^{n}$ he $=30.27$

Fuel Mass (grams):

$M_{f}:=6.339 \cdot 10^{6}$

MCO Water Inventory Values: See HNF-1523 and HNF-1527

UO3. $\mathrm{xH} 2 \mathrm{O}$ water mass per unit area gram $/ \mathrm{m}^{\wedge} 2$

Max $\mathrm{g} \mathrm{H} 2 \mathrm{O}$ from UO3. $\mathrm{xH} 2 \mathrm{O}$ Adhering Partic.

Max $\mathrm{g}$ of $\mathrm{Al}(\mathrm{OH}) 3 \mathrm{Clad}$ Film:

Free $\mathrm{H} 2 \mathrm{O}, \mathrm{g}$, bounding value:

Amount of water from $\cup 04.2 \mathrm{H} 2 \mathrm{O}$ if no $\mathrm{AL}(\mathrm{OH}), \mathrm{g}$

MCO Power - Temperature Relations:

Heat transfer conductances: Scrap, Low T. fuel, Avg. T fuel, High T. fuel, W/K:

Fraction of assemblies per fuel group, low to high:

Conservative annual average vault $T$ and half-amplitude Hanford avg. is 12 , High is 26 , Low is -3 ; Vautt is $6 \mathrm{C}$ higher.

$g(H 2)$ and $g(O 2)$ Values from HNF-SD-SNF-CN-006:

$\begin{array}{lll}\text { Rad type } & g(H 2) & g(O 2) \\ \text { alpha } & 1.5^{*} x & 0.75^{*} x \\ \text { beta } & 0.45^{*} x & 0.225^{*} x \\ \text { gamma } & 1.2 \text { for } & x \text { for } x<0.1 \text {, eise } \\ & 0.04<x<0.35 & 0.0861+0.139 * x\end{array}$

$\mathrm{g}(\mathrm{H} 2)$ value for $\mathrm{Al}(\mathrm{OH}) 3$, molec/100 eV $\mathrm{g}(\mathrm{O} 2)$ value for $\mathrm{Al}(\mathrm{OH}) 3$, moled $100 \mathrm{eV}$ $\mathrm{g}(\mathrm{H} 2)$ values for $\mathrm{UO} 3$ hydrates, molec/100 ev $\mathrm{g}(\mathrm{O} 2)$ values for $\mathrm{UO} 3$ hydrates, molec/100 ev $\mathrm{g}(\mathrm{H} 2)$ values for free $\mathrm{H} 2 \mathrm{O}$, moleci100 ev $\mathrm{g}(\mathrm{O} 2)$ values for free $\mathrm{H} 2 \mathrm{O}$, molec/100 ev Relative gamma absorption for $\mathrm{Al}, \mathrm{U}, \mathrm{H} 2 \mathrm{O}$ :

$$
\begin{array}{ll}
\mu:=50 & \text { !! BEST-ESTIMATE } 50, \text { BOUND } 100 ! ! \\
\mathrm{UH}_{\max }:=1036 & \text { !! 0 scrap: } 297 \mathrm{~g} ; 1 \text { scrap; } 667 \mathrm{~g} ! ! \\
\mathrm{AL}_{\max }:=10650 & \\
\mathrm{FW}_{\max }:=200 & \\
\mathrm{~m}_{\text {uo4 }}:=52 &
\end{array}
$$

$$
U_{s c}:=\$ 2.4
$$

$U_{\mathrm{fl}}:=9.5$

$U_{\mathrm{fa}}:=8.7$

$U_{f h}:=8.2$

$\mathrm{N}_{\mathrm{fl}}:=\frac{18}{54}$

$\mathrm{N}_{\text {fa }}:=\frac{30}{54}$

$N_{\text {fh }}:=\frac{6}{54}$

$\mathrm{T}_{\mathrm{av}}:=12+3 \quad \mathrm{dT}$ av $:=12$

$\begin{array}{lll}\mathrm{g}_{\text {hac }}:=0.525 & \mathrm{~g}_{\text {hap }}:=0.1575 & \mathrm{~g}_{\text {hay }}:=1.2 \\ \mathrm{~g}_{\text {oad }}:=0.2625 & \mathrm{~g}_{\text {oap }}:=0.07875 & \mathrm{~g}_{\text {oay }}:=0.135 \\ \mathrm{~g}_{\text {hua }}:=0.165 & \mathrm{~g}_{\text {hup }}:=0.05 & \mathrm{~g}_{\text {huy }}:=1.2 \\ \mathrm{~g}_{\text {oud }}:=0.083 & \mathrm{~g}_{\text {oup }}:=0.025 & \mathrm{~g}_{\text {ouy }}:=0.101 \\ \mathrm{~g}_{\text {hwa }}:=1.6 & \mathrm{~g}_{\text {hwp }}:=0.53 & \mathrm{~g}_{\text {hwy }}:=0.5 \\ \mathrm{~g}_{\text {owa }}:=0.8 & \mathrm{~g}_{\text {owp }}:=0.265 & \mathrm{~g}_{\text {owy }}:=0.25 \\ \mathrm{rQ}_{\text {ay }}:=0.35 & \mathrm{rQ}_{\text {uy }}:=0.86 & \mathrm{rQ}\end{array}$


File: gét0ج99-Scrap0-ol.mcd Date: 2/4/99 Page: 3SNF-3951, Rev. 0

Decay Power Variation with Time: HNF-SD-SNF-CN-006 Regulatory/Safety Design Basis

$\begin{array}{llllll}\text { source } & 1995 & 2040 & \text { lamda } & \text { tau } & \text { Where lamda in 1/year and tau in year } \\ \text { alpha } & 26.3 & 32 & -4.36 \mathrm{e}-3 & -159 & \text { Alpha increases as fraction with time } \\ \text { beta } & 65 & 22 & +2.41 \mathrm{e}-2 & 28.8 & \\ \text { gamma } & 42.4 & 14.3 & +2.42 \mathrm{e}-2 & 28.7 & \text { Note decay power in W/MT here } \\ \text { TOTAL } & 133.7 & 68.3 & 1.49 \mathrm{e}-2 & 46.4 & \end{array}$

Initial power fractions; Each

independently decayed with time.

$\mathrm{fQ}_{\infty .0}:=\frac{26.3}{133.7} \quad \mathrm{fQ}_{\beta 0}:=\frac{65}{133.7} \quad \mathrm{fQ}_{\% \mathrm{O}}:=\frac{42.4}{133.7}$

Decay rates for alpha,beta,gamma, and total power based on 1995 to 2040 changes. Note aipha

$$
\begin{array}{ll}
\lambda_{\alpha}:=\frac{-1}{45} \cdot \ln \frac{32}{26.3} & \lambda_{\alpha}=-4.36 \cdot 10^{-3} \\
\lambda_{\beta}:=\frac{-1}{45} \cdot \ln \frac{22}{65} & \lambda_{\beta}=0.02 \\
\lambda_{y}:=\frac{-1}{45} \cdot \ln \left(\frac{14.3}{42.4}\right. & \lambda_{y}=0.02
\end{array}
$$$$
\text { power increases slightly, so rate is negative. }
$$

$\lambda_{\mathrm{q}}:=\frac{-1}{45} \cdot \ln \left(\frac{68.3}{(133.7}\right)$

$\lambda_{\mathrm{q}}=0.01$

*** CASES FOR ZERO SCRAP BASKETS ***

$$
\begin{aligned}
& A L_{\text {max }}:=10650 \\
& \mathrm{UH}_{\text {max }}:=297
\end{aligned}
$$

2.1 TIME-DEPENDENT POWER FRACTIONS: Multiply by initial power to get power(time) for each mode:
$\mathrm{fQ}_{\alpha}(t):=f \mathrm{Q}_{\alpha 0} \exp \left(-\lambda_{\alpha} t\right)$
$\mathrm{fQ}_{\beta}(t):=\mathrm{fQ}_{\beta 0} \cdot \exp \left(-\lambda_{\beta} \cdot t\right)$
$\mathrm{fQ}_{\gamma}(\mathrm{t}):=\mathrm{fQ}_{\gamma_{0}} \cdot \exp \left(-\lambda_{\gamma} \cdot \mathrm{t}\right)$
Example for use of alpha power:
$\mathrm{fQ}_{\mathrm{a}}(45)=0.24$
$32 \cdot(32+22+14.3)^{-1} \cdot \exp \left(-\lambda q^{45}\right)=0.24$

\subsection{FUNCTIONS FOR DECAY CONSTANTS AND EXAMPLES}

\section{Decay constant for free $\mathrm{H} 2 \mathrm{O}$ radiolysis: $\mathrm{WH}=\mathrm{H} 2$ yleld, $\mathrm{WO}=\mathrm{O} 2$ yield}

$$
\begin{aligned}
& \lambda_{\text {wo }}:=M_{\mathbf{f}}{ }^{-1} \cdot M_{\mathbf{w}}(\mathrm{Jev} \cdot \mathrm{Na})^{-1} \cdot \text { Secy } \\
& f_{w h}(t):=g_{h w a} \cdot \mathrm{PQ}_{\alpha}(t)+g_{h w p} \cdot \mathrm{PQ}_{\beta}(t)+g_{h w y} \cdot \mathrm{QQ}_{w \gamma} \cdot \mathrm{fQ}_{\gamma}(\mathrm{t}) \quad \mathrm{fg}_{w h}(0)=0.63 \\
& f_{w_{0}}(t):=g_{o w g} \cdot f Q_{a}(t)+g_{o w p} f Q_{\beta}(t)+g_{o w} \cdot R_{w y} \cdot f Q_{y}(t) \quad f g_{w o}(0)=0.32 \\
& \lambda_{w h}(Q, t):=\lambda_{w o} \cdot Q \cdot f_{w h}(t) \\
& \mathrm{f}_{\mathrm{wh}}(396,0)=2.33 \cdot 10^{-3} \\
& \lambda_{\text {wo }}(Q, t):=\lambda_{w o} \cdot Q \cdot f_{\text {wo }}(t) \\
& \text { f. } \text { wo }(396,0)=1.16 \cdot 10^{-3}
\end{aligned}
$$


Decay constant for $\mathrm{Al}(\mathrm{OH}) 3$ radiolysis: $\mathrm{AC}=\mathrm{Cladding}$ Film

$$
\begin{aligned}
& \dot{i}_{\text {ao }}=\left[\mathrm{M}_{\mathrm{f}}^{-1} \cdot \mathrm{M}_{\mathrm{ah}} \cdot(\mathrm{JeV} \cdot \mathrm{Na})^{-1} \cdot \text { Secy }\right] \\
& \mathrm{fg}_{\mathrm{ach}}(\mathrm{t}):=\mathrm{g}_{\text {hay }} \cdot \mathrm{Q}_{\mathrm{ay}} \mathrm{fQ}, \mathrm{t}(\mathrm{t}) \\
& \mathrm{fg}_{\text {aco }}(\mathrm{t}):=\mathrm{g}_{\text {oay }} \cdot \mathrm{TQ} \text { ay } \mathrm{fQ}_{\gamma}(\mathrm{t}) \\
& \mathrm{f} \lambda_{\operatorname{ach}}(\mathrm{Q}, \mathrm{t}):=\lambda_{\text {ao }} \mathrm{Q} \cdot \mathrm{fg}_{\mathrm{ach}}(\mathrm{t}) \\
& \mathrm{f}_{\mathrm{aco}}(\mathrm{Q}, \mathrm{t}):=\lambda_{\mathrm{ao}} \mathrm{Q} \cdot \mathrm{fg}_{\mathrm{aco}}(\mathrm{t})
\end{aligned}
$$

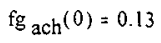$$
\mathrm{fg}_{\mathrm{aco}}(0)=0.01
$$$$
\mathrm{f}_{\mathrm{ach}}(396,0)=2.12 \cdot 10^{-3}
$$$$
f \lambda_{\mathrm{aco}}(396,0)=2.39 \cdot 10^{-4}
$$

Al clad fraction at 40 years, average power MCO: $\left.\quad \int_{0}^{40} \frac{2}{3} \cdot \mathrm{fl}_{\operatorname{ach}}(400, \mathrm{t}) \mathrm{dt}\right\}=0.96$

\section{Decay constant for $\mathrm{Al}(\mathrm{OH}) 3$ radiolysis: $\mathrm{AP}=\mathrm{Al}$ in Adhering Particulate}

$$
\begin{aligned}
& \mathrm{fg}_{\mathrm{aph}}\left(\mathrm{f}_{\mathrm{u}}, \mathrm{t}\right):=\mathrm{f}_{\mathrm{u}}\left(\mathrm{g}_{\text {had }} \cdot \mathrm{PQ}_{\alpha}(\mathrm{t})+\mathrm{g}_{\text {haß }} \cdot \mathrm{PQ}_{\beta}(\mathrm{t})\right)+\mathrm{g}_{\text {hay }} \cdot \mathrm{rQ}_{\alpha y} \cdot \mathrm{PQ}_{y}(\mathrm{t}) \quad \mathrm{fg}_{\mathrm{aph}}(0.2,0)=0.17 \\
& \mathrm{fg}_{\text {apo }}\left(\mathrm{f}_{\mathrm{u}}, \mathrm{t}\right):=\mathrm{f}_{\mathrm{u}} \cdot\left(\mathrm{g}_{\text {oad }} \cdot \mathrm{PQ}_{\alpha}(\mathrm{t})+\mathrm{g}_{\text {oa }} \cdot \mathrm{PQ}_{\beta}(\mathrm{t})\right)+\mathrm{g}_{\text {oay }} \cdot \mathrm{P}_{\text {ay }} \cdot \mathrm{PQ}_{y}(\mathrm{t}) \quad \mathrm{fg}_{\text {apo }}(0.2,0)=0.03 \\
& a_{\operatorname{aph}}\left(Q, f_{u}, t\right):=\lambda_{a o} \cdot Q \cdot f_{\operatorname{aph}}\left(f_{u}, t\right) \\
& \lambda_{\mathrm{aph}}(396,0.2,0)=2.7 \cdot 10^{-3} \\
& a_{\text {apo }}\left(Q, f_{u}, t\right):=\lambda_{\text {ao }} \cdot Q \cdot f g \text { apo }\left(f_{u}, t\right) \\
& a_{\text {apo }}(396,0.2,0)=5.26 \cdot 10^{-4}
\end{aligned}
$$

\section{Decay constant for U03.2H2O radiolysis}

$$
\begin{aligned}
& \lambda_{\text {uo }}:=\left[\mathrm{M}_{\mathrm{f}}^{-1} \cdot \mathrm{M}_{\mathrm{uh}} \cdot(\mathrm{Jev} \cdot \mathrm{Na})^{-1} \cdot \operatorname{Secy}\right] \\
& \mathrm{fg}_{\mathrm{uh}}(\mathrm{t}):=\mathrm{g}_{\text {hua }} \cdot \mathrm{fQ}_{Q}(\mathrm{t})+\mathrm{g}_{\text {hup }} \cdot \mathrm{fQ}_{\beta}(\mathrm{t})+\mathrm{g}_{\text {huj }} \cdot \mathrm{rQ}_{\mathrm{uj}} \cdot \mathrm{fQ}_{y}(\mathrm{t})
\end{aligned}
$$

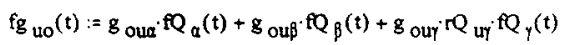

$$
\begin{aligned}
& \mathrm{fg}_{\mathrm{uh}}(0)=0.38 \\
& \mathrm{fg}_{\text {uo }}(0)=0.06 \\
& \lambda_{\mathrm{uh}}(\mathrm{Q}, \mathrm{t}):=\lambda_{\mathrm{uov}} \cdot \mathrm{Q} \cdot \mathrm{fg}_{\mathrm{uh}}(\mathrm{t}) \\
& \mathrm{f}_{\text {uh }}(396,0)=0.03 \\
& \lambda_{\mathrm{uo}}(Q, t):=\lambda_{\mathrm{uo}} \cdot Q \cdot \mathrm{fg}_{\mathrm{uo}}(t) \\
& f_{u o}(396,0)=3.69 \cdot 10^{-3} \\
& \exp -\int_{0}^{40} \frac{1}{2} \cdot \mathrm{th}_{\mathrm{uh}}(400, \mathrm{t}) \mathrm{dt}=0.71
\end{aligned}
$$




\subsection{FUNCTIONS FOR U GETTERING RATE AND WATER VAPOR PRESSURE}

Water vapor pressure: $\quad f P_{s a t}(T):=e^{25.339-\frac{\$ 154.7}{T}} \quad \mathrm{fP}_{\text {sat }}(323)=1.19 \cdot 10^{4} \quad 50 \mathrm{C} \mathrm{OK}$

Ritchie correlation for U-H2O-O2, below $100 \% \mathrm{RH}$, below $100 \mathrm{C}$, agrees best with data BUT goes below dry air correlation at about $37 \mathrm{C}$ - so switch to McGillivray dry air. Ritchie units of $\mathrm{mg} / \mathrm{cm}^{\wedge} 2 / \mathrm{hr}$, converted to grams $\mathrm{O} 2$ per $\mathrm{m}^{\wedge} 2$ per year.; McGillivray units of $\mathrm{kg} / \mathrm{m}^{\wedge} 2 / \mathrm{s}$ similarly converted.

$K_{\text {rit }}(T):=10^{13.8808-5769.6 \cdot \mathrm{T}^{-1}} \cdot 10.8766 \quad$ Ritchie $\quad K_{\text {trim }}(T):=10^{7.19-3732 \cdot \mathrm{T}^{-1}} \cdot 10 \cdot 8766 \quad$ Trimble

$T_{\text {cor }}:=(5769.6-3732) \cdot(13.8808-7.19)^{-1} \quad T_{\text {cor }}=304.54 \quad$ Switch correlations here, $31 \mathrm{C}$

Moist Air Getter Function 100\% RH:

$\mathrm{fK}_{\mathrm{o}}(323) \cdot 0.1 \cdot(8766)^{-1}=1.04 \cdot 10^{-4}$

$\mathrm{fK}_{\mathrm{o}}(323) \cdot 10^{-3} \cdot\left(3.15 \cdot 10^{7}\right)^{-1}=2.9 \cdot 10^{-10}$

fK $\left.\mathrm{o}^{(} \mathrm{T}_{\text {cor }}+0.01\right) \cdot 10^{-3} \cdot\left(3.15 \cdot 10^{7^{2}}\right)^{-1}=2.4 \cdot 10^{-11}$
$\mathrm{fK}_{\mathrm{o}}(\mathrm{T}):=\mathrm{if} / \mathrm{T} \geq \mathrm{T}$ cor $, \mathrm{K}_{\text {rit }}(\mathrm{T}), \mathrm{K}_{\text {trim }}(\mathrm{T})$

OK@ $50 \mathrm{C}$ in $\mathrm{mg} / \mathrm{cm}^{\wedge} 2 / \mathrm{hr}$

OK@ $90 \mathrm{C}$ in $\mathrm{kg} / \mathrm{m}^{\wedge} 2 / \mathrm{s}$

fX o $\left(\mathrm{T}_{\operatorname{cor}}-0.01\right) \cdot 10^{-3} \cdot\left(3.15 \cdot 10^{7}\right)^{-1}=2.4 \cdot 10^{-11}$

\section{Gettering of Water vapor when Oxygen-Free:}

$\mathrm{fK}_{\mathrm{w}}(\mathrm{T}):=\mid \begin{aligned} & \mathrm{P}_{\mathrm{st}} \leftarrow 10^{-3} \cdot \mathrm{PP}_{\text {sat }}(\mathrm{T}) \\ & \mathrm{K} \leftarrow \mathrm{P}_{\mathrm{St}}{ }^{0.5} \cdot 10^{4.33-2144 \cdot \mathrm{T}^{-1}} \\ & \mathrm{~K} \leftarrow \mathrm{K} \cdot 10.8766\end{aligned}$
$\begin{array}{ll}\mathrm{EK}_{\mathrm{w}}(323)=1.49 \cdot 10^{3} & \frac{1486}{9.14}=162.58 \\ \mathrm{fK}_{\mathrm{o}}(323)=9.14 & \end{array}$

\subsection{RELATIONSHIP BETWEEN MCO POWER AND GAS TEMPERATURE}

Conservative relationships based on $733 \mathrm{~W} M C O$, zero scrap case for fuel and one scrap case for scrap. Vault gas-tube $d T=28 \mathrm{C}$, Fuel tube-MCO gap $d T=39 \mathrm{C}$, Scrap gap $d T=27 \mathrm{C}$. Inside MCO, fuel dT's are $12.5,20$, and $26 \mathrm{C}$; scrap dT is $4 \mathrm{C}$. Function yields scrap and low to high fuel $\mathrm{T}$ 's in that order:

fTget $\left(Q_{0}, t\right):=Q_{o} \cdot e^{-\lambda} q^{\cdot t} \cdot\left[\frac{1}{U_{s c}} \frac{1}{U_{f l}} \frac{1}{U_{f a}} \frac{1}{U_{f h}}\right]^{T}+T_{a v}$

$\operatorname{fTget}(400,0)^{\mathrm{T}}=\left[\begin{array}{llll}47.26 & 57.11 & 60.98 & 63.78\end{array}\right] \quad \operatorname{fTget}(770,0)^{\mathrm{T}}=\left[\begin{array}{llll}77.1 & 96.05 & 103.51 & 108.9\end{array}\right]$ 


\subsection{ACCOUNT FOR ANNUAL TEMPERATURE VARIATION BY INTEGRAL AVERAGE FOR A YEAR}

Create an interpolation table over the temperature range of interest, then define a new rate law function which automatically. incorporates the average annual enhancement factor. Input $\mathrm{T}$ in Kelvins!

$$
\begin{aligned}
& \mathrm{fT}_{\mathrm{a}}(\mathrm{T} \cdot \mathrm{t}):=\mathrm{T}+\mathrm{dT} \mathrm{T}_{\mathrm{av}} \cdot \sin (2 \cdot \pi \cdot \mathrm{t}) \quad \mathrm{f}=(\mathrm{T}):=\left.\mathrm{fK}_{\mathrm{o}}(\mathrm{T})^{-1}\right|_{0} ^{1} \mathrm{fK}_{\mathrm{o}} \mathrm{fT}_{\mathrm{a}}(\mathrm{T}, \mathrm{t}) \mathrm{dt} \\
& \mathrm{j}:=0 . .60 \quad \mathrm{~T} \xi_{\mathrm{j}}:=283+2 \cdot \mathrm{j} \quad \bar{\xi}_{\mathrm{j}}:=\mathrm{E} \mathrm{T} \xi_{\mathrm{j},} \quad \mathrm{f}(\mathrm{T}):=\operatorname{linterp}(\mathrm{T} \xi, \Xi, \mathrm{T}) \quad \mathrm{fK}_{\mathrm{l}}(\mathrm{T}):=\mathrm{f}(\mathrm{T}) \cdot \mathrm{fK}, \mathrm{o}(\mathrm{T}) \\
& \text { Values at low, medium, high T: } f \xi(288)=1.38 \quad f \xi(333)=1.54 \quad f(383)=1.29
\end{aligned}
$$

\subsection{FUNCTIONS TO SET UP INITIAL CONDTIONS}

User specifies:

(1) $Q=$ MCO Initial power, $W$;

(2) As = Scrap reactive area, $m^{\wedge} 2$;

(3) Af= Fuel reactive area, $m^{\wedge} 2$;

(4) $\mathrm{ma}=\mathrm{Al}(\mathrm{OH}) 3$ film mass, $\mathrm{g}$;

(5) mwcp = Canister particulate water mass, $g$;

(6) fUcp $=U$ fraction of can. partic. for alpha, beta

(7) fwUcp: $U$ water fraction of can. particulate;

(8) $\mathrm{mu}$ : Mass/area water from UO3.2H2O;

(9) $\mathrm{mfw}$ : Free water mass per area, $g / \mathrm{m}^{\wedge} 2$.

Other assumptions of note:

(1) Initial water vapor mass determined by scrap T;

(2) Residual free water prevents hydrate thermal decomposition.
State vector $V$ assigned based on these inputs:

Actual state variables are:

(0) nac $=\mathrm{Al}(\mathrm{OH}) 3$ cladding fitm water moles

(1) nap $=\mathrm{Al}(\mathrm{OH}) 3$ can particulate water moles

(2) nu=UO3.2 $\mathrm{H} 2 \mathrm{O}$ water moles

(3) $\mathrm{nw}=$ free $\mathrm{H} 2 \mathrm{O}$ moles

(4) $\mathrm{nh} 2=\mathrm{H} 2+\mathrm{H} 2 \mathrm{O}$ vapor moles

(5) no2 $=02$ moles

Parameters are:

(6) $Q=$ Power,

(7) AS = Scrap area,

(8) $A F=$ Fuel Area,

(9) fucp $=U$ fraction of canister particulate

Initial steam from free water, assumed sufficient; free water not depleted; scrap T (index 0 ) used:

$\mathrm{fn}_{s t}(\mathrm{Q}):=\mid \begin{aligned} & \mathrm{T}_{\mathrm{o}} \leftarrow \mathrm{fTget}(\mathrm{Q}, 0)_{0}+273 \\ & \mathrm{P}_{\text {sat }}\left(\mathrm{T}_{\mathrm{o}}\right) \cdot \mathrm{V}_{\text {mco }} \cdot\left(\mathrm{R}_{\mathrm{gas}} \cdot \mathrm{T}_{\mathrm{o}}\right)^{-1}\end{aligned}$

Function for water moles of $U 03.2 \mathrm{HO}$ plus $\mathrm{UO} 4.2 \mathrm{H} 2 \mathrm{O}$ given $\mathrm{m}=\mathrm{kg} / \mathrm{m}^{\wedge} 2$ from $\mathrm{UO} 3.2 \mathrm{H} 2 \mathrm{O}$, A=fuel reactive area, and adding $\mathrm{UO} 4$ contribution in proportion the fraction not covered with $\mathrm{Al}(\mathrm{OH}) 3$, given its mass ma.

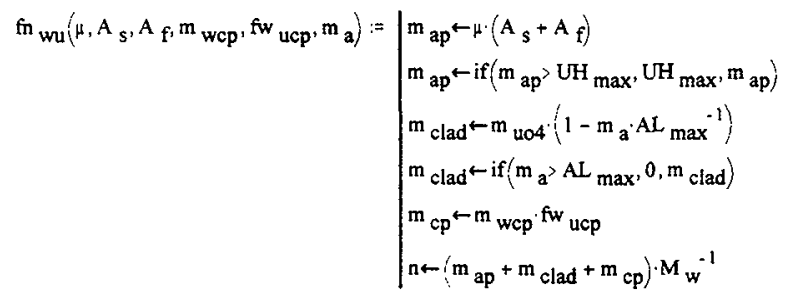

$f_{f w}\left(m_{f w}, A_{s}, A_{f}\right):=\mid \begin{aligned} & m \leftarrow m_{f w} \cdot\left(A_{s}+A_{f}\right) \\ & n \leftarrow i f\left(m>F W_{\text {max }}, F W_{\text {max }}, m_{f} \cdot M_{w}{ }^{-1}\right.\end{aligned}$ 


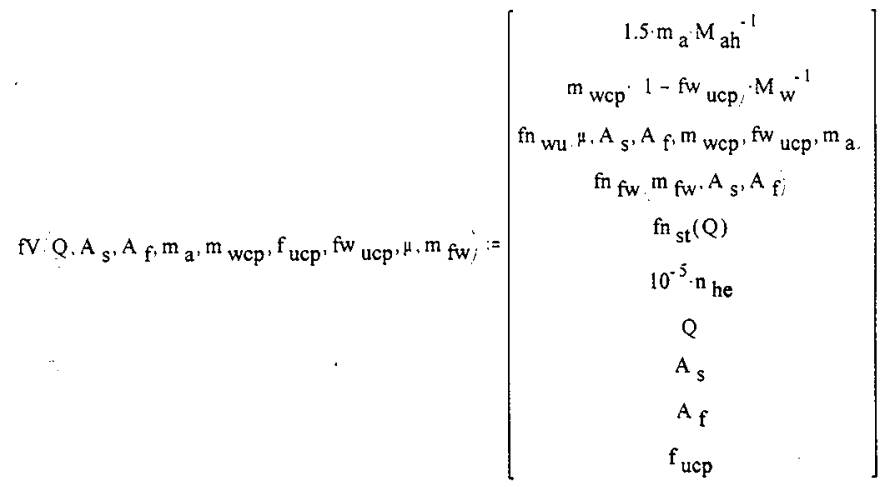

Test for bounding conditions, one scrap basket:

$\mathrm{fV}(733,4.5,3.16,10050,192,0.1,0.1,100,30)^{\mathrm{T}}=193.279 .617 .7311 .116 .223 .03 \cdot 10^{-4} 733$

\subsection{FUNCTIONS FOR H2, O2 SOURCE AND SINK; R=Radiolysis Source, G=Getter}

Current $\mathrm{O} 2$ model assumes $\mathrm{O} 2$ gettering phase from beginning of transient.

Current $\mathrm{H} 2$ model assumes no gettering.

$$
\begin{aligned}
& \mathrm{R}_{\mathrm{O} 2}\left(\mathrm{Q}, \mathrm{t}, \mathrm{n}_{\mathrm{ac}}, \mathrm{n}_{\mathrm{ap}}, \mathrm{n}_{\mathrm{u}}, \mathrm{n}_{\mathrm{w}}, \mathrm{f}_{\mathrm{ucp} /}\right):=\mathfrak{a}_{\mathrm{aco}}(\mathrm{Q}, \mathrm{t}) \cdot \mathrm{n}_{\mathrm{ac}}+\mathrm{a}_{\mathrm{apo}}\left(\mathrm{Q}, \mathrm{f}_{\mathrm{ucp}}, \mathrm{t}\right) \cdot \mathrm{n}_{\mathrm{ap}}+\mathrm{t}_{\mathrm{uo}}(\mathrm{Q}, \mathrm{t}) \cdot \mathrm{n}_{\mathrm{u}}+\mathrm{t}_{\mathrm{wo}}(\mathrm{Q}, \mathrm{t}) \cdot \mathrm{n}_{\mathrm{w}}
\end{aligned}
$$

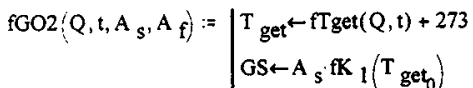

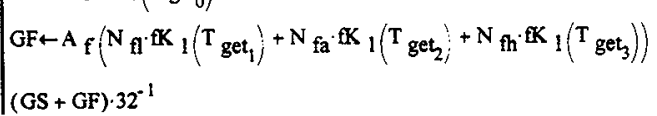

\subsection{RATES OF CHANGE OF RADIOLYSIS SOURCES \& PRODUCTS}

Need a trick because Mathcad demands a function $F$ whose arguments are $t, Y$ where $t$ is time and $Y$ is a vector of state variables. Output of $F$ is a vector $\mathrm{dY} / \mathrm{dt}$. Trick: $\mathrm{dY} / \mathrm{dt}=0$ for constant terms needed.

State variables thus include parameters expected to vary from case to case. Coding first assigns scrutable names to the state vector; see comment below. Coding for readability, not compactness. 


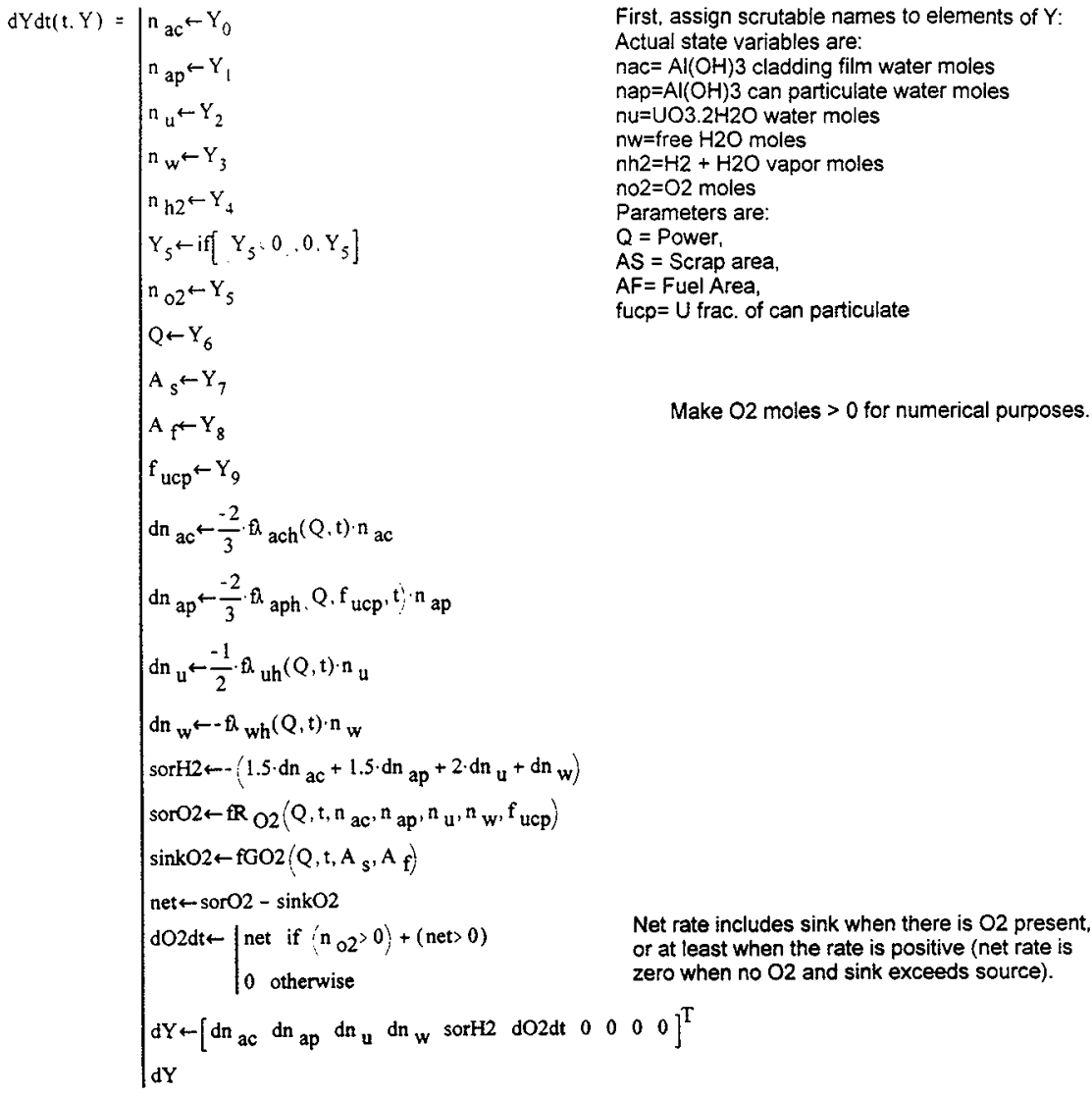

\section{Function to get End-of-Life values after integration of a single case:}

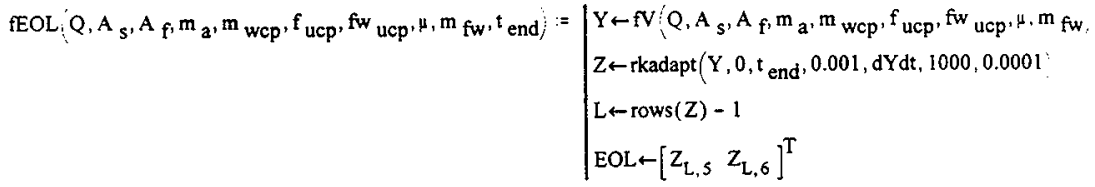




\subsection{COMBUSTION FUNCTIONS}

4.1 GAS SPECIFIC HEAT DATA: CV(T) POLYNOMIAL FIT.: Gases are entered in the order: H2, He, N2, O2, H2O from HANSF input GASPROP.DAT. Values in $\mathrm{J} / \mathrm{g}$-mole/K!!! $\mathrm{FW}$ is the formula weight vector.

$$
\mathrm{CCV}:=\left[\begin{array}{ccccc}
21.136 & -1.529 \cdot 10^{-3} & 1.978 \cdot 10^{-6} & 4.018 \cdot 10^{-10} & -1.171 \cdot 10^{-13} \\
12.47 & 0 & 0 & 0 & 0 \\
20.785 & -3.871 \cdot 10^{-3} & 1.34 \cdot 10^{-5} & -7.216 \cdot 10^{-9} & 1.16 \cdot 10^{-12} \\
17.045 & 0.014 & -4.96 \cdot 10^{-6} & 1.375 \cdot 10^{-10} & 1.375 \cdot 10^{-13} \\
24.044 & -7.883 \cdot 10^{-5} & 1.513 \cdot 10^{-5} & -7.323 \cdot 10^{-9} & 1.087 \cdot 10^{-12}
\end{array}\right] \quad \quad F W:=\left[\begin{array}{l}
2 \\
4 \\
28 \\
32 \\
18
\end{array}\right]
$$

Functions for $\mathrm{CV}$ and $\mathrm{Ug}$ of a specific gas:

$$
\begin{aligned}
& \mathrm{fCv}(\mathrm{i}, \mathrm{T}):=\mathrm{CCV}_{\mathrm{i}, 0}+\mathrm{CCV}_{\mathrm{i}, 1} \cdot \mathrm{T}+\mathrm{CCV}_{\mathrm{i}, 2} \cdot \mathrm{T}^{2}+\mathrm{CCV}_{\mathrm{i}, 3} \cdot \mathrm{T}^{3}+\mathrm{CCV}_{\mathrm{i}, 4} \cdot \mathrm{T}^{4} \\
& \mathrm{fug}(\mathrm{i}, \mathrm{T}):=\mathrm{T} \cdot\left[\mathrm{CCV}_{\mathrm{i}, 0}+\mathrm{T} \cdot\left[\frac{1}{2} \cdot \mathrm{CCV}_{\mathrm{i}, 1}+\mathrm{T} \cdot\left[\frac{1}{3} \cdot \mathrm{CCV}_{\mathrm{i}, 2}+\mathrm{T} \cdot\left(\frac{1}{4} \cdot \mathrm{CCV}_{\mathrm{i}, 3}+\mathrm{T} \cdot \frac{1}{5} \cdot \mathrm{CCV}_{i, 4}\right)\right]\right]\right]
\end{aligned}
$$

Function for energy of a gas with mole vector $\mathrm{N}$ at temperature $\mathrm{T}$ (without integration constant):

$$
\mathrm{fUg}(\mathrm{N}, \mathrm{T}):=\mid \begin{aligned}
& U \leftarrow 0 \\
& \text { for } i \in 0 . .4 \\
& U \leftarrow U+N_{i} \cdot \operatorname{fug}(i, T) \\
& U
\end{aligned}
$$

2.0 AICC Function input is mole vector (see order above) and initial Temperature, Output is a vector with: post-burn mole vector, AICC temperature, AICC pressure.

$$
\begin{aligned}
& \operatorname{fAICC}\left(\mathrm{N}, \mathrm{T}_{\mathrm{O}}, \mathrm{V}\right):=\mid \begin{array}{l}
\mathrm{H} 2 \leftarrow \mathrm{N}_{0} \\
\mathrm{O} 2-\mathrm{N}_{3}
\end{array} \\
& \triangle \mathrm{H} 2 \mathrm{O} \leftarrow \mathrm{if}(\mathrm{H} 2 \leq 2 \cdot \mathrm{O} 2, \mathrm{H} 2,2 . \mathrm{O} 2) \\
& \mathrm{NP} \leftarrow\left[\begin{array}{llll}
\mathrm{H} 2 & -\triangle \mathrm{H} 2 \mathrm{O} \quad \mathrm{N}_{1} & \mathrm{~N}_{2} & \mathrm{O} 2 \\
-0.5 \cdot \Delta \mathrm{H}_{2} \mathrm{O} \quad \mathrm{N}_{4}+\Delta \mathrm{H} 2 \mathrm{O}
\end{array}\right]^{\mathrm{T}} \\
& Q \leftarrow \mathrm{AH} 2 \mathrm{O} \cdot 241.8 \cdot 10^{3} \\
& \mathrm{U}_{\mathrm{o}} \leftarrow \mathfrak{f} \mathrm{Ug}\left(\mathrm{N}, \mathrm{T}_{\mathrm{o}}\right) \\
& \begin{array}{l}
T \leftarrow T_{0}+Q \cdot\left(f U g\left(N, T_{0}+1\right)-U_{0}\right)^{-1} \\
T_{f} \leftarrow \operatorname{root}\left(\mathrm{Ug}(\mathrm{NP}, \mathrm{T})-\mathrm{U}_{0}-\mathrm{Q}, \mathrm{T}\right)
\end{array} \\
& \begin{array}{l}
\mathrm{n}_{\mathrm{f}} \leftarrow \Sigma \mathrm{NP} \\
\mathrm{P}_{\mathrm{f}} \leftarrow \mathrm{n}_{\mathrm{f}} 8.314 \cdot \mathrm{T}_{\mathrm{f}} \mathrm{V}^{-1} \\
\mathrm{TP} \leftarrow\left[\mathrm{T}_{f} \mathrm{P}_{\mathrm{f}}\right]^{\mathrm{T}} \\
\mathrm{f} \leftarrow \operatorname{stack}(\mathrm{NP}, \mathrm{TP}) \\
\mathrm{f}
\end{array}
\end{aligned}
$$




\subsection{K-West Bounding Case \& High Power: High Al(OH)3, High Canister+Adhering Particulate}

5.1A Define highest K-West Power, $530 \mathrm{~W}$, and Investigate Fuel area up to $4 \mathrm{~m}^{\wedge} 2$ :
$\mathrm{a}:=1.10$
$A_{a}:=$ if $(a \geq 7 . a-6$. if $(a>1 .(a-1) \cdot 0.05 \cdot 0.01))$
$A_{0}:=0$
$\mathbf{a}:=0.10$

Zero Scrap:

$A_{S}:=0$

Bounding Can. partic:

$m_{\text {wep }}:=240$

Bounding $\mathrm{Al}(\mathrm{OH}) 3$ :

$m_{a}:=10650$

Bounding Can. partic U:

$\mathrm{f}_{\text {ucp }}:=0.2$

Bounding Adher. Partic:

$\mu:=100$

Can. water frac. from $U$

$f_{\text {ucp }}:=0.08$

Free water $\mathrm{g} / \mathrm{m}^{\wedge} 2$ :

$m_{f w}:=66.7$

MCO Power

$Q_{0}:=530$

$\left[\begin{array}{c}n h 2_{a} \\ n o 2_{a}\end{array}\right]:=f E O L\left(Q_{0}, A_{s}, A_{a}, m_{a}, m_{w c p}, f_{u c p}, f w_{u c p}, 4, m_{f w}, 40\right)$

ntot $\left._{a}:=n_{h e}+n_{a}+n h 2_{a} \quad O 2 \%_{a}:=n_{a} 2_{a} \cdot n^{\prime} t_{a}\right)^{-1} \quad O 2 \%_{a}:=$ if $\left(02 \%_{a}>0,100 \cdot 02 \%_{a}, 0\right.$

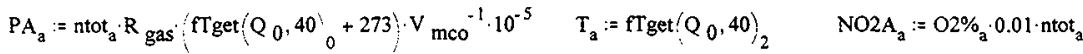

For $\mathrm{A}=0$. vary moles of $\mathrm{H} 2$ from value with no getter until stoichiometric, and get post-combustion pressure.

$\left.\mathrm{n}_{\mathrm{st}}:=\mathrm{fn}_{\mathrm{st}}\left(\mathrm{Q}_{0}\right) \quad \delta \mathrm{nh} 2:=0.1 \cdot \mathrm{nh}_{0}-\mathrm{n}_{\mathrm{st}}-2 \cdot \mathrm{no}_{0}\right) \quad \mathrm{n}_{\mathrm{st}}=3.13 \quad \mathrm{no}_{0}=2.03 \quad \mathrm{nh}_{0}=19.69$

$i:=0.10 \quad n i H 2_{i}:=n h 2_{0}-n_{s t}-i \cdot \delta n h 2 \quad 02 \% 1_{j}:=100 \cdot n_{0} 2_{0}\left(n_{h e}+n_{s t}+n_{0} 2_{0}+n 1 H 22_{i}\right.$

$\mathrm{N1}_{0, \mathrm{i}}:=\mathrm{n} 1 \mathrm{H} 2_{\mathrm{i}} \quad \mathrm{N1} \mathbf{l}_{1, \mathrm{i}}:=\mathrm{n}_{\text {he }} \quad \mathrm{N1}_{2, \mathrm{i}}:=0 \quad \mathrm{Nl}_{3, \mathrm{i}}:=\mathrm{no}_{0} \quad \mathrm{NI}_{4, \mathrm{i}}:=\mathrm{n}_{\text {st }} \quad \mathrm{Tk}:=\mathrm{T}_{0}+273$

$A 1^{\langle i\rangle}:=\mathrm{fAICC}\left(\mathrm{Nl}^{\langle\mathrm{i}\rangle}, \mathrm{Tk}, \mathrm{V}_{\mathrm{mco}}\right) \quad \mathrm{Pl}_{\mathrm{i}}:=\mathrm{Al}_{6, \mathrm{i}} \cdot 101325^{-1} \quad \mathrm{~T}_{0}=48.53 \quad \mathrm{Tk}=321.53 \quad \mathrm{Pl}_{0}=11.89$

$5.2 \mathrm{Q}=400 \mathrm{~W}: \quad \mathrm{Q}_{0}:=400 \quad\left[\begin{array}{c}\mathrm{nh} 2_{\mathrm{a}} \\ \mathrm{no2} 2_{\mathrm{a}}\end{array}\right]:=\mathrm{fEOL}\left(\mathrm{Q}_{0}, \mathrm{~A}_{\mathrm{s}}, \mathrm{A}_{\mathrm{a}}, \mathrm{m}_{\mathrm{a}}, \mathrm{m}_{\mathrm{wcp}}, \mathrm{f}_{u c p}, \mathrm{fw}_{u c p}, 4, \mathrm{~m}_{\mathrm{fw}}, 40\right)$

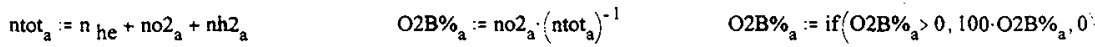

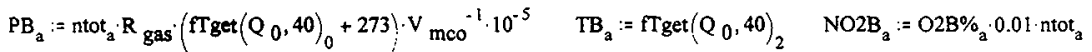

$\mathrm{n}_{\mathrm{st}}:=\mathrm{fn}_{\mathrm{st}}\left(\mathrm{Q}_{0}\right) \quad \delta \mathrm{nh} 2:=0.1 \cdot\left(\mathrm{nh}_{\mathrm{0}}-\mathrm{n}_{\mathrm{st}}-2 \cdot \mathrm{no}_{0}\right) \quad \mathrm{n}_{\mathrm{st}}=1.94 \quad \mathrm{no}_{0}=1.55 \quad \mathrm{nh} 2_{0}=14.54$

$\mathrm{i}:=0.10 \quad \mathrm{n} 1 \mathrm{H} 2_{\mathrm{i}}:=\mathrm{nh} 2_{0}-\mathrm{n}_{\mathrm{st}}-\mathrm{i} \cdot \delta \mathrm{nh} 2 \quad \mathrm{O} 2 \% 2_{\mathrm{i}}:=100 \cdot \mathrm{no} 2_{0}\left(\mathrm{n}_{\mathrm{he}}+\mathrm{n}_{\mathrm{st}}+\mathrm{no2} 2_{0}+\mathrm{n} 1 \mathrm{H} 2_{\mathrm{i}}^{i-1}\right.$

$\mathrm{Nl}_{0, \mathrm{i}}:=\mathrm{n} 1 \mathrm{H} 2_{\mathrm{i}} \quad \mathrm{N} 1_{1, i}:=\mathrm{n}_{\text {he }} \quad \mathrm{Nl}_{2, \mathrm{i}}:=0 \quad \mathrm{Nl}_{3, \mathrm{i}}:=\mathrm{no2}_{0} \quad \mathrm{Nl}_{4, \mathrm{i}}:=\mathrm{n}_{\text {st }} \quad \mathrm{TK}:=\mathrm{T}_{0}+273$

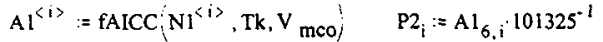


$\mathrm{N}$ : mber of moles of $\mathrm{O} 2$ at 40 years as function of reactive area and power:

$$
A^{T}=\begin{array}{lllllllllll}
0 & 0.01 & 0.05 & 0.1 & 0.15 & 0.2 & 0.25 & 1 & 2 & 3 \\
\hline
\end{array}
$$

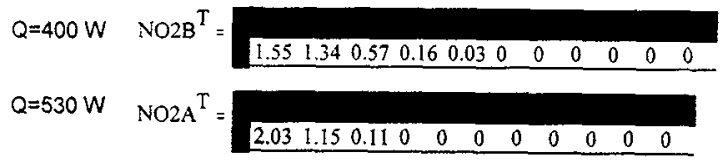

Pressure (no $\mathrm{H} 2$ gettering) at 40 years as function of reactive area and power:

$$
A^{T}=\begin{array}{llllllllll}
0 & 0.01 & 0.05 & 0.1 & 0.15 & 0.2 & 0.25 & 1 & 2 & 3 \\
\hline
\end{array}
$$

$Q=400 \mathrm{~W} \quad \mathrm{~PB}^{\mathrm{T}}=$\begin{tabular}{llllllllll}
2.36 & 2.35 & 2.32 & 2.3 & 2.31 & 2.31 & 2.32 & 2.46 & 2.64 \\
\hline
\end{tabular}

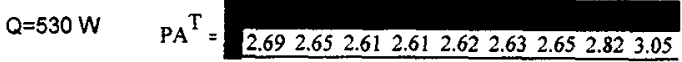

Moles Oxygen at 40 years for K-West Zero-Scrap Bounding Water Content as function of Reactive Area ( $\left.M^{\wedge} 2\right), Q=530 \mathrm{~W}$ and $Q=400 \mathrm{~W}$

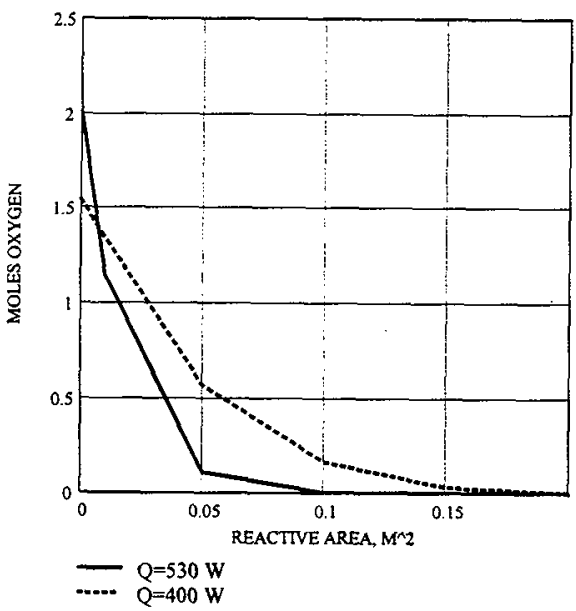


Pressure vs Oxygen Concentration for Zero Scrap, K-West bounding water inventory. Lower lines with symools indicate MCO conditions for various reactive areas with no combustion. Upper lines with no symbols are for post-burn sensitivity cases with hydrogen gettering to increase the $\mathrm{O} 2$ concentration up to stoichiometry.

Combustion is impossible for $02<4 \%$. The worst case group is for $A=0$, zero reactive area, because this maximizes the number of moles of oxygen. The worst case is for the highest power, hence highest moles of oxygen. The highest post-burn pressure is $11.9 \mathrm{~atm}$.

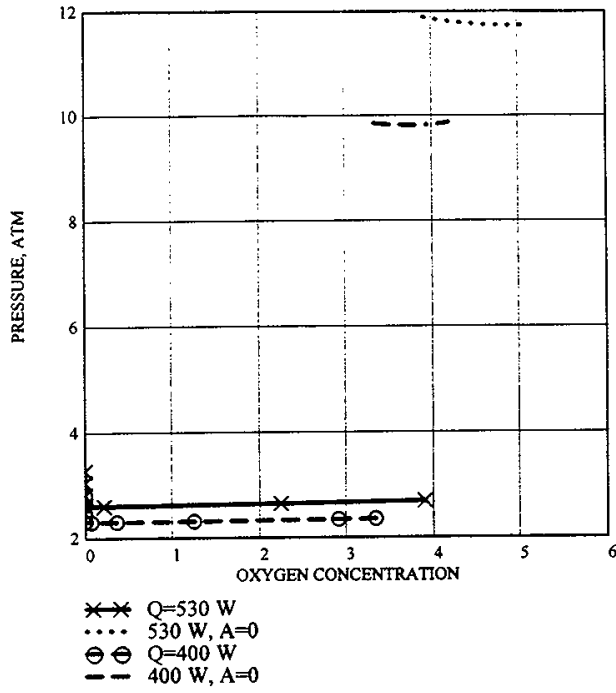


$k:=0 . .6 \quad P L_{k}:=31 \quad O 2 L_{k}:=k$

Pressure vs Oxygen Concentration for Zero Scrap, K-West bounding water inventory. Lower lines with symbols indicate MCO conditions for various reactive areas with no combustion. Upper lines with no symbols are for post-burn sensitivity cases with hydrogen gettering to increase the $\mathrm{O} 2$ concentration up to stoichiometry. The upper horizontal dashed line is the MCO design pressure 450 psig ( 31 atm absolute).

Combustion is impossible for $\mathrm{O} 2<4 \%$. The worst case group is for $\mathrm{A}=0$, zero reactive area, because this maximizes the number of moles of oxygen. The worst case is for the highest power, hence highest moles of oxygen. The highest post-burn pressure is 11.9 atm.

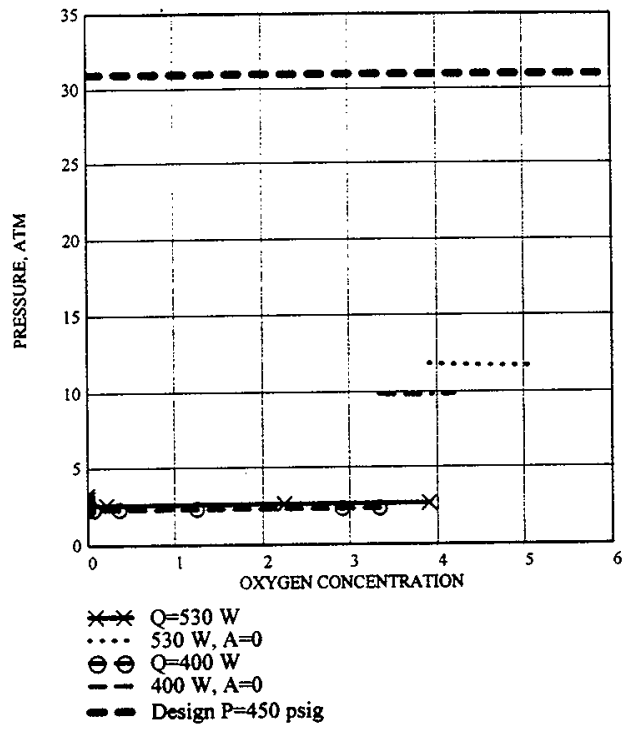




\section{MCO O2\% AND PRESSURIZATION: RADIOLYSIS AND GETTERING OF O2 AND COMBUSTION}

\section{ZERO SCRAP BASKET END-OF-LIFE HIGH HELIUM CASE}

BY: Martin G. Plys, Fauske \& Associates, inc. 16W070 W.83rd St. Burr Ridge IL 60521 Phone 630-323-8750

FOR: Hanford Spent Nuclear Fuel Project - Duke Engineering \& Services Hanford - Richland, WA Contact: Darrell Duncan 509-372-1013.

DATE: October, 1998.

Calculation Technical Basis and Assumptions:

1. Decay power varies per HNF-SD-SNF-CN-006 Regulatory/Safety Design Basis; see below. Alpha, beta, and gamma fractions are applied for all total MCO powers. Absorption based on fuel mass of $6339 \mathrm{~kg}$.

2. Water-bearing materials are: $\mathrm{Al}(\mathrm{OH}) 3$ cladding film, Canister particulate composed of $(\mathrm{Al}, \mathrm{Fe})(\mathrm{OH}) 3$, adhering particulate containing $\mathrm{UO} 3.2 \mathrm{H} 2 \mathrm{O}$, and free water. Other sources are negligible for radiolysis.

3. $\mathrm{g}(\mathrm{O} 2)$ and $g(\mathrm{H} 2)$ values from HNF-SD-SNF-CN-006; see below.

4. Gamma absorption by $\mathrm{Al}(\mathrm{OH}) 3, \mathrm{UO} 3.2 \mathrm{H} 2 \mathrm{O}$, and $\mathrm{H} 2 \mathrm{O}$ relative to that by $\mathrm{U}$ based on $0.6 \mathrm{MeV}$ gamma.

5. Al(OH)3 cladding film radiolysis is by gamma dose alone; all other materials get alpha, beta, and gamma.

6. Canister particulate has alpha, beta dose $/ \mathrm{kg}$ reduced by the $U$ fraction; $20 \%$ for bounding case.

7. Uranium Oxide Hydrates are conservatively represented by $\mathrm{UO} 3.2 \mathrm{H} 2 \mathrm{O}$.

8. No thermal decomposition of hydrates - residual $\mathrm{H} 2 \mathrm{O}$ evaporates first, system is saturated.

9. Fuel and scrap temperatures related to decay power as a function of time by conservative conductances.

10. No hydrogen gettering - only occurs when Oxygen is depleted. This allows the maximum presssure to be calculated, before substantial $\mathrm{H} 2$ gettering.

11. Oxygen gettering by Ritchie's moist air correlation, since $\mathrm{H} 2 \mathrm{O}$ present, with a minimum limit of Trimble's dry air correlation.

12. MCO is backfilled to $1.5 \mathrm{~atm}$ He at $25 \mathrm{C}$ - normally. Neglect difference between atm and $10^{\star \star} 5$ Pascals.

12. Calculations may be conducted with bounding or bestestimate values.

Parameter

$\mathrm{H} 2 \mathrm{O}$ from U03.2H $2 \mathrm{O}$ canister particulate

Scrap reactive area / basket

Fuel reactive area / basket

$\mathrm{H} 2 \mathrm{O}$ from $\mathrm{UO} 3.2 \mathrm{H} 2 \mathrm{O}$

$\mathrm{H} 2 \mathrm{O}$ from canister particulate

water:
Bound

$100 \mathrm{~g} \mathrm{H}^{2} \mathrm{O} / \mathrm{m}^{\wedge} 2$

$4.5 \mathrm{~m}^{\wedge} 2$

$0.79 \mathrm{~m}^{\wedge} 2$

$1036 \mathrm{~g}$ two scrap

$667 \mathrm{~g}$ one scrap

$297 \mathrm{~g}$ no scrap

$80 \%$ Al, $20 \%$ U hydrate $25 \%$ Al, $75 \%$ U hydrate

$144 \mathrm{~g}$ two scrap

$192 \mathrm{~g}$ one scrap

$240 \mathrm{~g}$ no scrap

$66.7 \mathrm{grams} / \mathrm{m}^{\wedge} 2,200 \mathrm{gram}$ limit, all cases!
Best-Est.

$$
50 \mathrm{~g} \mathrm{H}_{2} \mathrm{O} / \mathrm{m}^{\wedge} 2
$$

$1.7 \mathrm{~m}^{\wedge} 2$

$0.0425 \mathrm{~m}^{\wedge} 2$

$25 \%$ Al, $75 \%$

$39 \mathrm{~g}$ one scrap

$49 \mathrm{~g}$ no scrap

Free

** Units: time in years, mass in grams, area in $m^{\wedge} 2$, with appropriate conversions used. 


\subsection{INPUT AND DERIVED VALUES}

\section{Constants}

Avogadro's number

$\mathrm{Na}:=6.022 \cdot 10^{23}$

Conversion factor $\mathrm{J} / 100 \mathrm{ev}$

$\mathrm{Jev}:=1.6 \cdot 10^{-17}$

Seconds in a year

Secy $:=3600 \cdot 24 \cdot 365$

Ideal gas constant

$\mathrm{R}_{\text {gas }}:=8.314$

Molecular weights of $\mathrm{Al}(\mathrm{OH}) 3, \mathrm{UO} 3.2 \mathrm{H} 2 \mathrm{O}, \mathrm{H} 2 \mathrm{O}$ :

$M_{\text {ah }}:=78$

$M_{\text {uh }}:=322$

$\mathrm{M}_{\mathrm{W}}:=18$

\section{MCO Backfill and Fuel Inventory HIGH HELIUM BACKFILL}

MCO volume, $m^{\wedge} 3$, backfill temperature, $K$

$\mathrm{V}_{\text {mco }}:=0.5$

MCO backfill temperature, $K$, and Pressure, atm:

$T_{b f}:=273$

$P_{b f}:=1.86$

Helium backfill moles:

$\mathrm{n}_{\text {he }}:=\mathrm{P}_{\mathrm{bf}} 10^{\mathrm{S}} \cdot \mathrm{V}_{\text {mco }}\left(\mathrm{R}_{\text {gas }} \cdot \mathrm{T}_{\mathrm{bf}}\right)^{-1}$

$n_{h e}=40.97$

Fuel Mass (grams):

$M_{f}:=6.339 \cdot 10^{6}$

MCO Water Inventory Values: See HNF-1523 and HNF-1527

UO3. $\mathrm{xH} 2 \mathrm{O}$ water mass per unit area gram $/ \mathrm{m}^{\wedge} 2$

Max g H2O from UO3.xH2O Adhering Partic.

Max $\mathrm{g}$ of $\mathrm{Al}(\mathrm{OH}) 3$ Clad Film:

Free $\mathrm{H} 2 \mathrm{O}, \mathrm{g}$, bounding value:

Amount of water from $\mathrm{UO} 4.2 \mathrm{H} 2 \mathrm{O}$ if no $\mathrm{AL}(\mathrm{OH}), \mathrm{g}$

\section{MCO Power - Temperature Relations:}

Heat transfer conductances: Scrap, Low T. fuel,

Avg. T fuel, High T. fuel, W/K:

Fraction of assemblies per fuel group, low to high:

Conservative annual average vault $T$ and half-amplitude Hanford avg. is 12, High is 26 , Low is -3 ; Vault is $6 \mathrm{C}$ higher,

$$
\mu:=50
$$$$
\mathrm{UH}_{\max }:=1036 \quad \text { !! } 0 \text { scrap: } 297 \mathrm{~g} ; 1 \text { scrap; } 667 \mathrm{~g} \text { !! }
$$$$
\mathrm{AL}_{\max }:=10650
$$$$
\text { FW } \text { max }_{\text {max }}:=200
$$

$\mathrm{m}_{\text {uo4 }}:=52$

$$
\mathrm{U}_{\mathrm{sc}}:=12.4
$$

$U_{\text {ก }}:=9.5$

$\mathrm{U}_{\mathrm{fa}}:=8.7$

$\mathrm{U}_{\mathrm{fh}}:=8.2$

$\mathrm{N}_{\mathrm{fl}}:=\frac{18}{54}$

$\mathrm{N}_{\mathrm{fa}}:=\frac{30}{54}$

$\mathrm{N}_{\mathrm{fh}}:=\frac{6}{54}$

$\mathrm{T}_{\mathrm{av}}:=12+3 \quad \mathrm{dT} \mathrm{T}_{\mathrm{av}}:=12$

$g(H 2)$ and $g\left(\mathrm{O}_{2}\right)$ Values from HNF-SD-SNF-CN-006:

$\begin{array}{lll}\text { Rad type } & g(\mathrm{H} 2) & g(\mathrm{O} 2) \\ \text { alpha } & 1.5^{*} x & 0.75^{*} x \\ \text { beta } & 0.45^{*} x & 0.225^{*} x \\ \text { gamma } & 1.2 \text { for } & x \text { for } x<0.1 \text {, else } \\ & 0.04<x<0.35 & 0.0861+0.139^{*} x\end{array}$

$\mathrm{g}(\mathrm{H} 2)$ value for $\mathrm{Al}(\mathrm{OH}) 3$, molec/ $100 \mathrm{eV}$

$\begin{array}{lll}\mathrm{g}_{\text {had }}:=0.525 & \mathrm{~g}_{\text {hap }}:=0.1575 & \mathrm{~g}_{\text {hay }}:=1.2 \\ \mathrm{~g}_{\text {oad }}:=0.2625 & \mathrm{~g}_{\text {oap }}:=0.07875 & \mathrm{~g}_{\text {oay }}:=0.135 \\ \mathrm{~g}_{\text {hua }}:=0.165 & \mathrm{~g}_{\text {hup }}:=0.05 & \mathrm{~g}_{\text {huy }}:=1.2 \\ \mathrm{~g}_{\text {oud }}:=0.083 & \mathrm{~g}_{\text {oup }}:=0.025 & \mathrm{~g}_{\text {ouy }}:=0.101 \\ \mathrm{~g}_{\text {hwa }}:=1.6 & \mathrm{~g}_{\text {hwp }}:=0.53 & \mathrm{~g}_{\text {hwy }}:=0.5 \\ \mathrm{~g}_{\text {owa }}:=0.8 & \mathrm{~g}_{\text {owp }}:=0.265 & \mathrm{~g}_{\text {owy }}:=0.25 \\ \mathrm{rQ}_{\text {ay }}:=0.35 & \mathrm{rQ}_{\text {uy }}:=0.86 & \mathrm{R}_{\text {wy }}:=0.38\end{array}$

$\mathrm{g}(\mathrm{O} 2)$ value for $\mathrm{Al}(\mathrm{OH}) 3, \operatorname{molec} 100 \mathrm{eV}$

$\mathrm{g}(\mathrm{H} 2)$ values for UO3 hydrates, moled $100 \mathrm{ev}$

$\mathrm{g}(\mathrm{O} 2)$ values for $\mathrm{UO} 3$ hydrates, moled $100 \mathrm{ev}$

$\mathrm{g}(\mathrm{H} 2)$ values for free $\mathrm{H} 2 \mathrm{O}$, moled $100 \mathrm{ev}$

$g(\mathrm{O} 2)$ values for free $\mathrm{H} 2 \mathrm{O}$, molec/100 ev

Relative gamma absorption for $\mathrm{Al}, \mathrm{U}, \mathrm{H} 2 \mathrm{O}$ :

$\mathrm{rQ}_{a \gamma}:=0.35$

$\mathrm{rQ}_{\text {ury }}:=0.86$ 
File: get0299-Scrapo-eol-hiHe.mcd Date: 2/4/99 Page: 3

Decay Power Variation with Time: HNF-SD-SNF-CN-006 Regulatory/Safety Design Basis

$\begin{array}{llllll}\text { source } & 1995 & 2040 & \text { lamda } & \text { tas } & \text { Where lamda in 1/year and tau in year } \\ \text { alpha } & 26.3 & 32 & -4.36 \mathrm{e}-3 & -159 & \text { Alpha increases as fraction with time } \\ \text { beta } & 65 & 22 & +2.41 \mathrm{e}-2 & 28.8 & \\ \text { gamma } & 42.4 & 14.3 & +2.42 \mathrm{e}-2 & 28.7 & \text { Note decay power in W/MT here } \\ \text { TOTAL } & 133.7 & 68.3 & 1.49 \mathrm{e}-2 & 46.4 & \end{array}$

Initial power fractions; Each

independently decayed with time.

$$
\begin{array}{ll}
\mathrm{fQ}_{\infty \mathrm{O}}:=\frac{26.3}{133.7} \quad \mathrm{fQ}_{\beta \mathrm{O}}:=\frac{65}{133.7} \quad \mathrm{fQ}_{\gamma \mathrm{O}}:=\frac{42.4}{133.7} \\
\lambda_{\alpha}:=\frac{-1}{45} \cdot \ln \frac{32}{26.3} \quad \lambda_{\alpha}=-4.36 \cdot 10^{-3} \\
\lambda_{\beta}:=\frac{-1}{45} \cdot \ln \frac{22}{65} \quad \lambda_{\beta}=0.02 \\
\lambda_{Y}:=\frac{-1}{45} \cdot \ln \left(\frac{14.3}{42.4} \quad \lambda_{Y}=0.02\right.
\end{array}
$$$$
\text { Decay rates for alpha, beta,gamma, and total }
$$$$
\text { power increases slightly, so rate is negative. }
$$$$
\lambda_{q}:=\frac{-1}{45} \cdot \ln : \frac{68.3}{133.7 !} \quad \lambda_{q}=0.01
$$

**** CASES FOR ZERO SCRAP BASKETS ***

$$
\begin{aligned}
& \mathrm{AL}_{\text {max }}:=10650 \\
& \mathrm{UH}_{\text {max }}:=297
\end{aligned}
$$

2.1 TIME-DEPENDENT POWER FRACTIONS: Multiply by initial power to get power(time) for each mode:

$$
\begin{aligned}
& f Q_{\alpha}(t):=f Q_{\alpha o} \cdot \exp \left(-\lambda_{\alpha} \cdot t\right) \quad f_{\beta}(t):=f_{\beta} Q_{\beta 0} \exp \left(-\lambda_{\beta} \cdot t\right) \quad f_{\gamma}(t):=f Q_{\beta o} \cdot \exp \left(-\lambda_{\gamma} \cdot t\right) \\
& \text { Example for use of alpha power: } \quad f_{a}(45)=0.24 \quad 32 \cdot(32+22+14.3)^{-1} \cdot \exp \left(-\lambda q^{\cdot 45}\right)=0.24
\end{aligned}
$$

\subsection{FUNCTIONS FOR DECAY CONSTANTS AND EXAMPLES}

Decay constant for free $\mathrm{H} 2 \mathrm{O}$ radiolysis: $\mathrm{WH}=\mathrm{H} 2$ yleld, $\mathrm{WO}=\mathrm{O} 2$ yield

$$
\begin{aligned}
& \lambda_{w_{0}}:=M_{f}^{-1} \cdot M_{w}(\mathrm{Jev} \cdot \mathrm{Na})^{-1} \cdot \text { Secy }
\end{aligned}
$$

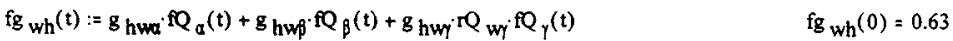

$$
\begin{aligned}
& f g_{w o}(t):=g_{\text {owa }} \cdot Q_{a}(t)+g_{o w p} \cdot Q_{\beta}(t)+g_{o w y} \cdot Q_{w j} \cdot Q_{y}(t) \quad f_{w o}(0)=0.32 \\
& \lambda_{w h}(Q, t):=\lambda_{w o} Q \cdot f_{w h}(t) \quad t_{w h}(396,0)=2.33 \cdot 10^{-3} \\
& f \lambda_{w_{0}}(Q, t):=\lambda_{w_{0}} Q \cdot \mathrm{fg}_{w_{0}}(t) \quad t_{w_{0}}(396,0)=1,16 \cdot 10^{-3}
\end{aligned}
$$


Decay constant for $\mathrm{Al}(\mathrm{OH}) 3$ radiolysis: $\mathrm{AC}=\mathrm{Cladding}$ Film

$$
\begin{aligned}
& \lambda_{\text {ao }}:=\left[\mathrm{M}_{\mathrm{f}}^{-1} \cdot \mathrm{M}_{\mathrm{ah}}(\mathrm{Jev} \cdot \mathrm{Na})^{-1} \cdot \text { Secy }\right] \\
& \mathrm{fg}_{\mathrm{ach}}(\mathrm{t}):=\mathrm{g}_{\text {hay }} \cdot \mathrm{PQ}_{\mathrm{ay}} \mathrm{fQ}_{\gamma}(\mathrm{t}) \\
& \mathrm{fg}_{\text {aco }}(\mathrm{t}):=\mathrm{g}_{\text {oay }}+\mathrm{QQ}_{\text {ay }} \mathrm{fQ}_{y}(\mathrm{t}) \\
& \mathrm{A}_{\operatorname{ach}}(\mathrm{Q}, \mathrm{t}):=i_{\text {ao }} \cdot \mathrm{Q} \cdot \mathrm{fg}_{\mathrm{ach}}(\mathrm{t}) \\
& \text { t aco }(Q, t):=\lambda_{\text {ao }} \cdot Q \cdot \mathrm{fg}_{\text {aco }}(t)
\end{aligned}
$$

$\operatorname{fg}_{\operatorname{ach}}(0)=0.13$

$\mathrm{fg}_{\mathrm{aco}}(0)=0.01$

$\mathrm{fl}_{\operatorname{ach}}(396,0)=2.12 \cdot 10^{-3}$

$\mathrm{f}_{\mathrm{aco}}(396,0)=2.39 \cdot 10^{-4}$

Al clad fraction at 40 years, average power MCO: $\left.\exp -\int_{0}^{40} \frac{2}{3} \cdot a \operatorname{ach}(400, t) d t\right)=0.96$

\section{Decay constant for $A((O H) 3$ radiolysis: $A P=A l$ in Adhering Particulate}

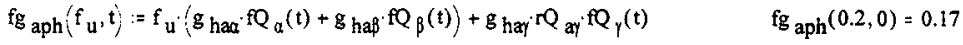

$$
\begin{aligned}
& f_{\text {apo }}\left(f_{u}, t\right):=f_{u} \cdot\left(g_{\text {oad }} \cdot \mathrm{fQ}_{\alpha}(t)+g_{\text {oap }} \cdot \mathrm{fQ}_{\beta}(t)\right)+g_{\text {oaj }} \cdot \mathrm{RQ}_{a j} \cdot \mathrm{PQ}_{y}(t) \quad \mathrm{fg}_{\text {apo }}(0.2,0)=0.03 \\
& \mathrm{f}_{\operatorname{aph}}\left(\mathrm{Q}, \mathrm{f}_{\mathrm{u}}, \mathrm{t}\right):=\lambda_{\mathrm{ao}} \cdot \mathrm{Q} \cdot \mathrm{fg}_{\operatorname{aph}}\left(\mathrm{f}_{\mathrm{u}}, \mathrm{t}\right) \\
& \mathrm{Aph}_{\mathrm{aph}}(396,0.2,0)=2.7 \cdot 10^{-3} \\
& \mathrm{t}_{\text {apo }}\left(\mathrm{Q}, \mathrm{f}_{\mathrm{u}}, \mathrm{t}\right):=\lambda_{\mathrm{ao}} \cdot \mathrm{Q} \cdot \mathrm{fg}_{\text {apo }}\left(\mathrm{f}_{\mathrm{u}}, \mathrm{t}\right) \\
& \mathrm{f}_{\mathrm{apo}}(396,0.2,0)=5.26 \cdot 10^{-4} \\
& \exp \left(-\int_{0}^{40} \mathrm{a}_{\mathrm{aph}}(400,0.2, \mathrm{t}) \mathrm{dt}\right)=0.93
\end{aligned}
$$

\section{Decay constant for UO3.2H2O radiolysis}

$$
\begin{aligned}
& \lambda_{\text {uo }}:=\left[\mathrm{M}_{\mathrm{f}}^{-1} \cdot \mathrm{M}_{\mathrm{uh}} \cdot(\text { Sev } \cdot \mathrm{Na})^{-1} \cdot \text { Secy }\right] \\
& f_{g_{\text {uh }}}(t):=g_{\text {hua }} f Q_{\alpha}(t)+g_{\text {hup }} \cdot \mathrm{PQ}_{\beta}(t)+g_{\text {huy }} \cdot \mathrm{Q}_{\text {uy }} f Q_{\gamma}(t)
\end{aligned}
$$

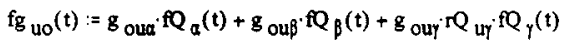

$$
\begin{aligned}
& \lambda_{u_{h}}(Q, t):=\lambda_{\text {uo }} \cdot Q \cdot f_{\text {uh }}(t) \\
& \lambda_{\text {uo }}(Q, t):=\lambda_{\text {uo }} \cdot Q \cdot f_{\text {uo }}(t)
\end{aligned}
$$$$
\mathrm{fg}_{\mathrm{uh}}(0)=0.38
$$$$
\mathrm{fg}_{\mathrm{uo}}(0)=0.06
$$$$
f_{\mathrm{uh}}(396,0)=0.03
$$$$
A_{\text {uo }}(396,0)=3.69 \cdot 10^{-3}
$$

$U$ Hydrates fraction at 40 years, average power MCO:

$$
\exp \left(-\int_{0}^{40} \frac{1}{2} \cdot \mathrm{et} u \mathrm{uh}(400, \mathrm{t}) \mathrm{dt}\right)=0.71
$$




\subsection{FUNCTIONS FOR U GETTERING RATE AND WATER VAPOR PRESSURE}

Water vapor pressure: $\quad \mathrm{fP}_{\text {sat }}(\mathrm{T}):=\mathrm{e}^{25.339-\frac{5154.7}{\mathrm{~T}}} \quad \mathrm{fP}_{\text {sat }}(323)=1.19 \cdot 10^{4} \quad 50 \mathrm{C} \mathrm{OK}$

Ritchie correlation for U-H2O-O2, below $100 \% \mathrm{RH}$, below $100 \mathrm{C}$, agrees best with data BUT goes below dry air correlation at about $37 \mathrm{C}$ - so switch to McGillivray dry ait. Ritchie units of $\mathrm{mg} / \mathrm{cm}^{\wedge} 2 / \mathrm{hr}$, converted to grams $\mathrm{O} 2$ per $\mathrm{m}^{\wedge} 2$ per year.; McGillivray units of $\mathrm{kg} / \mathrm{m}^{\wedge} 2 / \mathrm{s}$ similarly converted.

$\mathrm{K}_{\mathrm{rit}}(\mathrm{T}):=10^{13.8808-5769.6 \cdot \mathrm{T}^{-1}} \cdot 10 \cdot 8766 \quad$ Ritchie $\quad \mathrm{K}_{\text {trim }}(\mathrm{T}):=10^{7.19-3732 \cdot \mathrm{T}^{-1}} \cdot 10 \cdot 8766 \quad$ Trimble

$T_{\text {cor }}:=(5769.6-3732) \cdot(13.8808-7.19)^{-1} \quad T_{\text {cor }}=304.54 \quad$ Switch correlations here, $31 \mathrm{C}$

Moist Air Getter Function 100\% RH:

$\mathrm{fK}_{0}(323) \cdot 0.1 \cdot(8766)^{-1}=1.04 \cdot 10^{-4}$

fK $0(323) \cdot 10^{-3} \cdot\left(3.15 \cdot 10^{7}\right)^{-1}=2.9 \cdot 10^{-10}$

$\mathrm{fK}_{\mathrm{o}}\left(\mathrm{T}_{\mathrm{cor}}+0.01\right) \cdot 10^{-3} \cdot\left(3.15 \cdot 10^{7}\right)^{-1}=2.4 \cdot 10^{-11}$

$$
\left.\mathrm{fK}_{\mathrm{o}}(\mathrm{T}):=\mathrm{if} / \mathrm{T} \geq \mathrm{T}_{\text {cor }}, \mathrm{K}_{\text {rit }}(\mathrm{T}), \mathrm{K}_{\text {trim }}(\mathrm{T})\right)
$$

OK@ $50 \mathrm{C}$ in $\mathrm{mg} / \mathrm{cm}^{\wedge} 2 / \mathrm{hr}$

OK@ $50 \mathrm{Cin} \mathrm{kg} / \mathrm{m}^{\wedge} 2 / \mathrm{s}$

\section{Shows no} discontinuity

Gettering of Water vapor when Oxygen-Free:

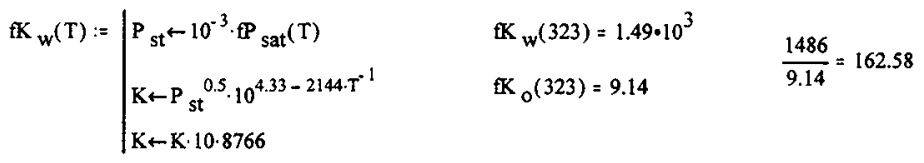

\subsection{RELATIONSHIP BETWEEN MCO POWER AND GAS TEMPERATURE}

Conservative relationships based on $733 \mathrm{~W}$ MCO, zero scrap case for fuel and one scrap case for scrap. Vault gas-tube $d T=28 \mathrm{C}$, Fuel tube-MCO gap $d T=39 \mathrm{C}$, Scrap gap $d T=27 \mathrm{C}$. Inside $M C O$, fuel dT's are $12.5,20$, and $26 \mathrm{C}$; scrap $\mathrm{dT}$ is $4 \mathrm{C}$. Function yields scrap and low to high fuel $\mathrm{T}$ 's in that order:

$\mathrm{fTget}\left(Q_{0}, t\right):=Q_{0} \cdot e^{-\lambda} q^{\cdot t} \cdot\left[\frac{1}{U_{s c}} \frac{1}{U_{f l}} \frac{1}{U_{f a}} \frac{1}{U_{f h}}\right]^{T}+T_{a v}$

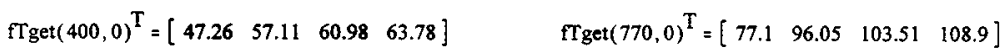




\subsection{ACCOUNT FOR ANNUAL TEMPERATURE VARIATION BY INTEGRAL AVERAGE FOR A YEAR}

Create an interpolation table over the temperature range of interest, then define a new rate law function which automatically incorporates the average annual enhancement factor. Input $T$ in Kelvins!

$$
\begin{aligned}
& \mathrm{fT}_{\mathrm{a}}(\mathrm{T}, \mathrm{t}):=\mathrm{T}+\mathrm{dT} \mathrm{av}_{\mathrm{v}} \sin (2 \cdot \pi \cdot t) \quad \mathrm{f}(\mathrm{T}):=\mathrm{fK}_{\mathrm{o}}(\mathrm{T})^{-1} \cdot \int_{0}^{1} \mathrm{fK}_{\mathrm{o}} \mathrm{fT}_{\mathrm{a}}(\mathrm{T}, \mathrm{t}), \mathrm{dt} \\
& \left.\mathrm{j}:=0.60 \quad T \xi_{\mathrm{j}}:=283+2 \cdot \mathrm{j} \quad \Xi_{\mathrm{j}}:=\mathrm{fE} \mathrm{T}_{\mathrm{j} /} \quad \mathrm{f}(\mathrm{T}):=\operatorname{linterp}\left(\mathrm{T} \xi, \Xi_{,}, \mathrm{T}\right) \quad \mathrm{fK},(\mathrm{T}):=\mathrm{f}(\mathrm{T}) \cdot \mathrm{fK}, \mathrm{T}\right) \\
& \text { Values at low, medium, high T: } \quad f(288)=1.38 \quad f \xi(333)=1.54 \quad f \xi(383)=1.29
\end{aligned}
$$

\subsection{FUNCTIONS TO SET UP INITIAL CONDTIONS}

\section{User specifies:}

(1) $Q=M C O$ Initial power, $W$;

(2) As = Scrap reactive area, $m^{\wedge} 2$;

(3) Af = Fuel reactive area, $m^{\wedge} 2$;

(4) $\ddot{\mathrm{m} a}=\mathrm{Al}(\mathrm{OH}) 3$ film mass, $\mathrm{g}$;

(5) mwCp = Canister particulate water mass, $g$;

(6) fUcp $=U$ fraction of can. partic. for alpha, beta

(7) fwUcp: $U$ water fraction of can. particulate;

(8) mu: Mass/area water from UO3.2 $\mathrm{H} 2 \mathrm{O}$;

(9) mfw: Free water mass per area, $g / m^{\wedge} 2$.

Other assumptions of note:

(1) Initial water vapor mass determined by scrap T;

(2) Residual free water prevents hydrate thermal decomposition.
State vector $V$ assigned based on these inputs:

Actual state variables are:

(0) nac $=\mathrm{Al}(\mathrm{OH}) 3$ cladding film water moles

(1) nap $=\mathrm{Al}(\mathrm{OH}) 3$ can particulate water moles

(2) $\mathrm{nu}=\mathrm{UO} 3.2 \mathrm{H} 2 \mathrm{O}$ water moles

(3) $\mathrm{nW}=$ free $\mathrm{H} 2 \mathrm{O}$ moles

(4) $n$ h2 $=\mathrm{H} 2+\mathrm{H} 2 \mathrm{O}$ vapor moles

(5) no2 $=02$ moles

Parameters are:

(6) $Q=$ Power,

(7) AS = Scrap area,

(8) AF= Fuel Area,

(9) fucp $=U$ fraction of canister particulate

Initial steam from free water, assumed sufficient; free water not depleted; scrap T (index 0 ) used:

$$
\mathrm{fn}_{\text {st }}(\mathrm{Q}):=\mid \begin{aligned}
& \mathrm{T}_{\mathrm{o}} \leftarrow \mathrm{fTget}(\mathrm{Q}, 0)_{0}+273 \\
& \mathrm{P}_{\text {sat }}\left(\mathrm{T}_{\mathrm{o}}\right) \cdot \mathrm{V}_{\text {mco }} \cdot\left(\mathrm{R}_{\text {gas }} \cdot \mathrm{T}_{\mathrm{o}}\right)^{-1}
\end{aligned}
$$

Function for water moles of UO3.2HO plus UO4.2H2O given $m=\mathrm{kg} / \mathrm{m}^{\wedge} 2$ from $\mathrm{UO} 3.2 \mathrm{H} 2 \mathrm{O}$, A=fuel reactive area, and adding $\mathrm{UO} 4$ contribution in proportion the fraction not covered with $\mathrm{Al}(\mathrm{OH}) 3$, given its mass ma.

$$
\begin{aligned}
& \mathrm{fn}_{w u}\left(\mu, A_{s}, A_{f}, m_{w c p}, f_{u c p}, m_{a}\right):=\mid m_{a p} \leftarrow \mu \cdot\left(A_{s}+A_{f}\right) \\
& m_{\text {ap }} \leftarrow \text { if }\left(m_{\text {ap }}>U_{\text {max }}, U_{\text {max }}, m_{\text {ap }}\right) \\
& m_{\operatorname{clad}^{\leftarrow} \leftarrow m_{\text {uO4 }}}\left(1-m_{a} \cdot A L_{\max }{ }^{-1}\right) \\
& m_{\text {clad }} \leftarrow \text { if }\left(m_{a}>A L_{\text {max }}, 0, m_{\text {clad }}\right) \\
& m_{c p} \leftarrow m_{w c p} \cdot w_{u c p} \\
& \mathrm{n} \leftarrow\left(\mathrm{m}_{\mathrm{ap}}+\mathrm{m}_{\mathrm{clad}}+\mathrm{m}_{\mathrm{cp}}\right) \cdot \mathrm{M}_{\mathrm{w}}^{-1}
\end{aligned}
$$

$$
f_{f w}\left(m_{f w}, A_{s}, A_{f}\right):=\left\{\begin{array}{l}
m \leftarrow m f w \cdot\left(A_{s}+A_{f}\right) \\
n \leftarrow i f\left(m>F W_{\max }, F W_{\max }, m\right) \cdot M_{W}^{-1}
\end{array}\right.
$$




\begin{tabular}{|c|c|}
\hline$f V Q, A_{s}, A_{f}, m_{a}, m_{w c p}, f_{u c p}, f w_{u c p}, \mu, m_{f w}:=$ & 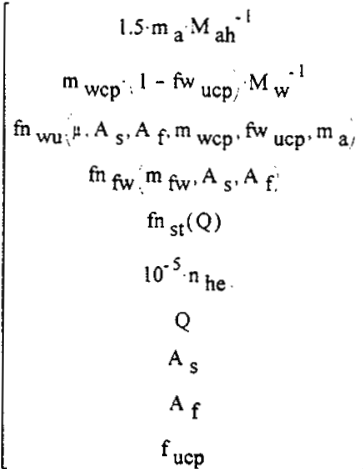 \\
\hline
\end{tabular}

Test for bounding conditions, one scrap basket:

$\mathrm{N}(733,4.5,3.16,10050,192,0.1,0.1,100,30)^{\mathrm{T}}=\quad$\begin{tabular}{l}
$193.279 .617 .7311 .116 .224 .1 \cdot 10^{-4} 7334.5$ \\
\hline
\end{tabular}

\subsection{FUNCTIONS FOR H2, O2 SOURCE AND SINK; R=Radlolysis Source, G=Getter}

Current $\mathrm{O} 2$ model assumes $\mathrm{O} 2$ gettering phase from beginning of transient. Current $\mathrm{H} 2$ model assumes no gettering.

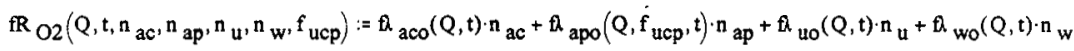

$$
\begin{aligned}
& \mathrm{fGO2}\left(\mathrm{Q}, \mathrm{t}, \mathrm{A}_{\mathrm{S}}, \mathrm{A}_{\mathrm{f}}\right):=\mid \begin{array}{l}
\mathrm{T}_{\text {get }} \leftarrow \mathrm{fTget}(\mathrm{Q}, \mathrm{t})+273 \\
\mathrm{GS} \leftarrow \mathrm{A}_{\mathrm{s}} \cdot \mathrm{fK}_{1}\left(\mathrm{~T}_{\mathrm{get}_{0}}\right) \\
\mathrm{GF} \leftarrow \mathrm{A}_{\mathrm{f}}\left(\mathrm{N}_{\mathrm{fl}} \cdot \mathrm{fK}_{1}\left(\mathrm{~T}_{\text {get }_{1}}\right)+\mathrm{N}_{\mathrm{fa}} \cdot \mathrm{EK}_{1}\left(\mathrm{~T}_{\text {get }_{2}}\right)+\mathrm{N}_{\mathrm{fh}} \cdot \mathrm{fK}_{1}\left(\mathrm{~T}_{\text {get }_{3}}\right)\right) \\
(\mathrm{GS}+\mathrm{GF}) \cdot 32 \cdot 1
\end{array}
\end{aligned}
$$

\subsection{RATES OF CHANGE OF RADIOLYSIS SOURCES \& PRODUCTS}

Need a trick because Mathcad demands a function $F$ whose arguments are $t, Y$ where $t$ is time and $Y$ is a vector of state variables. Output of $F$ is a vector $d Y / d t$. Trick: $d Y / d t=0$ for constant terms needed.

State variables thus include parameters expected to vary from case to case. Coding first assigns scrutable names to the state vector, see comment below. Coding for readability, not compactness. 


$$
\begin{aligned}
& d Y d t(t, Y):=\mid \begin{array}{ll}
n_{a c} \leftarrow Y_{0} & \text { First, assign scrutable names } \\
n_{a p} \leftarrow Y_{1} & \text { Actual state variables are: } \\
n \text { nac= Al(OH)3 cladding film }
\end{array} \\
& \begin{array}{ll}
\mathrm{n}_{\mathrm{u}} \leftarrow \mathrm{Y}_{2} & \text { nap=Al(OH)3 can particulate } \\
\mathrm{n}_{\mathrm{W}} \leftarrow \mathrm{Y}_{3} & \text { nu=UO3.2H2O water moles } \\
& \text { nwefree } \mathrm{H} 2 \mathrm{O} \text { moles }
\end{array} \\
& \mathrm{n}_{\mathrm{h} 2} \leftarrow \mathrm{Y}_{4} \quad \text { no2 }=02 \text { moles } \\
& \mathrm{Y}_{5} \leftarrow \mathrm{if}\left[\mathrm{Y}_{5}<0,0, \mathrm{Y}_{5}\right] \quad \text { Parameters } \\
& \begin{array}{ll}
\mathrm{n}_{\mathrm{o} 2} \leftarrow \mathrm{Y}_{5} & A S=\text { Scrap area } \\
& \text { AF }=\text { Fuel Area, }
\end{array} \\
& \mathrm{Q}-\mathrm{Y}_{6} \quad \text { fucp }=U \text { frac. of can particulate } \\
& A_{5} \leftarrow Y_{7} \\
& A_{\mathrm{f}} \leftarrow \mathrm{Y}_{8} \\
& \mathrm{f}_{\text {ucp }} \leftarrow \mathrm{Y}_{\mathrm{g}} \\
& \mathrm{dn}_{\mathrm{ac}} \leftarrow \frac{-2}{3} \cdot \mathrm{a}_{\mathrm{ach}}(\mathrm{Q}, \mathrm{t}) \cdot \mathrm{n} \mathrm{ac} \\
& d n_{\text {ap }} \leftarrow \frac{-2}{3} \cdot \mathrm{f}_{\text {aph }}\left(\mathrm{Q}, \mathrm{f}_{\mathrm{ucp}}, \mathrm{t}\right) \cdot \mathrm{n} \text { ap } \\
& \mathrm{dn}_{\mathrm{u}} \leftarrow \frac{-1}{2} \cdot \mathrm{fl}_{\mathrm{uh}}(\mathrm{Q}, \mathrm{t}) \cdot \mathrm{n}_{\mathrm{u}} \\
& d n_{w^{t}}-\mathrm{fh}_{w h}(Q, t) \cdot n_{w} \\
& \operatorname{sorH} 2 \leftarrow-\left(1.5 \cdot \mathrm{dn}_{\mathrm{ac}}+1.5 \cdot \mathrm{dn}_{\mathrm{ap}}+2 \cdot \mathrm{dn}_{\mathrm{u}}+\mathrm{dn}_{\mathrm{w}}\right) \\
& \text { sorO2 } \leftarrow \mathrm{R}_{\mathrm{O} 2}\left(\mathrm{Q}, \mathrm{t}, \mathrm{n}_{\mathrm{ac}}, \mathrm{n}_{\text {ap }}, \mathrm{n}_{\mathrm{u}}, \mathrm{n}_{\mathrm{w}}, \mathrm{f}_{\mathrm{ucp}}\right) \\
& \text { sinkO2↔fGO2 }\left(\mathrm{Q}, \mathrm{t}, \mathrm{A}_{\mathrm{s}}, \mathrm{A}_{\mathrm{f}}\right) \\
& \text { netњsorO2 - sinkO2 }
\end{aligned}
$$

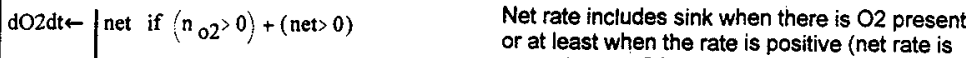

$$
\begin{aligned}
& 10 \text { otherwise } \\
& \text { Make } \mathrm{O} 2 \text { moles }>0 \text { for numerical purposes. } \\
& d Y \leftarrow\left[d n_{\text {ac }} d n_{\text {ap }} d n_{u} d n_{w} \text { sorH2 } \quad \text { dO2dt } \begin{array}{lllll}
0 & 0 & 0 & 0
\end{array}\right]^{\mathrm{T}} \\
& \text { dY } \\
& \text { zero when no } 02 \text { and sink exceeds source). }
\end{aligned}
$$

\section{Function to get End-of-Lffe values after integration of a single case:}

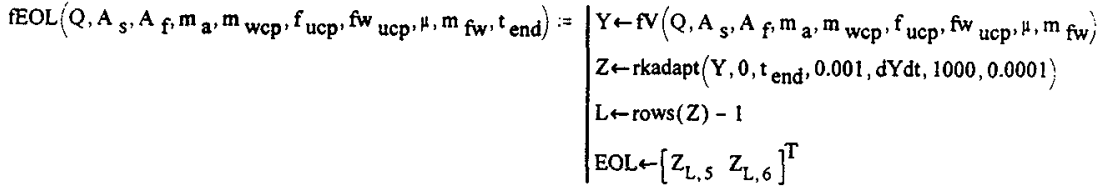


File: get0299-Scrap0-eol-hiHe.mcd Late: $\langle/ 4 / 99$ Page: 9

\subsection{COMBUSTION FUNCTIONS}

4.1 GAS SPECIFIC HEAT DATA: CV(T) POLYNOMIAL FIT.: Gases are entered in the order: H2, He, N2, O2, H2O from HANSF input GASPROP.DAT. Values in J/g-mole/K!!! FW is the formula weight vector.

$$
\operatorname{CCV}:=\left[\begin{array}{ccccc}
21.136 & -1.529 \cdot 10^{-3} & 1.978 \cdot 10^{-6} & 4.018 \cdot 10^{-10} & -1.171 \cdot 10^{-13} \\
12.47 & 0 & 0 & 0 & 0 \\
20.785 & -3.871 \cdot 10^{-3} & 1.34 \cdot 10^{-5} & -7.216 \cdot 10^{-9} & 1.16 \cdot 10^{-12} \\
17.045 & 0.014 & -4.96 \cdot 10^{-6} & 1.375 \cdot 10^{-10} & 1.375 \cdot 10^{-13} \\
24.044 & -7.883 \cdot 10^{-5} & 1.513 \cdot 10^{-5} & -7.323 \cdot 10^{-9} & 1.087 \cdot 10^{-12}
\end{array}\right] \quad \text { FW }:=\left[\begin{array}{c}
2 \\
4 \\
28 \\
32 \\
18
\end{array}\right]
$$

Functions for $\mathrm{Cv}$ and $\mathrm{Ug}$ of a specific gas:

$$
\begin{aligned}
& \mathrm{fCv}(\mathrm{i}, \mathrm{T}):=\mathrm{CCV}_{\mathrm{i}, 0}+\mathrm{CCV}_{\mathrm{i}, 1} \cdot \mathrm{T}+\mathrm{CCV}_{\mathrm{i}, 2} \cdot \mathrm{T}^{2}+\mathrm{CCV}_{\mathrm{i}, 3} \cdot \mathrm{T}^{3}+\mathrm{CCV}_{\mathrm{i}, 4} \cdot \mathrm{T}^{4} \\
& \mathrm{fug}(\mathrm{i}, \mathrm{T}):=\mathrm{T} \cdot\left[\mathrm{CCV}_{\mathrm{i}, 0}+\mathrm{T} \cdot\left[\frac{1}{2} \cdot \mathrm{CCV}_{\mathrm{i}, 1}+\mathrm{T} \cdot\left[\frac{1}{3} \cdot \mathrm{CCV}_{\mathrm{i}, 2}+\mathrm{T} \cdot\left(\frac{1}{4} \cdot \mathrm{CCV}_{\mathrm{i}, 3}+\mathrm{T} \cdot \frac{1}{5} \cdot \mathrm{CCV}_{\mathrm{i}, 4}\right)\right]\right]\right]
\end{aligned}
$$

Function for energy of a gas with mole vector $\mathrm{N}$ at temperature $\mathrm{T}$ (without integration constant):

$$
f U g(N, T):=\mid \begin{aligned}
& U \leftarrow 0 \\
& \text { for } i \in 0 . .4 \\
& U \leftarrow U+N_{i} \cdot f u g(i, T) \\
& U
\end{aligned}
$$

2.0 AICC Function input is mole vector (see order above) and initial Temperature, Output is a vector with: post-burn mole vector, AICC temperature, AICC pressure.

$$
\begin{aligned}
& \operatorname{fAICC}\left(\mathrm{N}, \mathrm{T}_{\mathrm{O}}, \mathrm{V}\right):=\mid \begin{array}{l}
\mathrm{H} 2 \leftarrow \mathrm{N}_{0} \\
\mathrm{O} 2 \leftarrow \mathrm{N}_{3}
\end{array} \\
& \triangle \mathrm{H} 2 \mathrm{O} \leftarrow \mathrm{if}(\mathrm{H} 2 \leq 2 . \mathrm{O} 2, \mathrm{H} 2,2 . \mathrm{O} 2) \\
& \mathrm{NP} \leftarrow\left[\begin{array}{lllll}
\mathrm{H} 2 & -\mathrm{AH} 2 \mathrm{O} & \mathrm{N}_{1} & \mathrm{~N}_{2} & \mathrm{O} 2 \\
-0.5 \cdot \Delta \mathrm{H}_{2} \mathrm{O} \quad \mathrm{N}_{4}+\Delta \mathrm{H}_{2} \mathrm{O}
\end{array}\right]^{\mathrm{T}} \\
& \mathrm{Q} \leftarrow \Delta \mathrm{H} 2 \mathrm{O} \mathrm{O} \cdot 241.8 \cdot 10^{3} \\
& U_{0} \leftarrow \mathrm{fUg}\left(\mathrm{N}, \mathrm{T}_{\mathrm{o}}\right) \\
& \begin{array}{l}
\mathrm{T} \leftarrow \mathrm{T}_{\mathrm{o}}+\mathrm{Q} \cdot\left(\mathrm{fU}_{\mathrm{g}}\left(\mathrm{N}, \mathrm{T}_{\mathrm{o}}+1\right)-\mathrm{U}_{0}\right)^{-1} \\
\mathrm{~T}_{\mathrm{f}} \leftarrow \operatorname{root}\left(\mathrm{fUg}(\mathrm{NP}, \mathrm{T})-\mathrm{U}_{0}-\mathrm{Q}, \mathrm{T}\right)
\end{array} \\
& n_{\mathrm{f}}+\sum \mathrm{NP}
\end{aligned}
$$

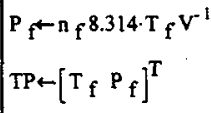

$$
\begin{aligned}
& \text { f } \leftarrow \text { - } \operatorname{stack}(N P, T P)
\end{aligned}
$$




\subsection{K-West Bounding Case \& High Power: High Al(OH)3, High Canister+Adhering Particulate}

5.1A Define highest $K$-West Power, $530 \mathrm{~W}$, and Investigate Fuel area up to $4 \mathrm{~m}^{\wedge} 2$ :
a $:=1 . .10$
$A_{a}:=\operatorname{if}(a \geq 7, a-6$, if $(a>1,(a-1), 0.05,0.01))$
$A_{0}:=0$
$a:=0.10$

Zero Scrap:

$A_{\mathrm{S}}:=0$

Bounding Can. partic:

$\mathrm{m}_{\text {wcp }}:=240$

Bounding $\mathrm{Al}(\mathrm{OH}) 3$ :

$\mathrm{m}_{\mathrm{a}}:=10650$

Bounding Can. partic U:

$f_{\text {ucp }}:=0.2$

Bounding Adher. Partic: $\quad \mu:=100$

Can. water frac. from U:

fw ucp $:=0.08$

Free water $\mathrm{g} / \mathrm{m}^{\wedge} 2$ :

$\mathrm{m}_{\mathrm{fw}}:=66.7$

MCO Power

$Q_{0}:=530$

$\left[\begin{array}{l}n h 2_{a} \\ n \circ 2_{a}\end{array}\right]:=f E O L\left(Q_{0}, A_{s}, A_{a}, m_{a}, m_{w c p}, f_{u c p}, f_{w c p}, \mu, m_{f w}, 40\right)$

ntot $_{\mathrm{a}}:=\mathrm{n}_{\mathrm{he}}+\mathrm{nO2}_{\mathrm{a}}+\mathrm{nh} 2_{\mathrm{a}} \quad \mathrm{O} 2 \%_{\mathrm{a}}:=\mathrm{no2}_{\mathrm{a}} \cdot\left(\mathrm{ntot}_{\mathrm{a}}\right)^{-1} \quad \mathrm{O} 2 \%_{\mathrm{a}}:=$ if $\left(02 \%_{\mathrm{a}}>0,100 \cdot 02 \%_{\mathrm{a}}, 0\right)$

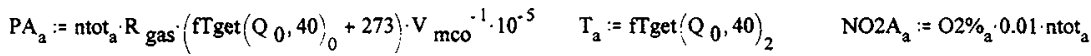

For $A=0$, vary moles of $\mathrm{H} 2$ from value with no getter until stoichiometric, and get post-combustion pressure.

$\mathrm{n}_{\mathrm{st}}:=\mathrm{fn}_{\mathrm{st}}\left(\mathrm{Q}_{0}\right) \quad \delta \mathrm{nh2}:=0.1 \cdot\left(\mathrm{nh}_{0}-\mathrm{n}_{\mathrm{st}}-2 \cdot \mathrm{no}_{0}\right) \quad \mathrm{n}_{\mathrm{st}}=3.13 \quad \mathrm{no}_{0}=2.03 \quad \mathrm{nh}_{0}=19.69$

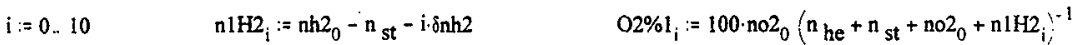

$\mathrm{N1}_{0, \mathrm{i}}:=\mathrm{n} 1 \mathrm{H} 2_{\mathrm{i}} \quad \mathrm{N1} 1_{1, i}:=\mathrm{n}_{\text {he }} \quad \mathrm{N1}_{2, \mathrm{i}}:=0 \quad \mathrm{N1}_{3, \mathrm{j}}:=\mathrm{no}_{0} \quad \mathrm{Nl}_{4, \mathrm{j}}:=\mathrm{n}_{\text {st }} \quad \mathrm{Tk}:=\mathrm{T}_{0}+273$

$\left.A 1^{\langle i\rangle}:=\operatorname{fAICC}^{(} \mathrm{N1}^{\langle\mathrm{i}\rangle}, \mathrm{Tk}, \mathrm{V}_{\text {mco }}\right) \quad \mathrm{P}_{\mathrm{i}}:=\mathrm{A} 1_{6, \mathrm{i}} \cdot 101325^{-1} \quad \mathrm{~T}_{0}=48.53 \quad \mathrm{Tk}=321.53 \quad \mathrm{P}_{0}=13.04$

$5.2 \mathrm{Q}=400 \mathrm{~W}: \quad \mathrm{Q}_{0}:=400 \quad\left[\begin{array}{c}\mathrm{nh} 2_{\mathrm{a}} \\ \mathrm{no} 2_{\mathrm{a}}\end{array}\right]:=\operatorname{fEOL}\left(\mathrm{Q}_{0}, \mathrm{~A}_{\mathrm{s}}, \mathrm{A}_{\mathrm{a}}, \mathrm{m}_{\mathrm{a}}, \mathrm{m}_{\text {wcp }}, \mathrm{f}_{\text {ucp }}, \mathrm{fw}_{\text {ucp }}, \mu, \mathrm{m}_{\mathrm{fw}}, 40\right)$

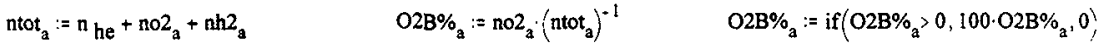

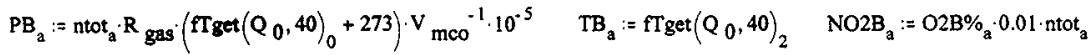

$\mathrm{n}_{\mathrm{st}}:=\mathrm{fn}_{\mathrm{st}}\left(\mathrm{Q}_{0}\right) \quad \delta \mathrm{nh2}:=0.1 \cdot\left(\mathrm{nh}_{0}-\mathrm{n}_{\mathrm{st}}-2 \cdot \mathrm{no}_{0}\right) \quad \mathrm{n}_{\mathrm{st}}=1.94 \quad \mathrm{no2}_{0}=1.55 \quad \mathrm{nh} 2_{0}=14.54$

$i:=0.10 \quad n 1 H 2_{i}:=n h 2_{0}-n_{s t}-i \cdot \delta n h 2 \quad 02 \% 2_{i}:=100 \cdot n o 2_{0}\left(n_{h e}+n_{s t}+n o 2_{0}+n 1 H 2_{i}\right)^{-1}$

$\mathrm{Nl}_{0, \mathrm{i}}:=\mathrm{n} 1 \mathrm{H} 2_{\mathrm{i}} \quad \mathrm{N1}_{1, \mathrm{i}}:=\mathrm{n}_{\text {he }} \quad \mathrm{Nl}_{2, \mathrm{i}}:=0 \quad \mathrm{Nl}_{3, \mathrm{i}}:=\mathrm{no}_{0} \quad \mathrm{Nl}_{4, \mathrm{i}}:=\mathrm{n}_{\text {st }} \quad \mathrm{Tk}:=\mathrm{T}_{0}+273$

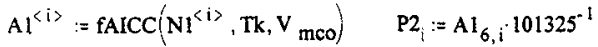


File: get0299-Scrapu-eol-nıHe.mca vare: L4/9y raye. I I

SNF-3951, Rev. 0

Number of moles of $\mathrm{O} 2$ at 40 years as function of reactive area and power:

$$
A^{\mathrm{T}}=\begin{array}{lllllllllll}
0 & 0.01 & 0.05 & 0.1 & 0.15 & 0.2 & 0.25 & 1 & 2 & 3 \\
\hline
\end{array}
$$

$\mathrm{Q}=400 \mathrm{~W} \quad \mathrm{NO}_{2} \mathrm{~B}^{\mathrm{T}}=$\begin{tabular}{llllllllllll}
1.55 & 1.34 & 0.57 & 0.16 & 0.03 & 0 & 0 & 0 & 0 & 0 & 0 \\
\hline
\end{tabular}

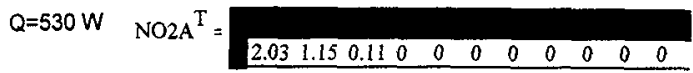

Pressure (no $\mathrm{H} 2$ gettering) at 40 years as function of reactive area and power:

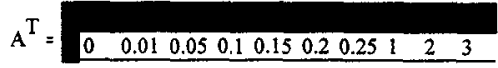

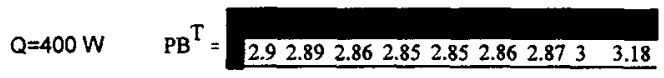

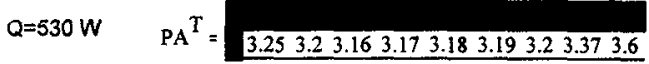

Moles Oxygen at 40 years for K-West Zero-Scrap Bounding Water Content as function of Reactive Area $\left(M^{\wedge} 2\right), Q=530 \mathrm{~W}$ and $Q=400 \mathrm{~W}$

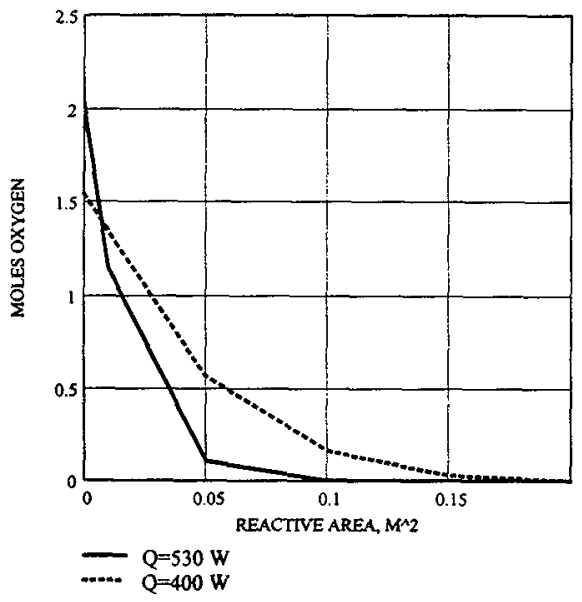


Pressure vs Oxygen Concentration for Zero Scrap, K-West bounding water inventory, and high helium backfill. Lower lines with symbols indicate $M C O$ conditions for various reactive areas with no combustion. Upper lines with no symbols are for post-burn sensitivity cases with hydrogen gettering to increase the $\mathrm{O} 2$ concentration up to stoichiometry.

Combustion is impossible for $\mathrm{O} 2<4 \%$. The worst case group is for $A=0$, zero reactive area, because this maximizes the number of moles of oxygen. The worst case is for the highest power, hence highest moles of oxygen. The highest post-burn pressure is $13 \mathrm{~atm}$.

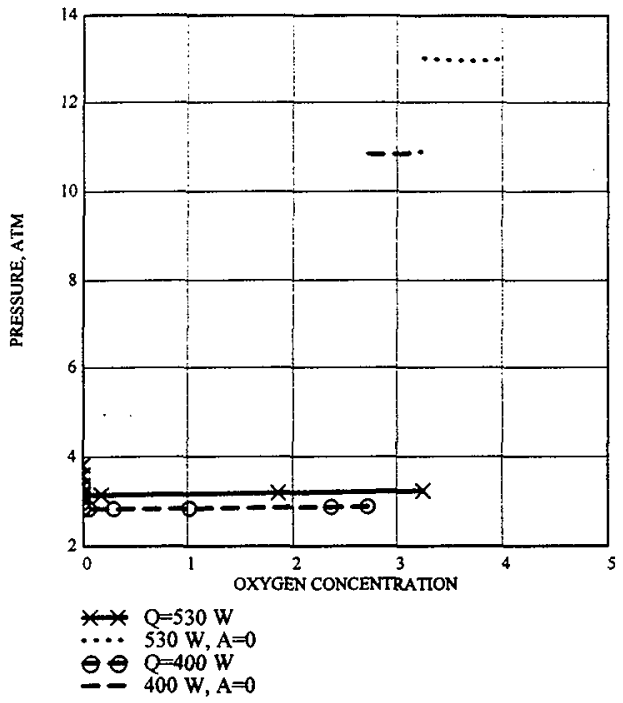


File: get02sis-\$crap0-eol-hiHe.med Date: $2 / 8 / 99$ rage: 13

$$
\mathrm{k}:=0 . .6 \quad \mathrm{PL}_{\mathrm{k}}:=31 \quad \mathrm{O} 2 \mathrm{~L}_{\mathrm{k}}:=\mathrm{k}
$$

Pressure vs Oxygen Concentration for Zero Scrap, K-West bounding water inventory, and high helium backfill. Lower lines with symbols indicate MCO conditions for various reactive areas with no combustion. Upper lines with no symbols are for post-burn sensitivity cases with hydrogen gettering to increase the $\mathrm{O} 2$ concentration up to stoichiometry. The upper horizontal dashed line is the MCO design pressure 450 psig ( 31 atm absolute).

Combustion is impossible for $\mathrm{O} 2<4 \%$. The worst case group is for $\mathrm{A}=0$, zero reactive area, because this maximizes the number of moles of oxygen. The worst case is for the highest power, hence highest moles of oxygen. The highest post-burn pressure is $13 \mathrm{~atm}$.

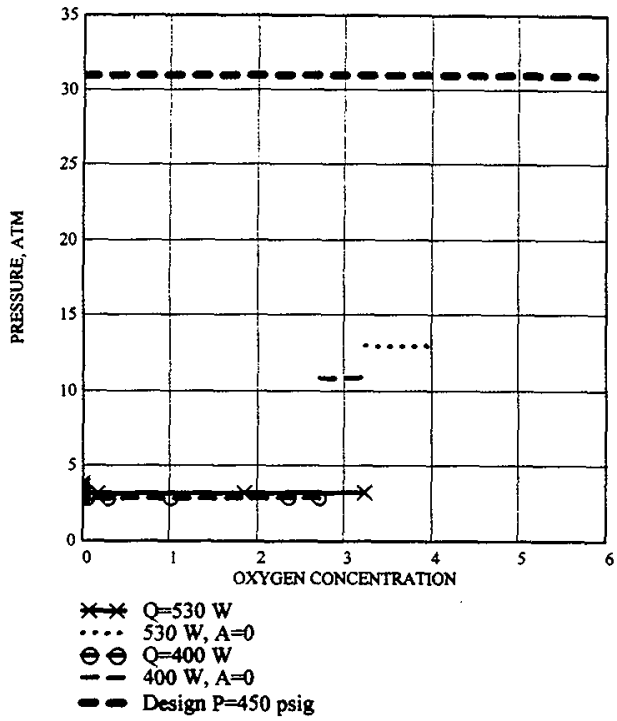




\section{APPENDIX D \\ QUALITY ASSURANCE DOCUMENTS}

Included here are:

1. Calculation Note Cover Sheet

2. Calculation Note Methodology Checklist. 
FAUSKE \& ASSOCIATES, INC.

CALCULATION NOTE COVER SHEET

SECTION TO BE COMPLETED BY AUTHOR(S):

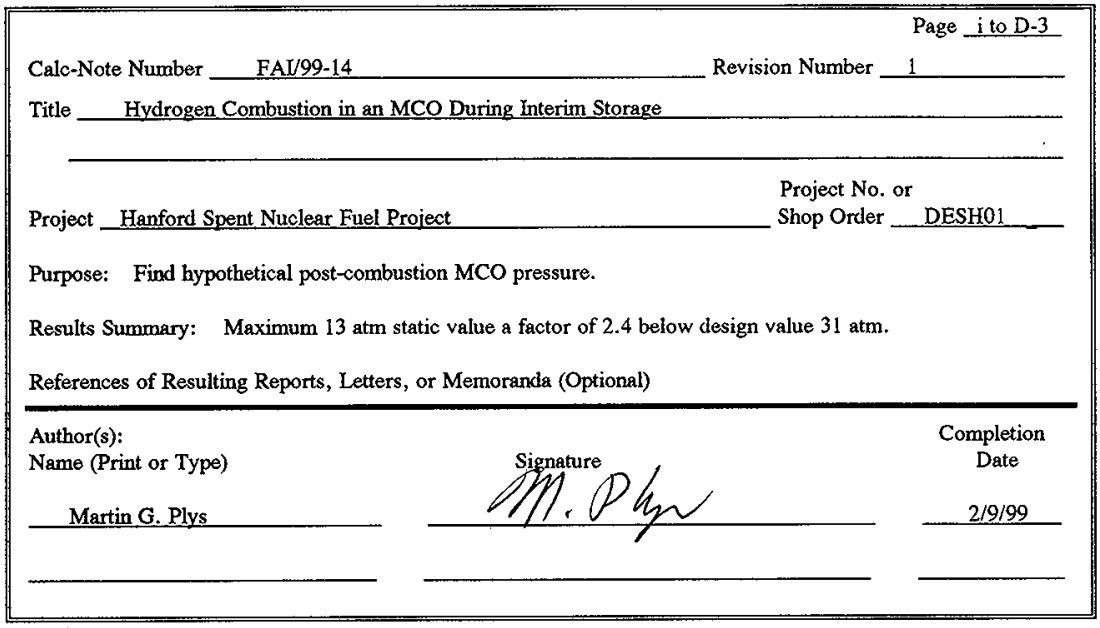

\section{SECTION TO BE COMPLETED BY VERIFIER(S):}

Verifier(s):

Name (Print or Type)

Boro Malinovic

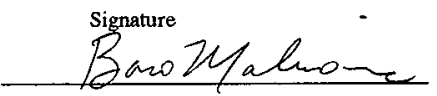

Completion

Date

$2 / 9 / 99$
Independent Review or Alternate Calculations

Other (specify)

\section{SECTION TO BE COMPLETED BY MANAGER:}

Responsible Manager:

Name (Print or Type)

Martin G. Plys

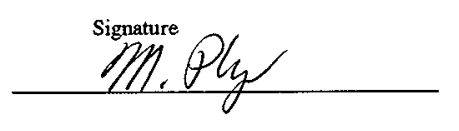

Approval

Date

$2 / 9 / 99$ 


\section{CALCULATION NOTE METHODOLOGY CHECKLIST}

1. Is the subject and/or the purpose of the design analysis clearly stated?..

2. Are the required inputs and their sources provided?

3. Are the assumptions clearly identified and justified?

4. Are the methods and units clearly identified?

5. Have the limits of applicability been identified?

6. Are the results of literature searches, if conducted, or other background data provided?

7. Are all the pages sequentially numbered and identified by the calculation note number?..

8. Is the project or shop order clearly identified?

9. Has the required computer calculation information been provided?

10. Were the computer codes used under configuration control?

11. Were the computer code(s) used applicable for modeling the physical and/or computational problems identified? (Is the correct computer code being used for the intended purpose.)

12. Are the results and conclusions clearly stated? YES - NO

13. Are Open Items properly identified YES - NO - N/A

14. Wero approved Design Control practices followed without exception? YES - NO - NQA (Approved Design Control practices refers to guidance documents within NSD that state how the work is to be performed, such as how to perform a LOCA anslysis.)

15. Have all related contract requirements been met?

NOTE: If NO to any of the above, Page Number containing justification 


\section{DISTRIBUTION SHEET}

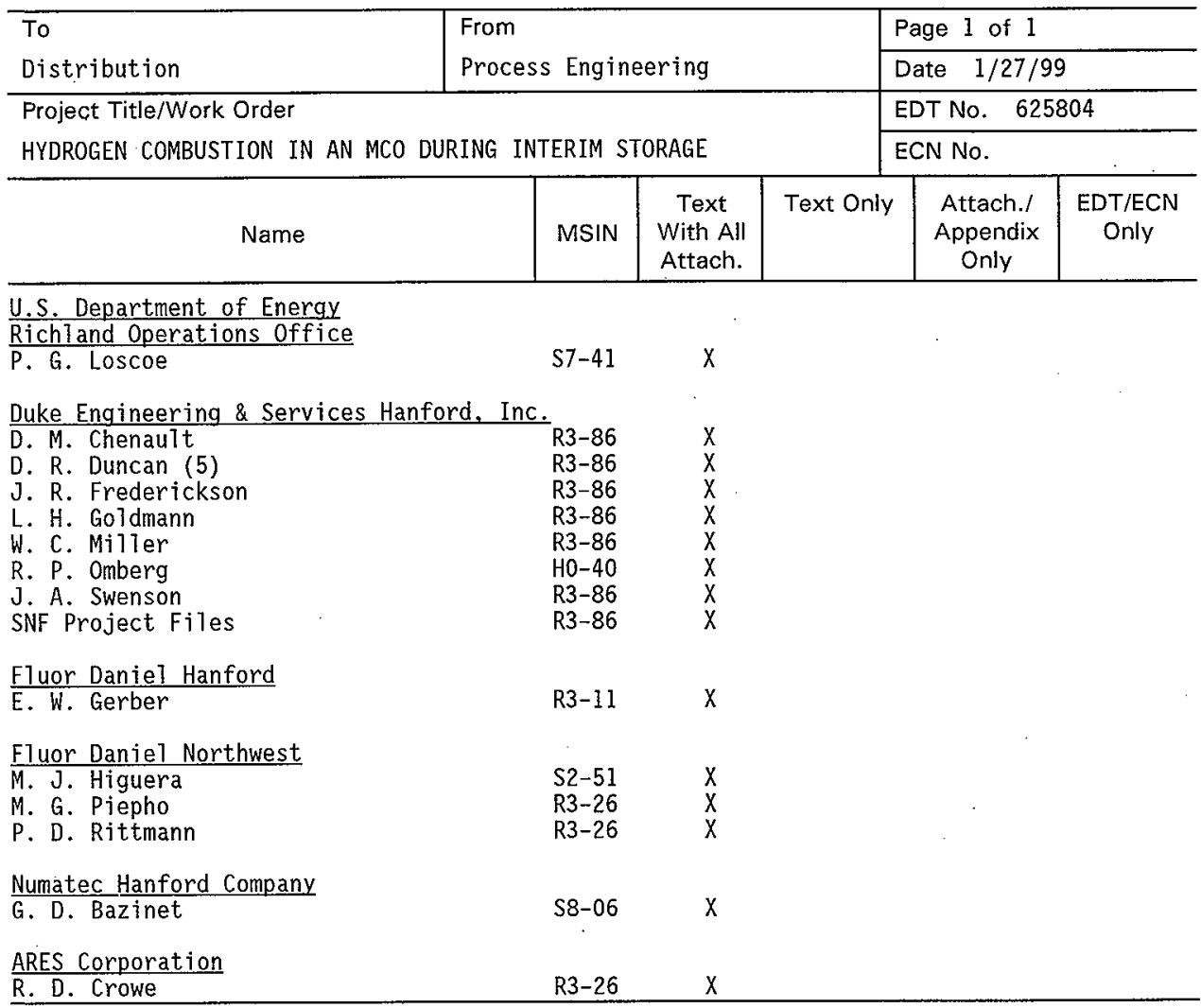

